\title{
Patterns of animal dispersal, vicariance and diversification in the Holarctic
}

\author{
ISABEL SANMARTÍN ${ }^{1 *}$, HENRIK ENGHOFF² ${ }^{2}$ and FREDRIK RONQUIST ${ }^{1}$ \\ ${ }^{1}$ Department of Systematic Zoology, Evolutionary Biology Centre, Uppsala University, Norbyvägen 18D, \\ SE-752 36 Uppsala, Sweden \\ ${ }^{2}$ Zoologisk Museum, Universitetsparken 15, DK-2100 Copenhagen, Denmark
}

Received 23 October 2000; accepted for publication 25 March 2001

\begin{abstract}
We analysed patterns of animal dispersal, vicariance and diversification in the Holarctic based on complete phylogenies of 57 extant non-marine taxa, together comprising 770 species, documenting biogeographic events from the Late Mesozoic to the present. Four major areas, each corresponding to a historically persistent landmass, were used in the analyses: eastern Nearctic (EN), western Nearctic (WN), eastern Palaeoarctic (EP) and western Palaeoarctic (WP). Parsimony-based tree fitting showed that there is no significantly supported general area cladogram for the dataset. Yet, distributions are strongly phylogenetically conserved, as revealed by dispersalvicariance analysis (DIVA). DIVA-based permutation tests were used to pinpoint phylogenetically determined biogeographic patterns. Consistent with expectations, continental dispersals (WP↔EP and WN↔EN) are significantly more common than palaeocontinental dispersals (WN $\leftrightarrow \mathrm{EP}$ and $\mathrm{EN} \leftrightarrow \mathrm{WP}$ ), which in turn are more common than disjunct dispersals ( $\mathrm{EN} \leftrightarrow \mathrm{EP}$ and $\mathrm{WN} \leftrightarrow \mathrm{WP}$ ). There is significant dispersal asymmetry both within the Nearctic $(\mathrm{WN} \rightarrow \mathrm{EN}$ more common than $\mathrm{EN} \rightarrow \mathrm{WN}$ ) and the Palaeoarctic $(\mathrm{EP} \rightarrow \mathrm{WP}$ more common than WP $\rightarrow \mathrm{EP})$. CrossBeringian faunal connections have traditionally been emphasized but are not more important than cross-Atlantic connections in our data set. To analyse changes over time, we sorted biogeographic events into four major time periods using fossil, biogeographic and molecular evidence combined with a 'branching clock'. These analyses show that trans-Atlantic distributions (EN-WP) were common in the Early-Mid Tertiary (70-20 Myr), whereas transBeringian distributions (WN-EP) were rare in that period. Most EN-EP disjunctions date back to the Early Tertiary (70-45 Myr), suggesting that they resulted from division of cross-Atlantic rather than cross-Beringian distributions. Diversification in WN and WP increased in the Quaternary (<3 Myr), whereas in EP and EN it decreased from a maximum in the Early-Mid Tertiary.

(C) 2001 The Linnean Society of London
\end{abstract}

ADDITIONAL KEY WORDS: historical biogeography - trans-Atlantic - trans-Beringian - disjunct.

\section{INTRODUCTION}

The surge of phylogenetic systematics in recent decades has created an increased interest in phylogenybased biogeographic analyses. However, beyond the fact that such analyses should be based on robust phylogenies of many groups of organisms with wellknown distributions, there is currently little agreement concerning methodology. The existing approaches can be roughly characterized as being event-based or pattern-based (Ronquist, 1997, 1998a). Pattern-based methods explicitly avoid making assumptions about evolutionary processes. The analyses identify patterns, which typically show some incongruence with the data.

* Corresponding author. E-mail: isabel.sanmartin@ebc.uu.se
This incongruence is measured in abstract terms, such as items of error or amount of homoplasy. The incongruence can then be interpreted a posteriori in terms of biogeographic events, such as dispersal and extinction. The exact procedure for this a posteriori translation remains elusive. Furthermore, because no model is specified, it is difficult to predict the analytical behaviour of pattern-based methods and counter-intuitive results often occur (e.g. Ronquist, 1995, 1996).

In contrast, event-based methods are explicitly derived from models of biogeographic processes. The relevant events are identified and associated with costs that are inversely related to the likelihood of the events. The analysis consists of a search for the reconstruction, which minimizes the total cost. This optimal reconstruction explicitly specifies the biogeographic events of interest, unlike pattern-based 
analyses, and no a posteriori interpretation is necessary. The direct relation between method, model and event-cost assignments makes it easy to understand the properties of an event-based method. For these reasons, we apply the event-based approach in this paper.

Phylogenetic biogeographic studies often focus solely on hierarchical patterns (area cladograms) and rarely test the significance of the resultant patterns. However, there is no theory predicting a prevalence of hierarchical patterns in historical biogeography. We believe that biogeographers should be more open-minded in their search for patterns and more critical in evaluating their results by using significance tests or other procedures for assessing uncertainty. By analysing each individual group separately before looking for general patterns, we have a better chance of finding multiple, incongruent histories than if the data set is reduced to a single dominant area cladogram (Noonan, 1988a).

Phylogeny-associated age estimates, whether derived from morphological or molecular clock estimates, fossil data or external biogeographic events, provide critical information in phylogenetic biogeographic studies. For instance, age estimates are essential in untangling pseudocongruence, that is, similar patterns of different age (Cunningham \& Collins, 1994). Therefore, we believe that phylogenetic biogeographers should include age estimates, even if they are uncertain, in their analyses.

In this paper, we present a comprehensive eventbased analysis of biogeographic patterns in the Holarctic following the principles outlined above.

\section{HOLARCTIC BIOGEOGRAPHY}

The southern Hemisphere has been a favourite region for historical biogeographic studies. One reason for this is the presence of many widely disjunct but closely related taxa on the southern continents, spurring interest in biogeographic processes. Another reason is the relatively simple geological history of the Southern continents (but see Seberg, 1991 for a different view). In contrast, large-scale Holarctic distribution patterns are less obvious and palaeogeographic reconstructions suggest a more complicated history. Nevertheless, some patterns have attracted considerable attention. The best example is perhaps the striking similarity between the floras of eastern Asia and eastern North America (Gray, 1840; Li, 1952; Tiffney, 1985a,b; Wolfe, 1969, 1975, 1985; Xiang, Soltis \& Soltis, 1998a; Xiang et al., 1998b; Wen, 1999). The much cited boreotropics hypothesis (Wolfe, 1985; Tiffney, 1985a) explains this disjunction as the result of the fragmentation of a once continuous warm-temperate forest that extended across the Northern Hemisphere during the Early-Mid Tertiary, leaving extant remnants only in eastern Asia and eastern North America. The extinction in other areas is attributed to a combination of climatic and geological changes during the Late TertiaryQuaternary (Tiffney, 1985b).

The eastern North America-Asia disjunction has been documented in a long series of plant taxa but there is still considerable controversy surrounding the processes that created it and only a few studies have documented the pattern phylogenetically (Wen, 1999). Estimates of divergence times based on the molecular clock suggest that this disjunct pattern evolved multiple times (polychronically) in the Tertiary (Wen, 1999). The disjunction has thus far only been demonstrated in a few animal groups (Suzuki et al., 1977; Patterson, 1981; Andersen \& Spence, 1992; Enghoff, 1993; Nordlander, Liu \& Ronquist, 1996; Savage \& Wheeler, 1999) and there is uncertainty concerning its general importance in the evolution of Holarctic faunas.

Another familiar Holarctic pattern is the unequal distribution of species diversity among infraregions, which has been extensively documented for temperate plant species (Latham \& Ricklefs, 1993; Qian \& Ricklefs, 1999, 2000). These authors discussed the causal factors creating this pattern in the Tertiary using data from fossil floras and simulated rarefaction of extant floras. However, their analyses were based on traditional classifications and did not include explicit phylogenetic information. Several additional studies of Holarctic plant biogeography could be mentioned but, to our knowledge, general Holarctic patterns have still not been documented in a large set of plant phylogenies.

There have been several studies of the biogeographic history of the Holarctic fauna (Allen, 1983; Noonan, 1988a,b; Enghoff, 1993, 1995; De Jong, 1998) but most of them cover only one or two of the Holarctic infraregions. Enghoff (1995) is the only comprehensive study of the entire Holarctic. It was based on phylogenies of 73 extant non-marine Holarctic animal groups. The phylogenies were divided into two groups: family clades (for groups at the family level or above) and genus clades (for groups at the genus level or below). The former were presumed to document older events than the latter, but dating of the clades was never attempted. Patterns were analysed in terms of four major areas ('infraregions'): western North America (WN), eastern North America (EN), western Palaeoarctic (WP) and eastern Palaeoarctic (EP). Using pattern-based methods, Enghoff (1995) found a strong hierarchical pattern in the genus clades reflecting the current continental configuration: ((WN, EN), (WP, EP)). However, the significance of this result was not tested and it contrasts with recent palaeogeographic reconstructions, indicating that the Late Mesozoic and Cenozoic biogeographic history of the Holarctic follows 
a reticulate scenario (Smith, Smith \& Funnell, 1994). Enghoff (1995) also analysed ancestral areas of each group and the frequency of different types of dispersal events. Unfortunately, only one of the dispersal patterns was tested statistically and this test was biased because it did not correct for differences in species richness among infraregions. Furthermore, none of these analyses was explicitly event-based.

Here we present a considerably more detailed analysis of Holarctic biogeographic patterns. We assembled published phylogenies of 57 non-marine animal groups occurring mainly or exlusively in the Holarctic. In contrast to Enghoff (1995), we only included phylogenies that were resolved down to the species level and which included a complete or almost complete sample of the species in the group. Age estimates suggest that the phylogenies in our data set document events from the Late Mesozoic to the present. In total, the phylogenies comprised 770 extant species connected by 713 lineage splitting (speciation) events. In analysing the data set, we consistently used eventbased methods, searched both for hierarchical and reticulate patterns, and tested the significance of our results using permutation tests designed specifically to reveal phylogenetically constrained biogeographic patterns. In some analyses, the ages of all nodes were estimated using various methods to allow tracking of patterns through time.

\section{SETTING THE SCENARIO}

To provide a basis for the discussion of biogeographic hypotheses pertaining to the Holarctic, we provide a brief summary of current reconstructions of the history of this region from the Mesozoic to the present (Figs $1-4)$.

Early Mesozoic: Pangaea (Cox, 1974; Raven \& Axelrod, 1974)

During the Triassic (200 million years ago (Myr)), all present continents formed a single landmass, Pangaea. Splitting of Pangaea started in the Early-Mid Jurassic (180 Myr) with the division into a northern continent, Laurasia, comprising North America and Eurasia, and a southern continent, Gondwana.

The major Laurasian landmasses, the eastern and western Nearctic and the eastern and western Palaeoarctic, were joined to each other in various combinations over time. In the Early Jurassic, Europe and North America were connected through the protoBritish Isles, which acted as a big 'stepping-stone' in the middle of a narrow Atlantic ocean (Smith et al., 1994). North America and Asia, however, were widely separated. This situation persisted through the Late Jurassic (Fig. 1).

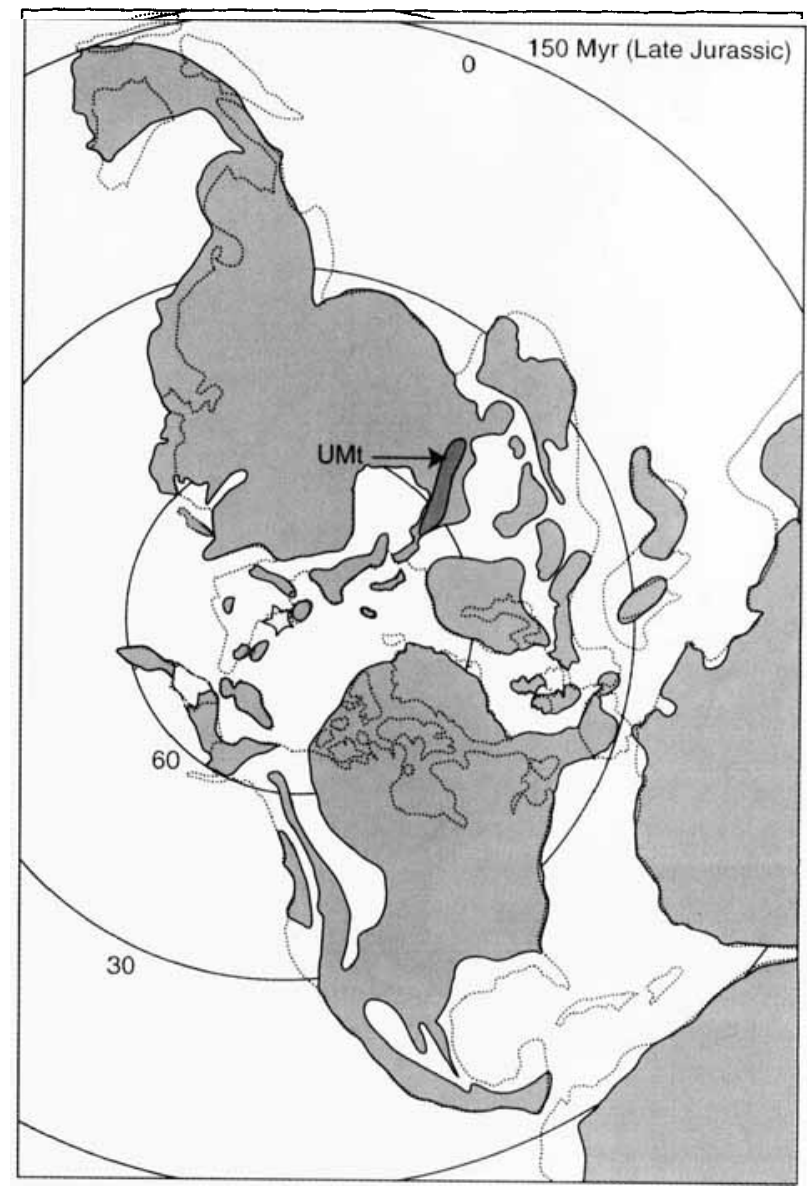

Figure 1. Palaeogeographic reconstruction of the Northern Hemisphere in the Late Jurassic (150 Myr) modified from Barron et al. (1981). Stereographic projection. Emergent land is shaded by grey and major mountain chains by dark grey. Current coastlines are indicated by thin lines. Abbreviations: UMt $=$ Ural Mountains.

Late Mesozoic: Euramerica-Asiamerica (Cox, 1974; Tiffney, 1985a)

In the Mid-Late Cretaceous (100-80 Myr), epicontinental seaways and intercontinental connections divided Laurasia into two palaeocontinents: Euramerica and Asiamerica. Europe and eastern North America (Euramerica) were still linked across the Atlantic, whereas Asia and western North America (Asiamerica) became connected by the Bering land bridge. Two epicontinental seaways separated Euramerica and Asiamerica: the Turgai Strait through central Asia and eastern Europe, and the Mid-Continental Seaway through central North America (Fig. 2). This continental arrangement lasted around 25-30 Myr, disintegrating at the end of the Cretaceous-Early Palaeocene (70-65 Myr) with the closing of the MidContinental Seaway. 


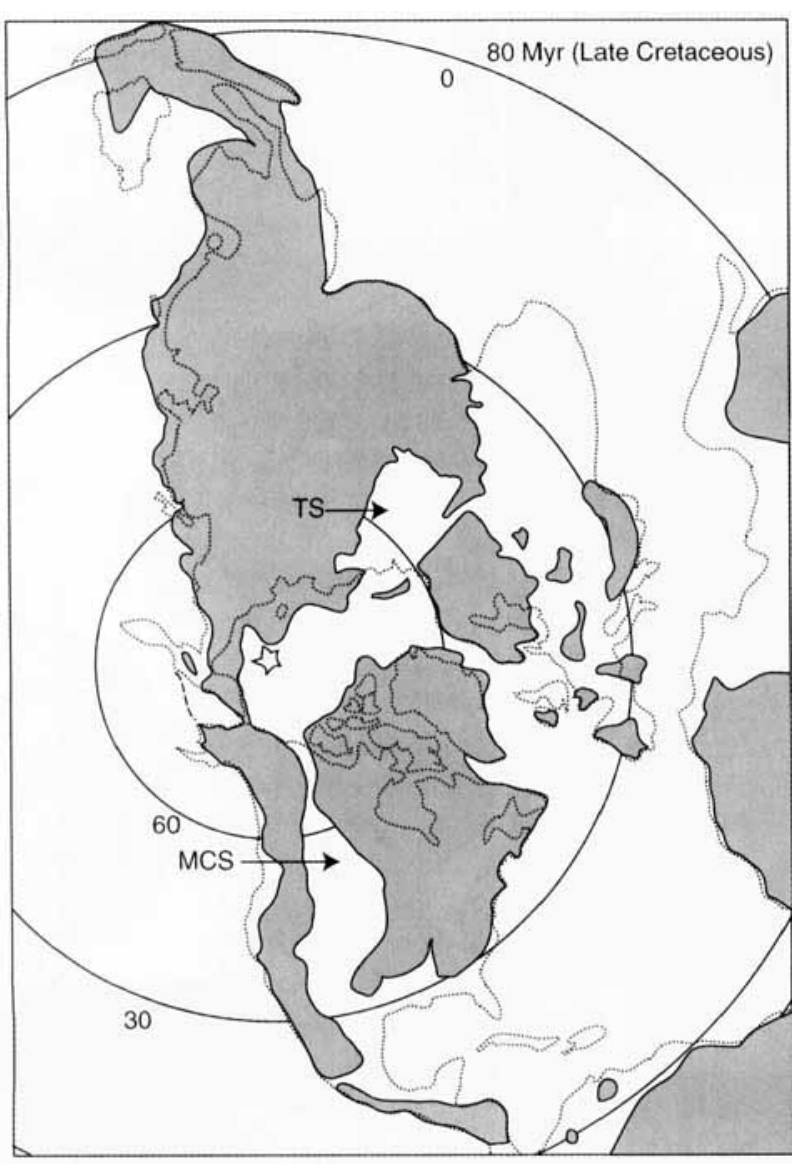

Figure 2. Palaeogeographic reconstruction of the Northern Hemisphere in the Late Cretaceous ( $80 \mathrm{Myr}$ ). Major source, projection and symbols as in Figure 1. Abbreviations: $\mathrm{MCS}=$ Mid-Continental Seaway, TS = Turgai Sea.

Trans-Atlantic land bridges (McKenna, 1983; Tiffney, 1985a,b; Liebherr; 1991)

The opening of the North Atlantic started in the Late Cretaceous (90 Myr) but terrestrial connections between Europe and North America persisted along various North Atlantic land bridges until at least the Early Eocene (50 Myr). Three different North Atlantic land bridges, geographically and temporally separated, have been postulated (McKenna, 1983; Tiffney, 1985b).

During the Early Tertiary, the Thulean Bridge is supposed to have connected southern Europe to Greenland through the British Isles. Greenland, in turn, was connected westwards with eastern North America through the Queen Elizabeth Islands (Fig. 3). The Thulean Bridge is considered to have been the most important route for exchange of temperate biota in the earliest part of the Early Eocene (55 Myr), when the climate became markedly warmer (McKenna, 1983). This interchange was suddenly interrupted with the breaking of the Thulean Bridge in the Early Eocene (50 Myr).
A more northern trans-Atlantic connection, the De Geer Bridge, persisted until the Late Eocene. It connected Scandinavia (Fennoscandia) to northern Greenland, and Greenland to eastern North America through the Canadian Arctic Archipelago. This route is considered far less important for biotic exchange than the Thulean Bridge because of its northern position, restricting it to cold-adapted organisms. Furthermore, Scandinavia was isolated from direct contact with Europe by the Danish-Polish trough through much of the Palaeogene. The Greenland Sea broke this northern route in the Late Eocene ( $39 \mathrm{Myr}$ ). A third connection between Europe and eastern North America, the Greenland-Faeroes bridge, probably persisted until the Miocene but this connection was apparently never more than a chain of islands, and is not considered to have been an important dispersal route.

Trans-Beringian land bridges (Mathews, 1979; McKenna, 1983; Lafontaine \& Wood, 1988; Tangelder, 1988; Nordlander et al., 1996)

Asia and Western North America became connected by land across the Bering Sea in the Mid Cretaceous (100 Myr). The continents remained joined by the Bering land bridge until the Pliocene. The Beringian transgression opened the Bering Strait in the Late Pliocene (3.5 Myr) but the land connection was reestablished several times during the Pleistocene (e.g. during the Illinoisan and Wisconsinan glaciations).

The climatic and floristic conditions prevailing on the Beringian land bridge changed considerably over time. Thus, the importance of Beringia as a dispersal route is likely to have varied considerably over time. Three consecutive phases with different climate and vegetation in the Beringian area may be recognized.

Beringian Bridge I. During the Early Tertiary, after some climatic fluctuations in the Palaeocene following the impact winter that ended the Cretaceous, climates in the Northern Hemisphere became much warmer and humid than they are today (the Early Eocene warming event). A continuous belt of vegetation, the boreotropical forest, is considered to have extended over the entire Northern Hemisphere during this period, from Asia through North America across Beringia (Wolfe, 1969, 1975, 1978). The boreotropical forest consisted of a mixture of deciduous hardwoods and evergreen subtropical elements (Wolfe, 1985). Deciduous plants were rare in the Late Cretaceous but the impact winter at the K'T boundary (65 Myr) may have promoted their rise to dominance in Early Tertiary forests (Wolfe, 1987). The origin of the boreotropical forest is associated with the evolution of a large number of modern plant taxa in the latest Cretaceous and Early Tertiary. The new plants spread 
rapidly over existing land bridges, ultimately forming a homogeneous flora. During this period, considerable exchange of terrestrial fauna and flora is thought to have occurred across the Beringian land bridge, predominantly in species adapted to warm-temperate climates and associated with the boreotropical forest (Tiffney, 1985a).

At the Eocene-Oligocene boundary (35 Myr), there was a drastic and global decline in climatic conditions, which became cooler and drier (the terminal Eocene event). This resulted in the demise of the boreotropical forest and subsequent trans-Beringian isolation and vicariance in the organisms living in the forest. The boreotropical forest was replaced by the mixed mesophytic forest (Wolfe, 1987), a mixed deciduous hardwood and coniferous forest, which became dominant in the mid-Tertiary. Although faunal exchange of coldtemperate groups across Beringia probably continued in the Oligocene and Miocene (Tiffney, 1985a), most dispersal of temperate groups across Beringia is considered to have stopped after the terminal Eocene event, marking the end of Beringian Bridge I.

Beringian Bridge II. As climates continued to deteriorate during the Miocene, the Beringian forest became successively more dominated by coniferous elements. From the Middle-Late Miocene (14-10 Myr) to the Late Pliocene (3.5 Myr), a continuous coniferous forest belt connected northern Asia with northern North America across Beringia. The forest was similar in composition to the present taiga but with the same conifer species occurring in both Siberia and North America. During this period, trans-Beringian dispersal was presumably dominated by boreal elements, while warm-temperate groups were restricted to widely disjunct refugia in the south (Lafontaine \& Wood, 1988).

Further deterioration of climatic conditions during the Pliocene and Pleistocene resulted in vicariance of the boreal coniferous forest into an eastern and a western portion. The division was reinforced in the Late Pliocene (3.5 Myr), when a marine transgression opened the Bering Strait and broke the terrestrial connections between America and Asia. Palaeoarctic and Nearctic forests have never come into contact since. These climatic, geographic and vegetational changes assumedly resulted in massive trans-Beringian vicariance in boreal groups, which is reflected by the high proportion of Nearctic-Palaeoarctic species pairs in the taiga fauna (Lafontaine \& Wood, 1988). Today, all species of conifers, and most other tree species as well, are different on the Siberian and Alaskan sides of Beringia (Pielou, 1979; Lafontaine \& Wood, 1988).

Beringian Bridge III. During the Pleistocene glaciations (1.5-1.0 Myr), terrestrial connections between
Asia and North America were re-established. A continuous tree-less steppe, the tundra, then connected Siberia with Alaska across Beringia. The tundra habitat acted as a barrier to mixing of taiga species, separating the Nearctic and Palaeoarctic portions of the boreal forest during the Pleistocene. During this period, trans-Beringian biotic exchange was probably dominated by arctic, tundra-adapted groups. Dispersal was eventually interrupted in the Late PleistoceneHolocene, with the retreat of the ice-sheets and the final marine transgression of the Bering area. Tundra species are still much the same on both sides of the Bering strait (Pielou, 1979; Lafontaine \& Wood, 1988).

The Neartic (Allen, 1983; Tiffney, 1985b; Noonan, 1986, 1988a; Tangelder, 1988; Askevold, 1991)

In the mid Cretaceous (100 Myr), the Mid-Continental Seaway, located to the east of the Rocky Mountains, completely divided the North American continent into an eastern and a western half from the Gulf of Mexico to the Canadian Arctic Archipelago (Fig. 2). The seaway partially retreated in the Late Cretaceous ( $84 \mathrm{Myr}$ ), allowing connections in the north, and finally disappeared at the end of the Cretaceous (70 Myr). This was presumably followed by an Early Cenozoic period of floral and faunal exchange between the eastern and western Nearctic. However, the disappearance of the Mid-Continental seaway was concurrent with the uplift of the Cordilleran Mountain System in the Late Cretaceous: the Rocky Mountains and the Sierra Madre Occidental (Fig. 3). As they rose, the Rocky Mountains cast an increasingly large rain shadow to the east. By the Late Eocene ( $35 \mathrm{Myr}$ ), this had created a dry-habitat barrier between the western and eastern Nearctic, even though migration corridors with wetter habitats persisted along rivers. The Eocene-Oligocene climatic deterioration resulted in the contraction of the original boreotropical flora in the western mountains and in the eastern part of North America, and in the geographical expansion of temperate deciduous elements in the mixed-mesophytic forest. By the Oligocene ( $30 \mathrm{Myr}$ ), erosion had completely wiped out the early Rocky Mountains and the entire Cordilleran range became a peneplain. This presumably enabled a second Cenozoic period of extensive dispersal between the western and eastern sides of the Nearctic.

In the Late Oligocene (25 Myr), and continuing in the Miocene, a new orogenic phase gave rise to the present western Cordilleran System, including new folding of the Rocky Mountains and Sierra Madre Occidental and the uplift of Sierra Madre Oriental (Fig. 4). This resulted in cooler and drier climates and, eventually, in the development of grassland biomes in central North America. The new topographic barrier definitively divided the western and eastern sides of 


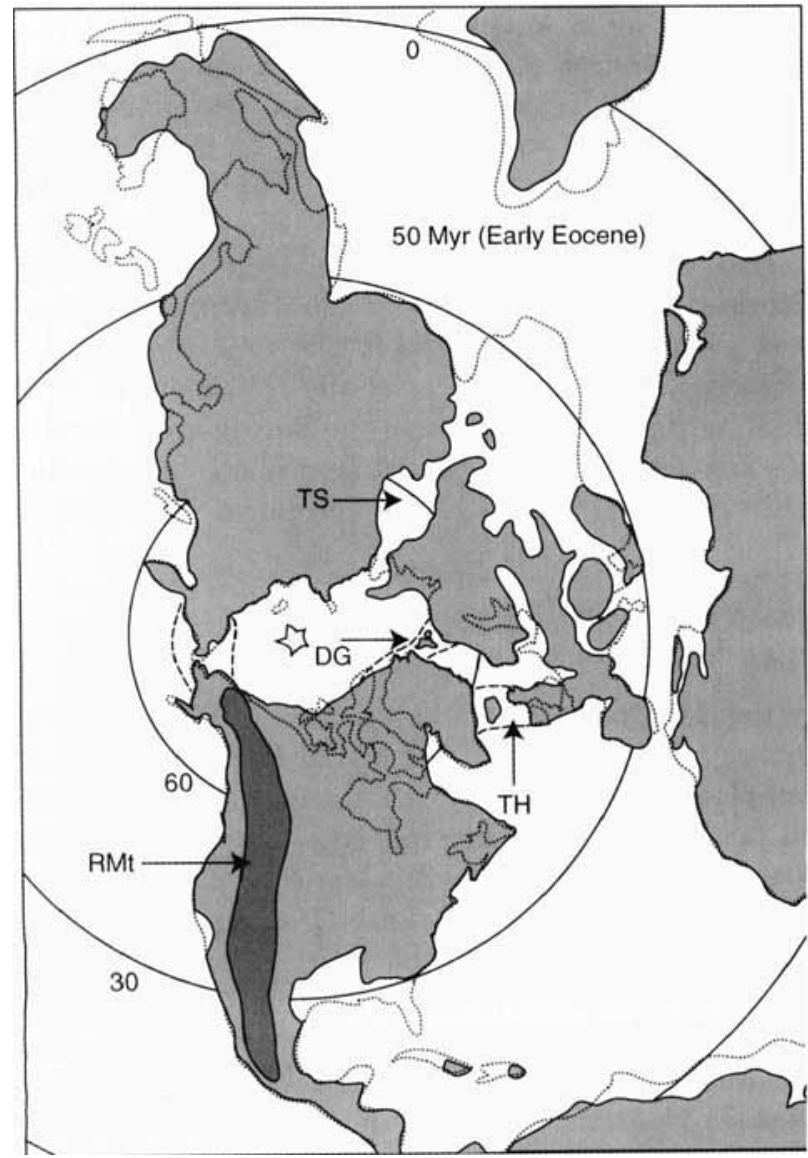

Figure 3. Palaeogeographic reconstruction of the Northern Hemisphere in the Early Tertiary (50 Myr). Major source, projection, and symbols as in Figure 1. Abbreviations: DG = 'De Geer' North-Atlantic bridge, RMtRocky Mountains, TH = 'Thulean' North-Atlantic bridge, $\mathrm{TS}=$ Turgai Sea.

the mixed-mesophytic forest and was presumably associated with massive vicariance in Nearctic biotas. The mesophytic elements became restricted to eastern North America and the west side of the Rocky Mountains, while a more drought-tolerant, temperate deciduous flora evolved in the western mountains (Tiffney, 1985b). Finally, the last remnants of the mixed-mesophytic forest were wiped out from western North America during the Pleistocene glaciations.

The Palaeoarctic (Cox, 1974; Tiffney, 1985b; Tangelder, 1988)

From the Mid-Jurassic (180 Myr) to the Late Tertiary (30 Myr), the Palaeoarctic was divided into an eastern and a western half by an epicontinental seaway, the Turgai Strait, located at the east of the Ural Mountains (Figs 1-3). However, some authors argue that floral and faunal exchange between Europe and Asia persisted

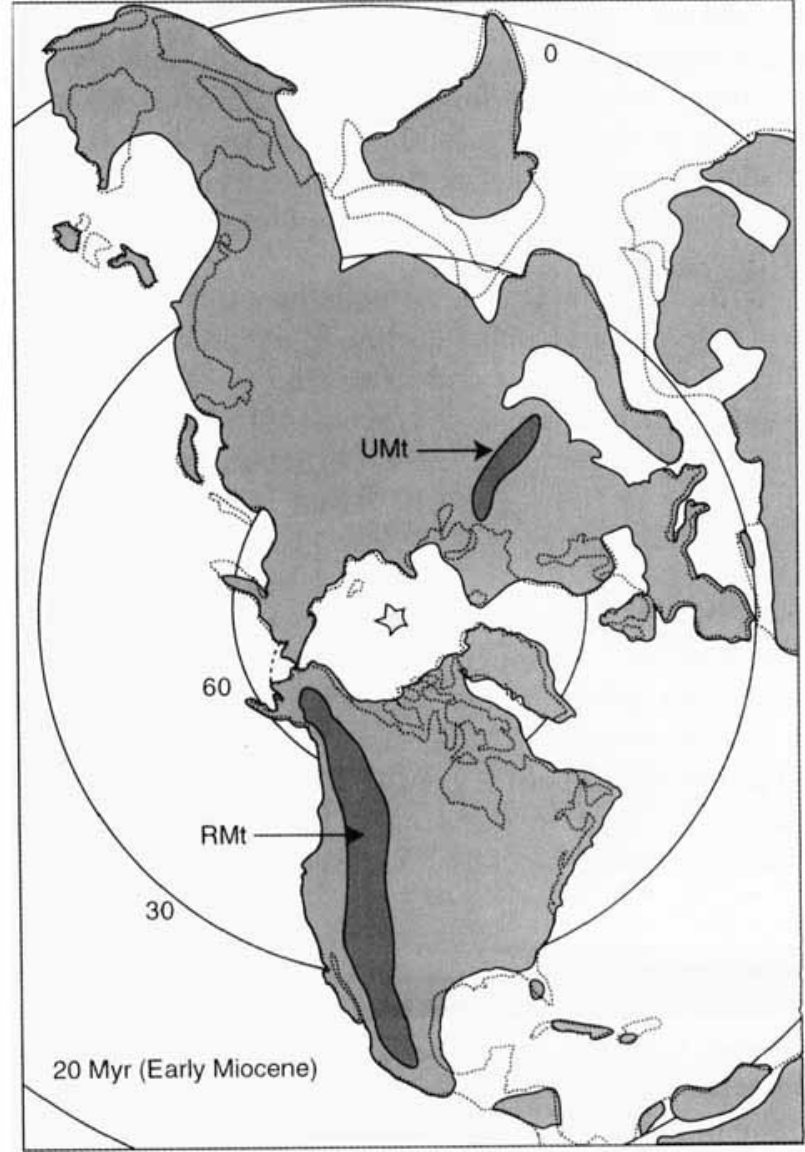

Figure 4. Palaeogeographic reconstruction of the Northern Hemisphere in the Late Tertiary (20 Myr). Major source, projection, and symbols as in Figure 1. Abbreviations: $\mathrm{RMt}=$ Rocky Mountains, $\mathrm{UMt}=$ Ural Mountains.

along the coasts and islands of the Tethys Seaway (Tiffney, 1985b). Temporary regression of the Turgai Sea in the Palaeocene allowed connections in the north but they were interrupted by a new transgression in the Eocene. The Turgai Strait finally dried up during the Oligocene (30 Myr), permitting extensive biotic exchange between both sides of the Palaeoarctic (Fig. 4). The closing of the Turgai Strait introduced a more continental climate in western Siberia. This led to the evolution of increasingly drought-tolerant, deciduous communities of plants, which ultimately invaded Europe from the east, replacing the mixed-mesophytic forest. The last remnants of the latter forest became extinct in Europe during the Quaternary glaciations (Tiffney, 1985b).

Several partial barriers between the two sides of the Palaeoarctic appeared after the Turgai Strait dried up. In the Late Oligocene, the uplift of the Tibet Mountains isolated Europe and West Asia from East Asia (Macey et al., 1999). During the Late Pliocene-Pleistocene, 
exchange between Asia and Europe was interrupted several times because of climatic fluctuations, which periodically reinforced the West-Siberian dry continental climate barrier (Beschovski, 1984). Opening of the Japanese Sea, which resulted in the vicariance between Japanese and Asian biotas, started in the Miocene but did not completely isolate the Japanese islands until the Late Miocene--Early Pliocene (6 Myr). The Himalayan Mountains were formed by the collision of India with Asia in the Middle Eocene, with the most intense orogenic phase occurring in the mid-Miocene (15 Myr) (Tangelder, 1988).

\section{BIOGEOGRAPHIC HYPOTHESES}

Based on the current views on the history of the Holarctic, reviewed above, we extracted the following hypotheses and ideas that we wanted to test.

\section{A general area cladogram for the Holarctic?}

Although the palaeogeographic history of the four Holarctic infraregions since the Late Mesozoic cannot easily be summarized in a general area cladogram, Enghoff (1995), using pattern-based methods (component analysis), found considerable support for the area cladogram ((WN, EN), (WP, EP)) in his genus phylogenies. However, the statistical significance of this result was not tested. To clarify whether Holarctic biogeography can be adequately summarized in a general area cladogram, we searched for such patterns both in Enghoff's and our own data using event-based methods and permutation tests to assess the significance of the results.

\section{Large-scale Holarctic patterns}

Holarctic geographic history combined with the effects of extinction and diversification predict that, among the events documented in phylogenies of extant organisms, continental dispersals (within the present landmasses North America and Eurasia, WN $\leftrightarrow$ EN and $\mathrm{WP} \leftrightarrow \mathrm{EP})$ should be more frequent than palaeocontinental dispersals (trans-Beringian and trans-Atlantic dispersals, $\mathrm{WN} \leftrightarrow \mathrm{EP}$ and $\mathrm{EN} \leftrightarrow \mathrm{WP}$ ), which in turn should be more frequent than disjunct dispersals between infraregions that have never been directly connected (EN $\leftrightarrow E P, W N \leftrightarrow W P)$. Enghoff (1995), using cladistic subordinateness as an indicator of dispersal (Enghoff, 1993), found a pattern consistent with this expectation but he did not correct for the effects of regional differences in species diversity, nor did he use explicit event-based methods in identifying the dispersals.

\section{Continental patterns}

Because the Turgai Sea divided the Palaeoarctic for a much longer time than the Mid-Continental Seaway isolated western and eastern North America, floral and faunal exchange should have been more frequent in the Nearctic than in the Palaeoarctic. Enghoff's (1995) pattern-based analysis supported this prediction weakly, but the significance of the result was not tested.

Although there is no obvious geological evidence for dispersal asymmetries in the Palaeoarctic, Enghoff (1995) found that dispersals from the eastern to the western Palaeoarctic were more common than dispersals in the other direction. Again, the significance of this result was not tested. This is problematic since the extant fauna of most groups of organisms is considerably more diverse in the eastern than in the western Palaeoarctic. Thus, by pure chance one would expect extant faunas to document more dispersal events from the east to the west than in the other direction. We re-examined Enghoff's results, correcting for such diversity differences.

The Tertiary orogenic activity in the western Nearctic presumably created cold and dry adapted forms that later became successful in the eastern Nearctic when climates in general deteriorated towards the end of the Tertiary and in the Quaternary. In addition, the dry continental climates of interior North America first originated close to the Rocky Mountains and then spread east as the mountains rose. Therefore, Tertiary and Quaternary dispersal in the Nearctic should have been predominantly from the west to the east. The role of western North America as a source area of continental dispersal is consistent with the presence there of many relict forms and a high proportion of endemic taxa (Shear \& Gruber, 1983; Kavanaugh, 1988). Enghoff's (1995) analyses indicated predominantly eastwards dispersal in the Nearctic, but the statistical significance of this asymmetry was not tested. Here, we address this hypothesis.

\section{Trans-Beringian and trans-Atlantic exchange}

Nearctic-Palaeoarctic disjunctions have usually been explained as being derived from ancestral distribution ranges extending across the Bering land bridge (Darlington, 1957). However, recent studies suggest that trans-Atlantic dispersal may have played a more important role in this type of disjunction than is commonly assumed (Tiffney, 1985b; Noonan, 1986, 1988b).

Trans-Beringian dispersal is presumed to have been more frequent from the eastern Palaeoarctic to western North America than in the other direction, at least during the Pleistocene (Pielou, 1979). The reason is that, during full-glacial periods, Beringia was essentially an eastward extension of Siberia. The land covered with ice was more extensive in western North America than in Asia and the unglaciated parts of Alaska and Yukon were separated from the rest of 
North America by the Laurentide and Cordilleran icesheets. Thus, only a small portion of the American fauna could access Beringian Bridge III. Beringia is considered to have contributed the bulk of tundra species that now range across northern North America, whereas forest and prairie species from non-Beringian areas of North America made little or no contribution to the present fauna of Siberia (George, 1988; Lafontaine \& Wood, 1988). We tested whether this predicted directional asymmetry was evident in our data.

\section{The eastern North America-Asia disjunction}

Although well known in plants, this disjunction has rarely been documented in animals (but see Suzuki et al., 1977; Patterson, 1981; Andersen \& Spence, 1992; Enghoff, 1993; Nordlander et al., 1996; Savage \& Wheeler, 1999). However, the boreotropics hypothesis predicts that this pattern should be common in animals associated with warm-temperate forests of boreotropical origin, in which case the pattern should be common in our data set.

There is considerable controversy concerning the origins of this disjunction. Faunal (and floral) exchange between Asia and eastern North America could have taken place via two different routes: either across Beringian Bridge I or across the Thulean Bridge. Botanists have usually considered the trans-Beringian route most important (Li, 1952) but Tiffney (1985b) argued that the boreotropical flora dispersed mainly across the North Atlantic land bridge. An important difference between these two hypotheses is in the predicted age of the disjunction. Trans-Beringian dispersal in warm-temperate groups presumably peaked during the warm period in the Eocene, which ended in the terminal Eocene event (about $35 \mathrm{Myr}$ ), whereas trans-Atlantic dispersal was unlikely after the breakup of the Thulean Bridge (about $50 \mathrm{Myr}$ ). We tested these predictions with dated phylogenies.

In contrast to the eastern North America-Asia disjunction, disjunct distributions between western North America and Europe have hardly been discussed in the literature. Thus, we expected such disjunctions to be significantly less frequent than EN-EP disjunctions.

\section{Diversification patterns}

For most organism groups, species richness differs widely among Holarctic infraregions. The eastern Palaeoarctic is usually the richest region whereas the western Palaeoarctic is the poorest (Latham \& Ricklefs, 1993; Mönkkönen \& Viro, 1997; Li \& Adair, 1994; Guo, 1999; Wen, 1999). Two different hypotheses have been proposed to explain these differences.

The refugium hypothesis explains them as a result of climatic changes in the Quaternary (Tiffney, 1985b). During the Pleistocene, continental ice-sheets covered most of Europe and advanced deeply into eastern North America (Pielou, 1979). Glaciation and the associated climatic cooling were supposedly associated with high extinction rates. In Asia, however, the ice never reached as far south and, in addition, the Asian fauna and flora could disperse freely into the warmer habitats of the Oriental region. Thus, thermophilic taxa that went extinct elsewhere survived in Asia, resulting in the high extant diversity of Asian faunas and floras (Tiffney, 1985a).

The diversification hypothesis assumes that the diversity asymmetries arose already in the Tertiary, before the climatic cooling and widespread extirpations of the Quaternary. The richness of the Asian flora and fauna would have resulted because the net diversification rates were higher in Asia than in other Holarctic infraregions during the Tertiary (Latham \& Ricklefs, 1993; Nordlander et al., 1996; Qian \& Ricklefs, 1999, 2000). We tested these hypotheses with our dated phylogenies.

\section{MA'TERIAL AND METHODS}

\section{SELECTION OF GROUPS FOR ANALYSIS}

Groups were selected according to the following criteria: (a) the group must be monophyletic and exclusively or predominantly Holarctic in distribution. (b) It must be represented in at least two of the Holarctic infraregions. (c) It must comprise four or more species (at least three nodes in the cladogram). (d) The phylogeny must include all or at least $95 \%$ of the species of the group. In a clade that is not resolved to species level, a terminal bifurcation may include numerous subsequent speciations. Failing to include all speciation events in the analysis would underestimate both the frequency of biogeographic events and the age of the group (see below under 'Dating'). (e) The cladogram must be well resolved. Phylogenies with more than one tetratomy or more than two trichotomies were considered too ambiguous for our analyses and were discarded. We selected all groups fitting these criteria that we could find in the literature. The selected groups and references are listed in Table 1; the area cladograms are given in the Appendix. We ended up with 57 phylogenies representing most groups of terrestrial and limnic organisms (Fig. 5A). Because we used different selection criteria, only 39 of our groups were identical with groups analysed by Enghoff (1995). Even for these groups, our data differed from that of Enghoff (1995), among other things because we never collapsed terminal clades of species occurring in the same area.

\section{DELIMITATION OF AREAS}

We used large areas because we needed a sufficient number of observations for adequate significance testing of the biogeographic hypotheses and because we 
Table 1. Overview of the 57 Holarctic groups analysed in this study. For the 39 phylogenies that were dated in some analyses, the age and evidence used for dating is given for each dated node (see Appendix for the position of the dated nodes in the phylogenies)

\begin{tabular}{|c|c|c|c|}
\hline Group & References & $\begin{array}{l}\text { Node }^{1}: \\
\text { Date (Myr) }\end{array}$ & Evidence $^{2}$ \\
\hline $\begin{array}{l}\text { Xestia (Schoyenia) } \\
\text { (Insecta, Lepidoptera, Noctuidae) }\end{array}$ & Lafontaine et al., 1983 & $\begin{array}{l}1: 2 \\
2: 1\end{array}$ & $\begin{array}{l}\text { IF } \\
\text { BBIII }\end{array}$ \\
\hline $\begin{array}{l}\text { Trichosilia } \\
\text { (Insecta, Lepidoptera, Noctuidae) }\end{array}$ & $\begin{array}{l}\text { Lafontaine \& } \\
\text { Kononenko, } 1986\end{array}$ & $\begin{array}{l}1: 17 \\
2: 8\end{array}$ & $\begin{array}{l}\mathrm{IF} \\
\mathrm{BBII}\end{array}$ \\
\hline $\begin{array}{l}\text { Sathon }^{\mathrm{E}} \\
\text { (Insecta, Hymenoptera, Braconidae) }\end{array}$ & Williams, 1988 & $\begin{array}{l}1: 50 \\
2: 25 \\
3: 8 \\
4: 6\end{array}$ & $\begin{array}{l}\mathrm{F}+\mathrm{N}-\mathrm{AT} \\
\mathrm{CU} \\
\text { BII } \\
\text { North and South America connected }\end{array}$ \\
\hline $\begin{array}{l}\text { Symmorphus debilitatus-group } \\
\text { (Insecta, Hymenoptra, Vespidae) }\end{array}$ & Cumming, 1989 & $\begin{array}{l}1: 17 \\
2: 8 \\
3: 6\end{array}$ & $\begin{array}{l}\mathrm{F}+\mathrm{IF} \\
\mathrm{BBII} \\
\mathrm{JAP}\end{array}$ \\
\hline $\begin{array}{l}\text { Ibaliidae }^{\mathrm{E}} \\
\text { (Insecta, Hymenoptera) }\end{array}$ & $\begin{array}{l}\text { Nordlander et al., } 1996 \\
\text { Ronquist, } 1999\end{array}$ & $\begin{array}{l}1: 150 \\
2: 8 \\
3: 6 \\
4: 1\end{array}$ & $\begin{array}{l}\text { PAN } \\
\text { BBII } \\
\text { JAP } \\
\text { BBIII }\end{array}$ \\
\hline Limnoporus $^{\mathrm{E}}$ (Insecta, Hemiptera, Gerridae) & $\begin{array}{l}\text { Andersen \& Spence, } \\
1992 \\
\text { Andersen, } 1993\end{array}$ & $\begin{array}{l}1: 55 \\
2: 35 \\
3: 6 \\
4: 1\end{array}$ & $\begin{array}{l}\text { F } \\
\text { BBI } \\
\text { JAP } \\
\text { BBIII }\end{array}$ \\
\hline Aquarius $^{\mathrm{E}}$ (Insecta, Hemiptera, Gerridae) & Andersen, 1990 & $1: 55$ & $\mathrm{~F}$ \\
\hline $\begin{array}{l}\text { Nabicula (Limnonabis) } \\
\text { (Insecta, Heteroptera, Nabidae) }\end{array}$ & Asquith \& Lattin, 1990 & $\begin{array}{l}1: 150 \\
2: 80 \\
3: 50 \\
4: 25\end{array}$ & $\begin{array}{l}\text { IF } \\
\text { EU-As } \\
\text { N-AT } \\
\text { CU }\end{array}$ \\
\hline $\begin{array}{l}\text { Nephrotoma dorsalis-group } \\
\text { (Insecta, Diptera, Tipulidae) }\end{array}$ & Tangelder, 1988 & $\begin{array}{l}1: 35 \\
2: 15 \\
3: 10 \\
4: 8 \\
5: 6 \\
6: 3.5 \\
7: 2\end{array}$ & $\begin{array}{l}\mathrm{F}+\mathrm{TE} \\
\text { HIM } \\
\text { Development of grasslands (Great } \\
\text { Plains) } \\
\text { Development of boreal forests } \\
\text { JAP } \\
\text { Opening of Bering strait } \\
\text { Spread of arctic conditions }\end{array}$ \\
\hline Potamanthidae $^{\mathbb{E}}$ (Insecta, Ephemeroptera) & $\begin{array}{l}\text { Bae \& McCafferty, } \\
1991\end{array}$ & $\begin{array}{l}1: 150 \\
2: 35 \\
3: 35 \\
4: 8\end{array}$ & $\begin{array}{l}\text { F + PAN } \\
\text { TE } \\
\text { Formation of the South China sea } \\
\text { Late Miocene cooling }\end{array}$ \\
\hline Blethisa $^{\mathrm{E}}$ (Insecta, Coleoptera, Carabidae) & $\begin{array}{l}\text { Goulet \& Smetana, } \\
1983\end{array}$ & $\begin{array}{l}1: 17 \\
2: 8 \\
3: 1\end{array}$ & $\begin{array}{l}F+I F \\
\text { BBII } \\
\text { BBIII }\end{array}$ \\
\hline $\begin{array}{l}\text { Elaphrus (Elaphroterus) } \\
\text { (Insecta, Coleoptera, Carabidae) }^{\mathrm{E}}\end{array}$ & Goulet, 1983 & $\begin{array}{l}1: 35 \\
2: 35 \\
3: 1\end{array}$ & $\begin{array}{l}\mathrm{F}+\mathrm{IF} \\
\mathrm{BBI} \\
\mathrm{BBIII}\end{array}$ \\
\hline
\end{tabular}


Table 1. continued

\begin{tabular}{|c|c|c|c|}
\hline Group & References & $\begin{array}{l}\text { Node }^{1}: \\
\text { Date (Myr) }\end{array}$ & Evidence $^{2}$ \\
\hline $\begin{array}{l}\text { Elaphrus (Neoelaphrus) } \\
\text { (Insecta, Coleoptera, Carabidae) }^{\mathrm{E}}\end{array}$ & Goulet, 1983 & $\begin{array}{l}1: 35 \\
2: 35 \\
3: 8 \\
4: 3 \\
5: 1\end{array}$ & $\begin{array}{l}\mathrm{F}+\mathrm{BBI} \\
\mathrm{TE} \\
\text { BBII } \\
\text { Late Pliocene cooling event } \\
\mathrm{G} \text { (Pyrenees) }\end{array}$ \\
\hline Sericoda (Insecta, Coleoptera, Carabidae) & Liebherr, 1991 & $\begin{array}{l}1: 17 \\
2: 8 \\
3: 1\end{array}$ & $\begin{array}{l}\text { IF } \\
\text { BBII } \\
\text { BBIII }\end{array}$ \\
\hline Anchonemus (Insecta, Coleoptera, Carabidae) & Liebherr, 1991 & $\begin{array}{l}1: 35 \\
2: 1\end{array}$ & $\begin{array}{l}\text { BBI } \\
G\end{array}$ \\
\hline Myadi (Insecta, Coleoptera, Carabidae) & Allen, 1980 & $1: 50$ & $\mathrm{~N}-\mathrm{AT}$ \\
\hline Loricera (Insecta, Coleoptera, Carabidae) & Ball \& Erwin, 1969 & $\begin{array}{l}1: 65 \\
2: 35 \\
3: 10 \\
4: 1 \\
5: 1\end{array}$ & $\begin{array}{l}\text { IF } \\
\text { BBI } \\
\text { Sierra Madre uplift (Miocene) } \\
\text { G } \\
\text { BBIII }\end{array}$ \\
\hline $\begin{array}{l}\text { Laccornis }^{\mathrm{E}} \\
\text { (Insecta, Coleoptera, Dytiscidae) }\end{array}$ & Wolfe \& Rougley, 1990 & $\begin{array}{l}1: 100 \\
2: 80 \\
3: 35 \\
4: 35 \\
5: 25 \\
6: 1\end{array}$ & $\begin{array}{l}\text { F+opening of Turgai strait } \\
\text { EU-As } \\
\text { BBI } \\
\text { TE } \\
\text { CU } \\
\text { G }\end{array}$ \\
\hline $\begin{array}{l}\text { Agabus affinis-group } \\
\text { (Insecta, Coleoptera, Dytiscidae) }\end{array}$ & $\begin{array}{l}\text { Nilsson \& Larson, } \\
1990\end{array}$ & $\begin{array}{l}1: 17 \\
2: 8 \\
3: 1\end{array}$ & $\begin{array}{l}\text { IF } \\
\text { BBII } \\
\text { BBIII }\end{array}$ \\
\hline $\begin{array}{l}\text { Dytiscus }{ }^{k} \\
\text { (Insecta, Coleoptera, Dystiscidae) }\end{array}$ & Roughley, 1990 & 1: 150 & PAN \\
\hline $\begin{array}{l}\text { Gymnusa } \\
\text { (Insecta, Coleoptera, Staphylinidae) }\end{array}$ & Klimaszewski, 1979 & $\begin{array}{l}1: 65 \\
2: 50 \\
3: 35\end{array}$ & $\begin{array}{l}\text { IF } \\
\text { N-AT } \\
\text { BBI }\end{array}$ \\
\hline $\begin{array}{l}\text { Deinopsis } \\
\text { (Insecta, Coleoptera, Staphylinidae) }\end{array}$ & Klimaszewski, 1979 & $\begin{array}{l}1: 65 \\
2: 35\end{array}$ & $\begin{array}{l}\mathrm{IF} \\
\mathrm{BBI}\end{array}$ \\
\hline $\begin{array}{l}\text { Cicindela sylvatica-group } \\
\text { (Insecta, Coleoptera, Cycindelidae) }\end{array}$ & Spanton, 1988 & $\begin{array}{l}1: 40 \\
2: 8 \\
3: 8\end{array}$ & $\begin{array}{l}\text { Temperate-deciduous forests in } \\
\text { North America } \\
\text { BBII } \\
\text { Dispersal from boreal forests to } \\
\text { grasslands in central N. Am. }\end{array}$ \\
\hline Pytho (Insecta, Coleoptera, Pythidae) & Pollock, 1991 & $\begin{array}{l}1: 150 \\
2: 50 \\
3: 8 \\
4: 6\end{array}$ & $\begin{array}{l}\mathrm{F}+\mathrm{PAN} \\
\mathrm{N}-\mathrm{AT} \\
\mathrm{BBII} \\
\mathrm{JAP}\end{array}$ \\
\hline $\begin{array}{l}\text { Hydrochara (Insecta, Coleoptera, } \\
\text { Hydrophilidae) }\end{array}$ & Smetana, 1980 & $\begin{array}{l}1: 80 \\
2: 50 \\
3: 35\end{array}$ & $\begin{array}{l}\text { EU-AS } \\
\text { N-AT } \\
\text { BBI }\end{array}$ \\
\hline
\end{tabular}


Table 1. continued

\begin{tabular}{|c|c|c|c|}
\hline Group & References & $\begin{array}{l}\text { Node }{ }^{\mathrm{l}}: \\
\text { Date (Myr) }\end{array}$ & Evidence $^{2}$ \\
\hline $\begin{array}{l}\text { Plateumaris }{ }^{\mathrm{E}} \\
\text { (Insecta, Coleoptera, Chrysomelidae) }\end{array}$ & Askevold, 1991 & $\begin{array}{l}1: 150 \\
2: 80 \\
3: 25 \\
4: 1\end{array}$ & $\begin{array}{l}\mathrm{F}+\mathrm{PAN} \\
\mathrm{MCS} \\
\mathrm{CU} \\
\mathrm{G} \text { (Nearctic) }\end{array}$ \\
\hline $\begin{array}{l}\text { Hypochilus }^{\mathrm{E}} \\
\text { (Arachnida, Araneae, Hypochilidae) }\end{array}$ & Catley, 1994 & $\begin{array}{l}1: 150 \\
2: 25 \\
3: 1\end{array}$ & $\begin{array}{l}\mathrm{F}+\mathrm{PAN} \\
\mathrm{CU} \\
\mathrm{G} \text { (Illinoisan) }\end{array}$ \\
\hline Pimoa $^{E}$ (Arachnida, Araneae, Pimoidae) & Hormiga, 1994 & $\begin{array}{l}1: 80 \\
2: 35\end{array}$ & $\begin{array}{l}\mathrm{F}+\mathrm{EU}-\mathrm{AS} \\
\mathrm{BBI}\end{array}$ \\
\hline $\begin{array}{l}\text { Callilepis }^{\mathrm{E}} \\
\text { (Arachnida, Araneae, Gnaphosidae) }\end{array}$ & Platnick, 1975, 1976 & $\begin{array}{l}1: 80 \\
2: 50 \\
3: 35 \\
4: 25\end{array}$ & $\begin{array}{l}\mathrm{F}+\mathrm{PAN}+\mathrm{EU}-\mathrm{AS} \\
\mathrm{N}-\mathrm{AT} \\
\mathrm{BBI} \\
\mathrm{CU}\end{array}$ \\
\hline Esox ${ }^{\bar{E}}$ (Teleostei, Esocidae) & Nelson, 1972 & $\begin{array}{l}1: 65 \\
2: 50\end{array}$ & $\begin{array}{l}\mathrm{F} \\
\mathrm{N}-\mathrm{AT}\end{array}$ \\
\hline Umbridae $^{\mathrm{E}}$ (Teleostei) & $\begin{array}{l}\text { Wilson \& Veilleux, } \\
1982\end{array}$ & $\begin{array}{l}1: 65 \\
2: 50 \\
3: 1\end{array}$ & $\begin{array}{l}\mathrm{F} \\
\mathrm{N}-\mathrm{AT} \\
\mathrm{BBIII}\end{array}$ \\
\hline Catostomidae $^{E}$ (Teleostei) & Smith, 1992 & $\begin{array}{l}1: 65 \\
2: 50 \\
3: 22 \\
4: 8\end{array}$ & $\begin{array}{l}F \\
F \\
F \\
F\end{array}$ \\
\hline $\begin{array}{l}\text { Oncorhynchus }{ }^{\mathrm{E}} \\
\text { (Teleostei, Salmonidae) }\end{array}$ & $\begin{array}{l}\text { Shedlock et al., } 1992 \\
\text { Domanico \& Philips, } \\
1995\end{array}$ & $\begin{array}{l}\text { 1: } 5 / 2: 4.5 / 3: \\
\text { 4.3. 4: } 3.5 / 5: \\
2: 9 / 6: 2.6 / 7: \\
2.5\end{array}$ & MC \\
\hline $\begin{array}{l}\text { Alectoris }{ }^{E} \\
\text { (Aves, Galliformes, Phasianidae) }\end{array}$ & Randi, 1996 & $\begin{array}{l}\text { 1: } 6 / 2: 2.4 / 3: \\
2.0 / 4: 1.0 / 5: \\
1.2 / 6: 3\end{array}$ & MC \\
\hline $\begin{array}{l}\text { Anthus }^{\mathrm{E}} \\
\text { (Aves, Passeriformes, Motacillidae) }\end{array}$ & Voelker, 1999a,b & $\begin{array}{l}\text { 1: } 7 / 2: 5.6 / 3: \\
\text { 4.2/4: } 2.7 / 5: \\
1.3 / 6: 1.8 / 7: \\
0.9 / 8: 4.7 / 9: \\
2.3\end{array}$ & $\mathrm{MC}$ \\
\hline $\begin{array}{l}\text { Sorex longimstris-group }{ }^{\mathrm{E}} \\
\text { (Mammalia, Soricidae) }\end{array}$ & George, 1988 & $\begin{array}{l}1: 2 \\
2: 1.5 \\
3: 1\end{array}$ & $\begin{array}{l}\mathrm{F} \\
\mathrm{G}(\text { Wisconsinan }) \\
\text { BBIII }\end{array}$ \\
\hline $\begin{array}{l}\text { Ursidae }^{\mathrm{E}} \\
\text { (Mammalia, Camivora) }\end{array}$ & $\begin{array}{l}\text { Talbot \& Shields, } 1996 \\
\text { Zhang \& Ryder, } 1994\end{array}$ & $\begin{array}{l}\text { 1: } 12.5 / 2: 7 / 3: \\
6 / 4: 5 / 5: 1.5 / \\
6: 5 / 7: 6.1\end{array}$ & $\mathrm{MC}$ \\
\hline $\begin{array}{l}\text { Chabaudgolvania } \\
\text { (Nematoda, Ascaridida, Quimperiidae) }\end{array}$ & $\begin{array}{l}\text { Adamson \& } \\
\text { Richardson, } 1989\end{array}$ & $1: 35$ & $\mathrm{~F}$ (fossil of host) $+\mathrm{BBI}$ \\
\hline
\end{tabular}


Table 1. continued

\begin{tabular}{|c|c|c|c|}
\hline Group & References & $\begin{array}{l}\text { Node }^{1}: \\
\text { Date (Myr) }\end{array}$ & Evidence \\
\hline $\begin{array}{l}\text { Daphnia longispina-group } \\
\text { (Crustacea, Cladocera) }\end{array}$ & $\begin{array}{l}\text { Taylor et al., } 1996 \\
\text { Lehman et al., } 1995\end{array}$ & $\begin{array}{l}\text { (cladograms } 1 \text { and } \\
2 \text { ) } 1: 100 / 2: 100 \\
\text { 3: } 53 / 4: 6 / 5: \\
1.8 / 6: 1.4 / 7: 1 / \\
\text { 8: 3.5/9: } 1 / 10: \\
26.5 / 11: 30 \\
\text { (cladogram } 3 \text { ) } 1 \text { : } \\
100 \\
2: 53 / 3: 6 / 4 \\
1.8 / 5: 1.4 / 6: 1 / \\
7: 3.5 / 8: 1 / 9: \\
26.5 / 10: 65 / 11: \\
30\end{array}$ & $\begin{array}{l}\mathrm{MC}+\mathrm{F} \\
\mathrm{MC}\end{array}$ \\
\hline
\end{tabular}

Heterotrissocladius (Insecta, Diptera,

Chrinomidae)

Hydrobaenus (Insecta, Diptera,

Chironomidae)

Mosillus (Insecta, Diptera, Ephydridae)

Pachyneuridae (Insecta, Diptera)

Lotophila (Insecta, Diptera, Sphaeroceridae)

Keroplatus (Insecta, Diptera, Keroplatidae)

Rocatelion (Insecta, Diptera, Keroplatidae)

Coelosia (Insecta, Diptera, Mycetophilidae)

Paraclemensia (Insecta, Lepidoptera,

Incurvariidae)

Nitidotachinus (Insecta, Coleoptera,

Staphylinidae)

Lygus (Insecta, Heteroptera, Miridae)

Atractotomus (Insecta, Heteroptera, Miridae)

Oxyethira (Insecta, Trichoptera,

Hydroptilidae)

Flexamia (Insecta, Homoptera, Cicadellidae)

Taenionema (Insecta, Plecoptera,

Taeniopterygidae)

Gasterosteiformes (Pisces, Teleostei)

Larus (Aves, Ciconiiformes, Laridae)

Marmota (Mammalia, Rodentia, Sciuridae)
Saether, 1975

Saether, 1976

Mathis et al., 1993

Wood, 1981

Norrbom \& Kim, 1984

Norrbom \& Marshall, 1988

Matile, 1990

Matile, 1990

Söli, 1997

Nielsen, 1982

Campbell, 1993

Schwartz \& Foottit, 1998

Stonedahl, 1990

Kelley, 1985

Dietrich et al., 1997

Stanger \& Baumann, 1993

Paepke, 1983

Chu, 1998

Kruckenhauser et al., 1998

* Three different solutions of the trichotomy (see Appendix).

${ }^{\mathrm{E}}$ Groups belonging to the externally dated set (only nodes dated with external evidence were considered in this analysis).

${ }^{1}$ Numbers refer to the numbered nodes in the cladogram of each group (see Appendix).

${ }^{2}$ Dating evidence: $\mathrm{F}=$ Fossil, $\mathrm{G}=$ Vicariance during Pleistocene glaciations, $\mathrm{IF}=$ Inferred from the age of a younger, dated node, $\mathrm{MC}=$ Molecular clock, $\mathrm{PAN}=$ Laurasia - Gondwana vicariance, $\mathrm{TE}=$ Vicariance due to the climatic cooling at the Terminal Eocene event. Other codes (BBI, CU, MCS) are explained in Table 4. Only F, MC and PAN datings are considered based on external evidence (the externally dated set). 
A

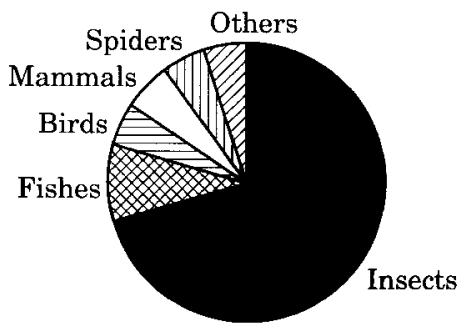

$\mathrm{C}$

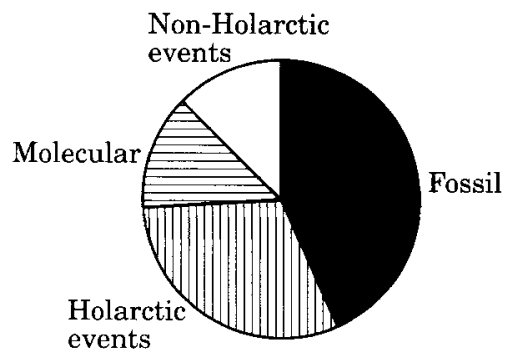

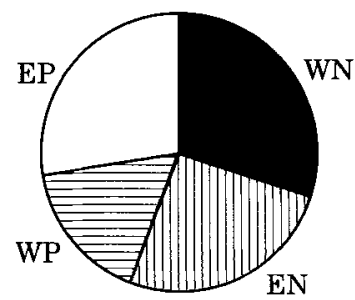

D

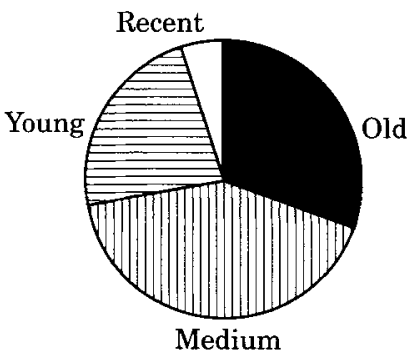

Figure 5. Pie charts summarizing various aspects of the data set analysed in this paper. (A) Taxonomic composition (number of groups). (B) Number of terminal taxa distributed in each Holarctic infraregion. (C) Type of evidence used for testing the basal divergence of each group (number of groups per category): fossil record (Fossil), molecular clock (Molecular), non-Holarctic biogeographic events (Non-Holarctic events), and Holarctic biogeographic events listed in Table 4 (Holarctic events). (D) Number of groups whose first divergence event is included within each time class.

wanted our results to be comparable with those of Enghoff (1995). Thus, the Holarctic was divided into four infraregions, each corresponding to a historically persistent landmass according to palaeogeographic reconstructions (Cox, 1974): the eastern and western Nearctic and the eastern and western Palaeoarctic. The eastern Nearctic (EN) was defined as North America east of the former Mid-Continental Seaway; the western Nearctic (WN) as North America west of the Mid-Continental Seaway; the western Palaeoarctic (WP) as Europe, North Africa and Asia west of the former Turgai Sea; and the eastern Palaeoarctic (EP) as non-tropical Asia east of the Turgai Sea.

The Holarctic region and its infraregions were interpreted in a wide sense. Thus, many Mexican distributions were considered as western Nearctic because Central America was connected to WN during the time of the Mid-Continental Seaway, and many Mexican taxa show close relationships with western North America via the Cordilleran Mountain System (Liebherr, 1991). However, tropical Mexican distributions were considered as outside occurrences (NT in Appendix). Similarly, taxa occurring in the northern part of the Oriental region (e.g. northern India (Burma), South China, Indochina, northwest Thailand, West Malaysia) were scored as eastern Palaeoarctic.
These terranes rifted from the margin of eastern Gondwana during the Late Carboniferous-Early Permian but were part of the Laurasian landmass by the Late Triassic-Early Jurassic (Yin, 1994). During the Early Tertiary, they were covered by the same boreotropical flora as Japan and China, indicating that, at least during that period, connections existed between the eastern Palaeoarctic and Oriental regions (Wolfe, 1977; Tiffney, 1985a).

The distribution of taxa was interpreted according to the original study. For example, if the author stated that a taxon occurs mainly in $\mathrm{WN}$ and that EN records are sporadic, unreliable, or due to late dispersal, the taxon was scored exclusively as WN.

The western Palaeoarctic is the least represented infraregion in the data set $(n=158)$ (Fig. 5B). The western Nearctic is the most common infraregion ( $n=$ $289)$, followed by the eastern Nearctic $(n=263)$ and the eastern Palaeoarctic ( $n=248$ ). This is significantly different from expected if taxa were equally distributed in the four infraregions ('goodness of fit' $\chi^{2}=40.6, \mathrm{df}=$ $3, P<0.01)$. Comparison with the geographic distribution of species in groups whose Holarctic fauna is well known suggests that, in our data set, the eastern Palaeoarctic is underrepresented and the Nearctic possibly over-represented (Table 2). 


\section{ANALYSES}

Testing the hierarchical scenario

An event-based tree-fitting criterion, Maximum Vicariance (MV) (Page, 1995; see also Ronquist, 1998a,b) was used to test for the existence of a general hierarchical vicariance pattern for the Holarctic. MV was used to fit each of the 18 possible labelled histories for the four Holarctic infraregions (Fig. 6) in turn to all the 57 cladograms in the data set using TreeFitter 1.0 (Ronquist, 2001). MV finds the maximum number of vicariance events that can be explained by a particular hierarchical scenario given the data set, disregarding the other events that must be postulated. The larger the number of vicariance events, the better the hierarchical scenario explains the observed data.

To test for significant fit between the best hierarchical scenario and the data set, we randomly permuted the terminal distributions in the original data set 10000 times and then calculated the fit between each random data set and the best hierarchical scenario using TreeFitter 1.0. The $P$ value was estimated as the proportion of the random data sets fitting the biogeographic scenario at least as well as the original data.

Widespread taxa (taxa distributed in more than one area) pose a problem for reconstructing hierarchical patterns because they introduce ambiguity in the data set (Morrone \& Crisci, 1995). This problem has not yet been satisfactorily solved in the literature. Here, we treated widespread taxa using each of three novel event-based options (Ronquist, in press). The recent option assumes that the wide distribution is of recent origin and explains it by dispersal; the ancient option considers the wide distribution to be of ancient origin and explains any mismatch between the distribution and the area cladogram by extinction (possible vicariance events within the widespread terminal not counted); and the free option treats the widespread terminal as an unresolved higher taxon consisting of one lineage occurring in each area, and permits any combination of events and any resolution of the terminal polytomy in explaining the wide distribution.

All possible dichotomous resolutions were considered for polytomous cladograms. Each alternative dichotomous cladogram was weighted such that the sum of the alternatives corresponded to the single cladogram of a fully resolved group. Thus, if there were three possible dichotomous cladograms, the results from each were weighted with $1 / 3$.

\section{General Holarctic patterns}

Dispersal-vicariance analysis (DIVA; Ronquist, 1996, 1997), an event-based parsimony method, was used to find general biogeographic patterns in the data set. Unlike other methods, DIVA does not enforce hierarchical area relationships so it can be used to address reticulate biogeographic scenarios. DIVA was first used to infer the biogeographic history of each individual group. If several equally optimal reconstructions existed, all alternatives were considered and each possibility down-weighted such that the sum of all alternatives corresponded to a single unambiguous reconstruction. DIVA reconstructions specify vicariance events, dispersal events, diversification events (speciation within a single unit area), and ancestral distributions (allowing assessment of past species richness in different unit areas). The frequencies of these inferred events and ancestral distributions were summed over all 57 cladograms.

We assessed the significance of the results in two

Table 2. Species richness in each Holarctic infraregion for some well-documented groups. Introduced species have not been counted, nor have species only occurring in areas formerly covered by the Mid-Continental Seaway or the Turgai Sea. The number of species per infraregion in our data set is also shown

\begin{tabular}{|c|c|c|c|c|}
\hline \multirow[b]{2}{*}{ Taxon } & \multicolumn{4}{|c|}{ Number of species } \\
\hline & WN & $\mathrm{EN}$ & WP & $\mathrm{EP}$ \\
\hline Testudines $^{1}$ (except Chelonidae and Dermochelyidae) & 12 & 25 & 9 & 23 \\
\hline Amphibia $^{2}$ & 73 & 126 & 76 & 262 \\
\hline Aves $^{3}$ & 476 & 318 & 435 & 800 \\
\hline Total & $\begin{array}{l}561 \\
(21 \%)\end{array}$ & $\begin{array}{l}469 \\
(18 \%)\end{array}$ & $\begin{array}{l}520 \\
(20 \%)\end{array}$ & $\begin{array}{l}1085 \\
(41 \%)\end{array}$ \\
\hline Holarctic data set (this study) & $\begin{array}{l}289 \\
(30 \%)\end{array}$ & $\begin{array}{l}263 \\
(27 \%)\end{array}$ & $\begin{array}{l}158 \\
(16 \%)\end{array}$ & $\begin{array}{c}248 \\
(26 \%)\end{array}$ \\
\hline
\end{tabular}

\footnotetext{
${ }^{1}$ Iverson (1992).

"Frost (1985), Duellman (1993).

${ }^{3}$ Howard \& Mooe (1991).
} 

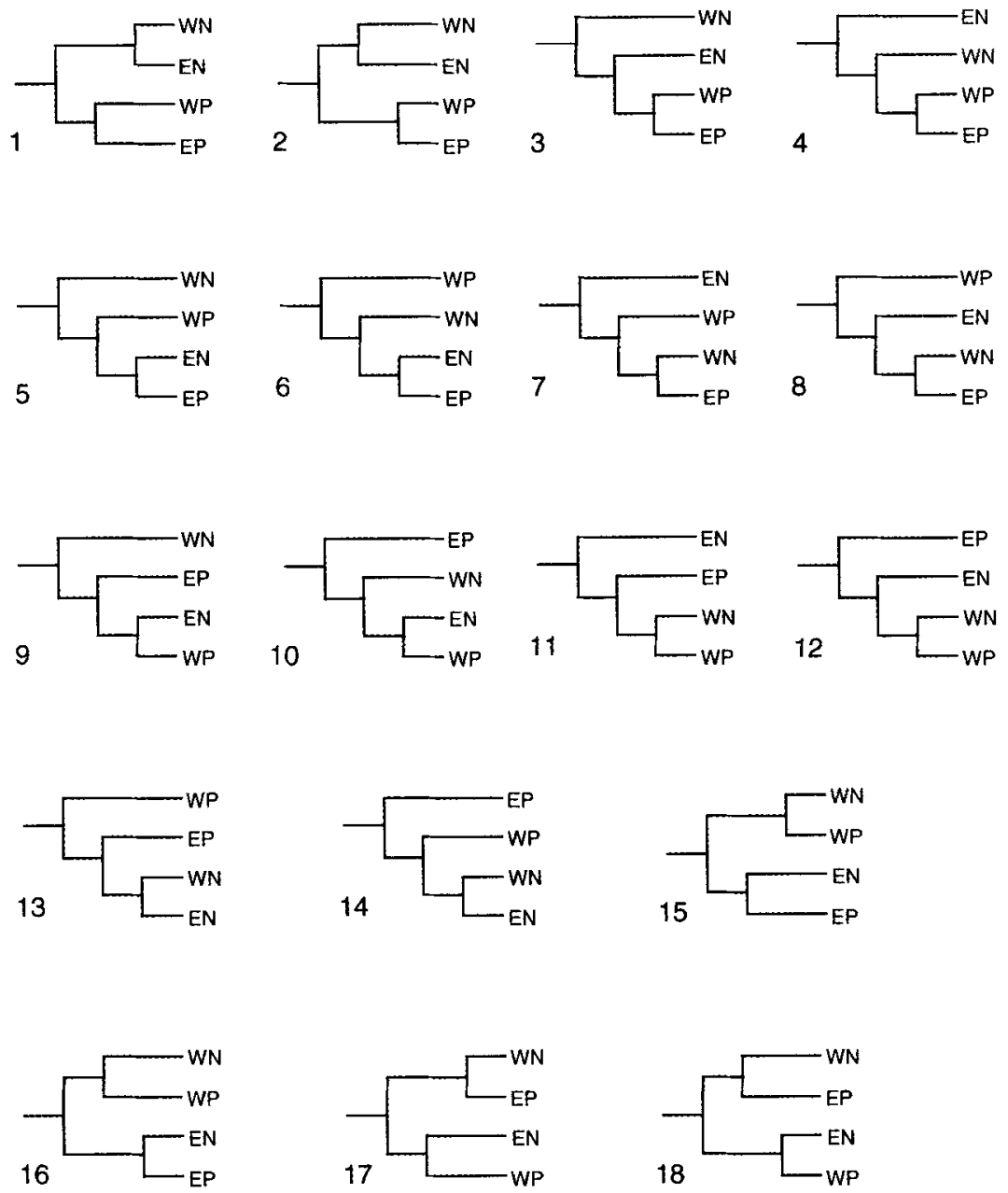

Figure 6. The 18 possible hierarchical scenarios for the Holarctic region. There are 15 possible branching arrangements of the four Holarctic infraregions. However, each of the three symmetrical branching arrangements produces two posssible labelled histories if the sequence of the splitting events is taken into account (the first two and the four bottom scernarios). This gives a total of 18 scenarios.

steps. First, we tested whether DIVA detected any overall patterns that were phylogenetically conserved by comparing the observed total cost over all 57 cladograms with the total cost over each of 100 data sets for which the terminal distributions had been randomly shuffled. Second, we tested whether the relative frequency of particular biogeographic events, relating to the hypotheses we wanted to test, differed from what would be expected by chance by a modified $\chi^{2}$-test, in which the expected frequency and the reference distribution were both calculated from 100 randomly permuted data sets. For simplicity, this permutation-based test statistic will be labelled $\chi^{2}$ but it should not be confused with an ordinary $\chi^{2}$-test using the standard $\chi^{2}$ distribution to assess significance.

\section{Holarctic patterns over time}

In order to analyse the variation of biogeographic patterns over time, DIVA-inferred events were sorted into time classes.

Events. The frequencies of most dispersal events were too low to infer patterns of variation through time. Instead, the variation in the frequency of two-area distributions was used as an indicator of the appearance and disappearance of dispersal barriers. When two isolated areas become connected, the corresponding two-area distributions should increase in frequency. As long as the areas are connected, the twoarea distributions should remain common. When a 
dispersal barrier separates the connected areas, we expect to see massive vicariance across the barrier and concomitant decrease in the frequency of the two-area distributions. We also recorded the variation in species richness and diversification in each infraregion over time.

Time classes. Age estimates (see below) suggest that the biogeographic events documented by the cladograms span from the Late Mesozoic to the present. This period was divided into four time classes (Table 3): old (before $70 \mathrm{Myr}$ ), medium (70-20 Myr), young (20-3 Myr), and recent (3-0 Myr). A finer division into more traditional geological periods (e.g. Eocene, Oligocene, Miocene, etc.) was not feasible because the dated events were too few, particularly in the older time periods. Time classes were delimited based on two criteria: (a) they must be wide enough to contain a sufficient number of cladogenetic events in our phylogenies; and (b) each time class should preferably contain or be delimited by only one of the postulated Holarctic dispersal-vicariance events of interest. The latter was not always possible to achieve. For instance, the medium time class included both the trans-Atlantic bridge (50 Myr) and the first Beringian Bridge (35 Myr). To separate trans-Atlantic and trans-Beringian dispersal routes, we used another division into four time classes, in which the medium time class was divided into two subclasses, 70-45 and 45-20 Myr, while the young and recent time classes were pooled. The time boundary of $45 \mathrm{Myr}$ was chosen to assure that, in the younger time class, the dispersal route between North America and Eurasia had switched definitely to Beringia from having been predominantly North Atlantic. This hypothesized event, when the cross-Atlantic Thulean route broke up and Beringia became warmer, has been dated to approximately 50 Myr (Pielou, 1979).

Dating. We used two different methods of dating, resulting in two different dated subsets of the data: the externally and fully dated sets. Table 1 indicates for each cladogram the dated nodes and the evidence used for dating them.

In the externally dated set, we used fossil evidence, molecular clock estimates or non-Holarctic biogeographic events for dating (Fig. 5C; Table 1). Molecular clock dates were taken from the original papers. All clocks were calibrated with the fossil record of the group in question, except for the genus Anthus (Voelker, 1999a). For fossil evidence, the oldest known fossil of the group was used to date the root node in the phylogeny. Occasionally, some internal nodes were also dated using fossil evidence (e.g., Catostomidae). Pleistocene fossils were only used if the group actually did originate during the Quaternary according to the author(s) of the original paper (e.g. Sorex longinostrisgroup). Non-Holarctic biogeographic events that were useful for dating included the split up of Pangaea (150 Myr) and the formation of a land bridge between Northern and Southern America (6 Myr) (Pielou, 1979). Twenty-seven of the phylogenies could be at least partially dated using these techniques (Fig. 5C).

In the fully dated set we used certain Holarctic biogeographic events as additional temporal reference points. The idea was to increase temporal resolution for patterns other than those used for dating and to allow dating of more phylogenies. Table 4 shows the vicariance events that were used and the dates assigned to each of them. In the case of vicariance involving the Beringian land bridges, the habitat specificity of each group was used to assign the event to the correct bridge (Table 4). Occasionally, the dated event was associated with a terminal species, in which case the date was assigned to the terminal node itself. To reduce investigator bias, the events listed in Table 4 were only used for dating if they were explicitly mentioned in the original study. Our dating, however, does not necessarily coincide with that of the authors, since the biogeographic-geologic events used for dating took place during a time interval. For example, vicariance across the first Beringian bridge was dated as $35 \mathrm{Myr}$, although dispersal of temperate groups was possible after that date. Patterns that could not be dated unambiguously, such as the disjunctions EN-EP and WN-WP, were not used for dating even if they were dated in the original study.

If the age of one or more internal nodes but not the basal node could be fixed using biogeographic events listed in Table 4 , the basal node was assigned a date consistent with the age of the internal node(s). Thus, the basal node was dated to $150 \mathrm{Myr}$ in groups showing an internal Euramerica-Asiamerica vicariance (EUAs), to 65 Myr for groups with internal trans-Atlantic (N-AT) or first trans-Beringian vicariance (BBI); to 17 Myr for groups with internal second trans-Beringian vicariance (BBII); and to $2 \mathrm{Myr}$ for groups with internal third trans-Beringian vicariance (BBIII). Thirty-nine groups could be at least partially dated using external (molecular, fossil, or non-Holarctic events) or Holarctic reference points (Fig. 5C). The remaining 18 groups could not be dated because of insufficient information in the original study. The age (root node age) of all dated phylogenies is summarized in Figure 5D.

Branching clock. For both the fully and externally dated sets, after the dates of one or more internal nodes had been fixed, a 'branching clock' was used to determine the age of the remaining nodes. First, any dated interior nodes were connected to each other, forming a backbone of dated nodes. This was done by 
Table 3. The four time classes used in this study. For each time class, the geological period covered by the time-class, the Holarctic biogeographic events that took place during that period (codes correspond to those in Table 4 and Fig. 10 ), and the main characteristics of the groups that originated during that period, are given

\begin{tabular}{lllll}
\hline Time class & Time period & Geological period & Biogeographic events & $\begin{array}{l}\text { Groups originating in this } \\
\text { period }\end{array}$ \\
\hline Old & >70 Myr & $\begin{array}{l}\text { Late Mesozoic (before } \\
\text { Late Cretaceous) }\end{array}$ & Euramerica-Asiamerica (EU-As) & $\begin{array}{l}\text { Warm-temperate groups } \\
\text { Groups with Southern } \\
\text { Hemisphere sister groups }\end{array}$ \\
Medium & $70-20 \mathrm{Myr}$ & Early-Mid Tertiary & $\begin{array}{l}\text { Trans-Atlantic (N-AT) } \\
\text { Trans-Beringian (BBI) }\end{array}$ & $\begin{array}{l}\text { Warm-temperate groups } \\
\text { associated with the } \\
\text { boreotropical-mixed } \\
\text { mesophytic forest }\end{array}$ \\
Young & $20-3 \mathrm{Myr}$ & Late Tertiary & Trans-Beringian (BBII) & $\begin{array}{l}\text { Boreal groups associated with } \\
\text { taiga-coniferous forests } \\
\text { Recent }\end{array}$ \\
& $3-0 \mathrm{Myr}$ & Quaternary & Trans-Beringian (BBIII) & $\begin{array}{l}\text { Arctic groups associated with } \\
\text { tundra vegetation }\end{array}$ \\
\hline
\end{tabular}

Table 4. Holarctic dispersal-vicariance events used for dating ancestral nodes in the phylogeny of the groups studied (the fully dated set). For each biogeographic event, the geologic event that caused the vicariance, the habitat specificity of the groups affected by the event, and the date assigned to it, are given

\begin{tabular}{|c|c|c|}
\hline Biogeographic event & Code (date) & Geologic event (habitat specificity) \\
\hline $\begin{array}{l}\text { Euramerica-Asiamerica } \\
(\mathrm{WN}+\mathrm{EP})-(\mathrm{EN}+\mathrm{WP})\end{array}$ & EU-AS (80 (Myr) & $\begin{array}{l}\text { Separation of the palaeocontinents } \\
\text { Euramerica-Asiamerica }\end{array}$ \\
\hline Trans-Atlantic (EN-WP) & N-AT (50 Myr) & $\begin{array}{l}\text { Closing of the Thulean North Atlantic bridge }{ }^{1} \\
\text { (Warm-temperate groups) }\end{array}$ \\
\hline $\begin{array}{l}\text { Beringian bridge I } \\
\text { (WN-EP) }\end{array}$ & BBI (35 Myr) & $\begin{array}{l}\text { Terminal Eocene event } \\
\text { (Warm-temperate groups) }\end{array}$ \\
\hline $\begin{array}{l}\text { Beringian bridge II } \\
\text { (WN-EP) }\end{array}$ & BBII (8 Myr) & $\begin{array}{l}\text { Late Miocene-Pliocene cooling } \\
\text { (Boreal-coniferous groups) }\end{array}$ \\
\hline $\begin{array}{l}\text { Beringian bridge III } \\
\text { (WN-EP) }\end{array}$ & BBIII (1 Myr) & Arctic climates dominant (Arctic-tundra groups) \\
\hline Nearctic (WN-EN) & $\begin{array}{l}\text { (1) MCS ( } 80 \mathrm{Myr}) \\
\text { (2) CU ( } 25 \mathrm{Myr})\end{array}$ & $\begin{array}{l}\text { (1) Opening of Mid-Continental Seaway } \\
\text { (2) Uplift of Cordilleran Mountain System }\end{array}$ \\
\hline Palaeoarctic (WP-EP) & PAL (30 Myr) & Closing of Turgai Strait \\
\hline $\begin{array}{l}\text { Other minor events: } \\
\text { Himalaya-Central Asia } \\
\text { Japan-Continental Asia }\end{array}$ & $\begin{array}{l}\text { (1) HIM (15 Myr) } \\
\text { (2) JAP ( } 6 \text { Myr) }\end{array}$ & $\begin{array}{l}\text { (1) Himalayan orogeny } \\
\text { (2) Opening of Japanese Sea }\end{array}$ \\
\hline
\end{tabular}

${ }^{\mathrm{I}}$ Subsequent North Atlantic land bridges (Late Eocene-Miocene) were presumably restricted to cold-adapted groups and far less important for cross-Atlantic faunal exchange (McKenna, 1983).

${ }_{2}^{2}$ Although the opening of the Bering Strait took place at $3.5 \mathrm{Myr}$, most authors explain trans-Beringian vicariance of boreal groups as a result of increasing climate cooling during the Later Miocene-Pliocene.

${ }^{4}$ Mountain folding continued through the Miocene but most authors indicate the Late Oligocene as the age of the main orogenic phase (Tiffney, 1985b). In some cases, the second Nearctic vicariance was dated 35 Myr if the author explained this vicariance as a result of the Late Eocene cooling event. 


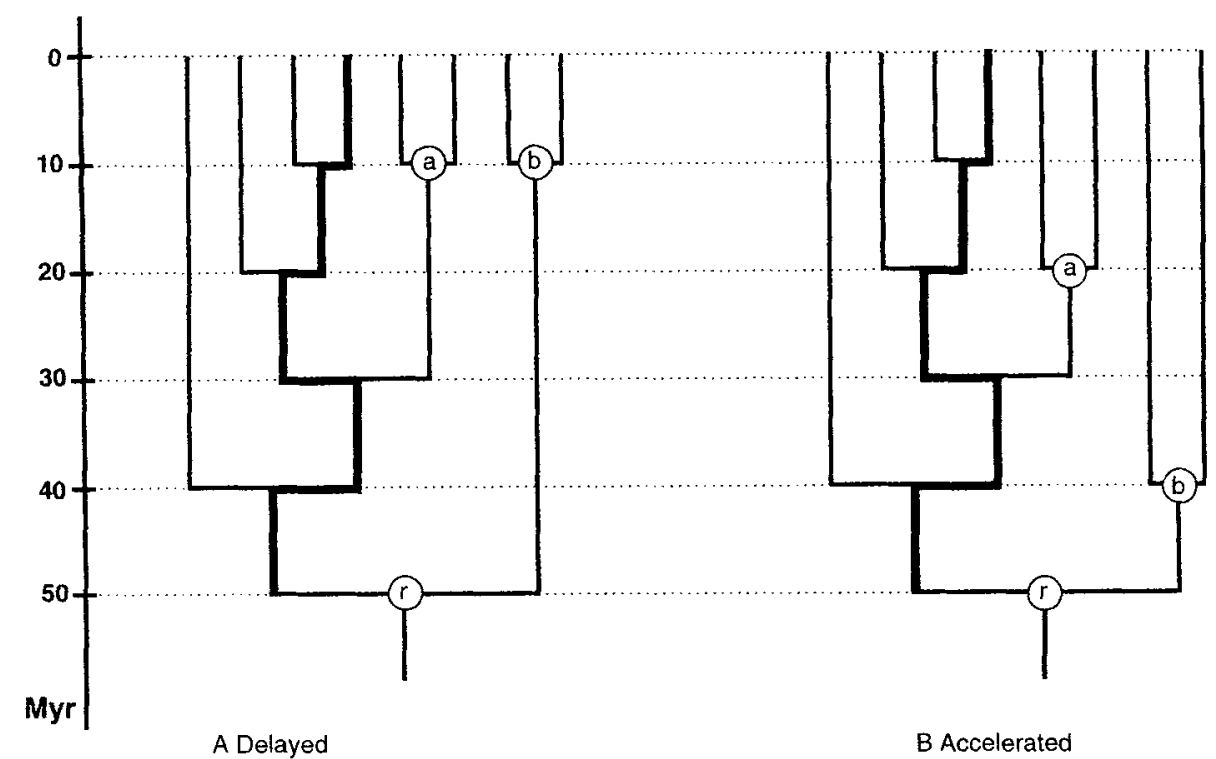

Figure 7. Schematic illustration of the branching clock method of estimating node dates. First, the longest sequence of speciation events linking the dated root ( $r$ ) to a terminal is identified (thick line). Then the branches in this sequence are assigned equal time duration ( $50 \mathrm{Myr} / 5=10 \mathrm{Myr}$ ). Finally, the remaining undated nodes (labelled $a$ and $b$ ) are assigned one of the dates in this sequence. (A). In delayed speciation, the undated nodes are assigned the youngest possible date. (B) In accelerated speciation, the undated nodes are assigned the oldest possible date.

first connecting the nodes separated by the fewest intermediate nodes. These intermediate nodes were then dated assuming equal branch lengths in the path between the dated nodes. Then, the next dated node closest to this backbone was connected and the intermediate nodes dated, until all dated nodes had been connected. Then, each tip of the dated backbone, which often consisted of only the root node (Fig. 7; node $r$ ), was connected to one of the terminal nodes from which it was separated by the largest number of speciation events (Fig. 7; bold line). Each branch in that sequence was assumed to have the same time duration. Finally, all remaining undated nodes (Fig. 7; node $a$ and $b$ ) were assigned one of the dates of the nodes in the closest dated clade by using one of two different methods. In delayed speciation, each node was assigned the youngest possible date (Fig. 7A); in accelerated speciation, the oldest possible date was used instead (Fig. 7B).

Significance tests. To identify significant variation in the frequency of biogeographic patterns over time, as evidenced by external dating, we compared the observed frequencies in each time class with the expected frequencies from 100 random data sets in which terminal distributions were randomly permuted. The permutation test could not be used with the fully dated set, since the age of some internal nodes in this set was determined based on the distributions of the terminals. If these distributions were permuted, the dating of the nodes would be nonsensical.

\section{RESULTS}

\section{TESTING THE HIERARCHICAL SCENARIO}

Figure 8 shows the cost of fitting each of the 18 possible hierarchical scenarios to the 57 phylogenies in our data set. Regardless of the event-based option used to treat widespread taxa (free, ancient or recent), the hierarchical scenarios 1 and 2 (Fig. 6) showed the best fit (the maximum number of vicariance events). These scenarios correspond to the same area cladogram ((WN, EN), (WP, EP)), depicting a basal separation of North America and Eurasia followed by eastern-western vicariance within each continent. They only differ in that scenario 1 assumes the eastern-western division to be older in the Palaeoarctic than in the Nearctic, whereas the reverse is true for scenario 2 (Fig. 6).

The difference in number of vicariance events between the best and the worst scenarios is quite small for the recent option but distinctly larger for the ancient option (Fig. 8). For the free option, the relative difference is small but the absolute difference is similar to the ancient option. Recall that the ancient option forces wide terminal distributions to be interpreted as supporting area relationships, whereas the recent 


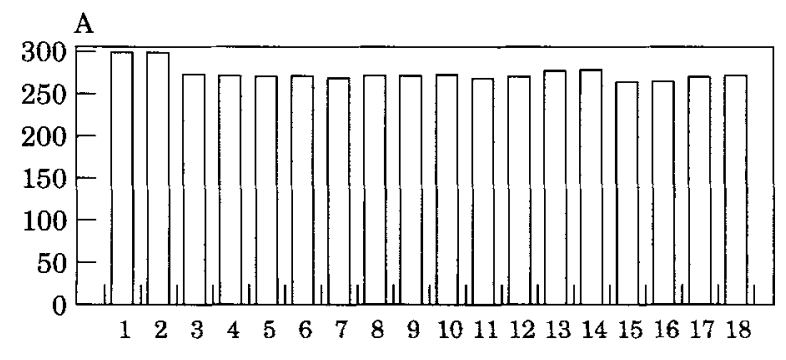

B

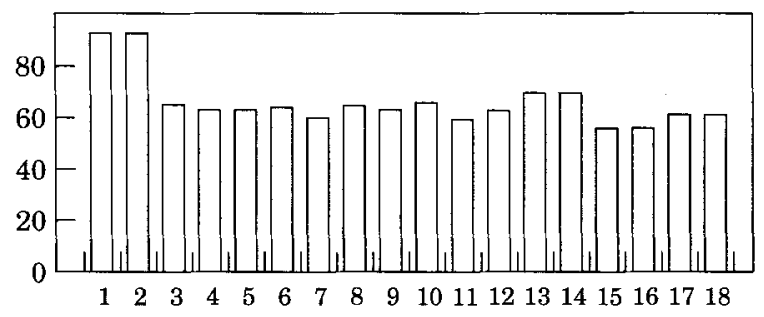

$\mathrm{C}$

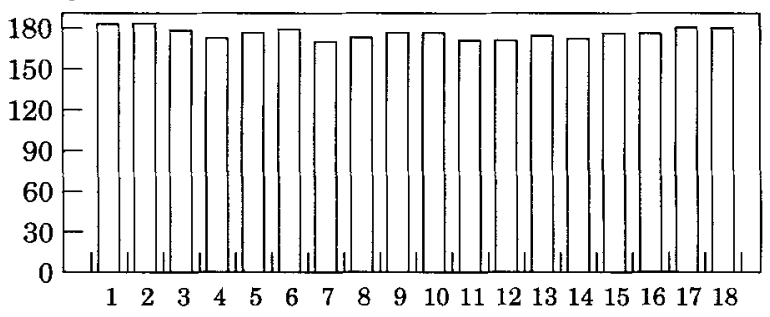

Figure 8. Bar diagrams showing the results of fitting each of the 18 Holarctic hierarchical scenarios (Fig. 6) to the entire data set of 57 Holarctic animal groups: (A) Free $(P>0.99)$; (B) Ancient $(P>0.99)$; (C) Recent $(P>0.99)$. The Maximum vicariance (Page, 1995; Ronquist, 1998a,b) criterion was used and the exact cost of each scenario was calculated using TreeFitter 1.0 (Ronquist, 2001). Maximum vicariance maximizes the number of vicariance events in the data that can be explained by the given scenario. Widespread taxa were treated using one of three event-based options: free, ancient or recent (see text). The statistical significance of the fit of the best scenario to the data was tested by comparison with the expected number of vicariance events in 10000 data sets in which the distributions had been randomly permuted in each group. For all options of treating widespread taxa, the fit was found to be nonsignificant ( $P>0.9999)$. This extraordinarily high $P$ value is caused by strong distribution duplication patterns (see text).

option never builds area relationships on widespread taxa. Thus, the small difference under the recent option indicates that the support for the best scenarios under the other options mainly comes from the prevalence of wide continental distributions $(\mathrm{WN}+\mathrm{EN}$ or $\mathrm{WP}+\mathrm{EP})$ among terminals, whereas internal nodes essentially group distributions randomly.

Permutations of the distributions showed that, regardless of the option used for widespread taxa, the best hierarchical scenarios did not fit the data set significantly better than expected by chance. Actually, all 10000 random data sets had more vicariance events than the original data, a highly significant result running in the opposite direction of the expected outcome ( $P>0.9999$ ). Such apparently anomalous results are expected in maximum vicariance analysis when local diversification (duplication) is common (Ronquist, in press). In any case, these results indicated that there was no hierarchical vicariance pattern that could adequately describe the data.

We also analysed Enghoff's (1995) data sets: the genus clades (groups at the genus level or below) and the family clades (groups at the family level or above). For the genus clades, the best hierarchical scenarios were numbers 1 and 2 (Fig. 6) (corresponding to RAC 13 in Enghoff, 1995) but the fit was not statistically significant, regardless of option used for widespread taxa ( $P=0.95$ for all options). For the family clades, the best hierarchical scenarios were again 1 and 2 for the free and ancient options but the fit was not statistically significant $(P=0.80$ for the free option and $P=0.65$ for the ancient option). For the recent option, however, the best hierarchical scenario was number 17 (Fig. 6), which showed a statistically significant fit to the data $(P=0.01)$. Scenario 17 has an initial split between Euramerica and Asiamerica, followed by 
further division within these palaeocontinents, the first being within Euramerica (Fig. 6).

\section{GENERAL HOLARCTIC PA'TTERNS}

Overall, DIVA analysis indicated less dispersal for the original data set than for any of the 100 permuted data sets. Thus, the observed number of dispersal events is significantly smaller than expected by chance $(P<0.01)$, which means that the observed distributions are strongly phylogenetically conserved.

Table 5 and Figure 9 show comparisons of the observed and expected frequencies of different types of dispersal events. Several general patterns were found.

\section{Large scale patterns}

Continental dispersals ( $\mathrm{WN} \leftrightarrow \mathrm{EN}$ and $\mathrm{WP} \leftrightarrow \mathrm{EP}$ ) are significantly more frequent than palaeocontinental (WN↔EP and $\mathrm{EN} \leftrightarrow \mathrm{WP}$ ) and disjunct (EN↔EP and $\mathrm{WN} \leftrightarrow \mathrm{WP})$ dispersals $\left(\chi^{2}=6.434, \quad P<0.01\right)$. Palaeocontinental dispersals, in turn, are significantly more frequent than disjunct dispersals $\left(\chi^{2}=1.965, P<0.01\right)$.

\section{Continental patterns}

The absolute number of dispersals within the Nearctic region (WN $\leftrightarrow \mathrm{EN}$ ) is larger than the number of dispersals within the Palaeoarctic region (WP $\leftrightarrow \mathrm{EP})$. However, when compared with expected frequencies, the opposite pattern is found: Palaeoarctic faunal exchange is significantly more frequent than expected by chance $\left(\chi^{2}=3.389, P<0.01\right)$. Within each continent, there is significant directional asymmetry. Dispersal from western North America to eastern North America $(\mathrm{WN} \rightarrow \mathrm{EN}$ ) is significantly more frequent than in the other direction $(\mathrm{EN} \rightarrow \mathrm{WN}):\left(\chi^{2}=2.656, P=0.03\right)$. In the Palaeoarctic, westward dispersals $(\mathrm{EP} \rightarrow \mathrm{WP})$ are significantly more frequent than eastward dispersals $(\mathrm{WP} \rightarrow \mathrm{EP}):\left(\chi^{2}=2.542, P=0.01\right)$.

\section{Trans-Beringian and trans-Atlantic exchange}

In absolute numbers, trans-Beringian dispersal between the eastern Palaeoarctic and western North America (WN $\rightarrow \mathrm{EP}$ ) is more frequent than trans-Atlantic dispersal between eastern North America and the western Palaeoarctic $(\mathrm{EN} \leftrightarrow \mathrm{WP})$. However, the difference is not significant $\left(\chi^{2}=0.0062 ; P=0.87\right)$. Western North America (WN $\rightarrow \mathrm{EP}$ ) is more frequently the source area of trans-Beringian dispersal than the eastern Palaeoarctic $(\mathrm{EP} \rightarrow \mathrm{WN})$, contrary to expectations, but the difference is not significant $\left(\chi^{2}=0.597, P=\right.$ $0.32)$. There is no significant directional asymmetry in the trans-Atlantic faunal exchange $(\mathrm{EN} \leftrightarrow \mathrm{WP})\left(\chi^{2}=\right.$ 1.221, $P=0.23$ ).

\section{EN-EP and WN-WP disjunctions}

There is no significant difference between the frequency of the eastern North America-eastern Palaeoarctic dispersals ( $\mathrm{EN} \leftrightarrow \mathrm{EP})$ and the western North America-western Palaeoarctic dispersals (WN↔WP) $\left(\chi^{2}=0.000002, P>0.99\right)$. Dispersal from western Palaeoarctic to western North America $(W P \rightarrow W N)$ is significantly more frequent than in the other direction $(\mathrm{WN} \rightarrow \mathrm{WP})\left(\chi^{2}=3.692, P<0.01\right)$, whereas there is no directional dispersal asymmetry for the EN-EP disjunction.

\section{Diversity differences}

The distribution of species richness among infraregions, summing over all ancestral nodes but disregarding terminal species, is significantly different from the distribution expected if species were distributed randomly with respect to infraregion $\left(\chi^{2}=\right.$ 38.891, $\mathrm{df}=3, P<0.01$ ). The western Palaeoarctic (WP) has the smallest diversity (153 ancestral species), followed by EP (244), EN (264) and WN (273) (cf. Fig. $5 \mathrm{~B}$, giving the species richness for extant species). The amount of diversification (the number of speciation events within each infraregion) is similarly distributed $\left(\mathrm{WP}=43, \mathrm{EP}=116, \mathrm{EN}=135, \mathrm{WN}=138 ; \chi^{2}=54.796\right.$, $P<0.01)$. These differences, however, are the result of the unequal representation of the four infraregions among terminal species. If the observed values are compared with the expected values obtained in the random data sets, i.e. correcting for the regional bias in extant faunal richness, differences are not significant ( $P=0.78$ for species richness, and $P=0.87$ for diversification). Thus, there are no phylogenetically determined differences in overall species richness or overall diversification rate among infraregions in our data set.

\section{HOLARCTIC PATTERNS OVER TIME}

\section{Dating accuracy}

With external dating, the branching clock was used to estimate the age of many internal nodes. Some of these nodes could also be dated using Holarctic biogeographic events (Table 4). This provided a useful test of the branching clock (Fig. 10; results shown for delayed speciation). The comparison reveals that the branching clock does well, at least for the older biogeographic events. In most cases, it appears to sort events correctly into one of the four broadly defined time classes we used. The most serious problem is with the younger events, which are consistently dated as being older than they are by the branching clock (Fig. 10). This bias is expected since the branching clock distributes nodes equally over time whereas, if speciation rates are roughly clock-like, extinctions will make sure that 
Table 5. Comparisons of the frequencies of different types of dispersals in the Holarctic data set. For each comparison, expected frequencies and statistically significant deviations from these were calculated based on 100 randomly permuted data sets (see text)

\begin{tabular}{|c|c|c|c|}
\hline $\begin{array}{l}\text { Dispersal events compared } \\
\text { Large-scale patterns }\end{array}$ & $\begin{array}{l}\text { Observed } \\
\text { frequency }\end{array}$ & $\begin{array}{l}\text { Expected } \\
\text { frequency }\end{array}$ & Significance \\
\hline $\begin{array}{l}\text { Continental } \\
\text { Palaeocontinental + Disjunct }\end{array}$ & $\begin{array}{r}138.570 \\
70.117\end{array}$ & $\begin{array}{r}113.300 \\
86.576\end{array}$ & $<0.01$ \\
\hline $\begin{array}{l}\text { Palaeocontinental } \\
\text { Disjunct }\end{array}$ & $\begin{array}{l}47.898 \\
22.220\end{array}$ & $\begin{array}{l}42.149 \\
27.968\end{array}$ & $<0.01$ \\
\hline $\begin{array}{l}\text { Nearctic }(\mathrm{WN} \leftrightarrow \mathrm{EN}) \\
\text { Palaeoarctic }(\mathrm{WP} \leftrightarrow \mathrm{EP})\end{array}$ & $\begin{array}{l}79.474 \\
59.097\end{array}$ & $\begin{array}{l}89.823 \\
48.748\end{array}$ & $<0.01$ \\
\hline $\begin{array}{l}\text { Trans-Beringian }(\mathrm{WN} \leftrightarrow \mathrm{EP}) \\
\text { Trans-Atlantic }(\mathrm{EN} \leftrightarrow \mathrm{WP})\end{array}$ & $\begin{array}{l}33.721 \\
14.177\end{array}$ & $\begin{array}{l}33.472 \\
14.426\end{array}$ & 0.87 \\
\hline $\begin{array}{l}\text { Disjunct } \\
(\mathrm{EN} \leftrightarrow \mathrm{EP}) \\
(\mathrm{WN} \leftrightarrow \mathrm{WP})\end{array}$ & $\begin{array}{r}13.379 \\
8.841\end{array}$ & $\begin{array}{r}13.376 \\
8.844\end{array}$ & 0.99 \\
\hline $\begin{array}{l}\text { Asymmetry Nearctic } \\
(\mathrm{WN} \rightarrow \mathrm{EN}) \\
(\mathrm{EN} \rightarrow \mathrm{WN})\end{array}$ & $\begin{array}{l}44.272 \\
35.202\end{array}$ & $\begin{array}{l}37.025 \\
42.449\end{array}$ & 0.03 \\
\hline $\begin{array}{l}\text { Asymmetry Palaeoarctic } \\
(\mathrm{EP} \rightarrow \mathrm{WP}) \\
(\mathrm{WP} \rightarrow \mathrm{EP})\end{array}$ & $\begin{array}{l}40.169 \\
18.928\end{array}$ & $\begin{array}{l}34.114 \\
24.983\end{array}$ & 0.01 \\
\hline $\begin{array}{l}\text { Asymmetry Trans-Beringian } \\
(\mathrm{WN} \rightarrow \mathrm{EP}) \\
(\mathrm{EP} \rightarrow \mathrm{WN})\end{array}$ & $\begin{array}{l}17.146 \\
16.575\end{array}$ & $\begin{array}{l}19.364 \\
14.357\end{array}$ & 0.32 \\
\hline $\begin{array}{l}\text { Asymmetry Trans-Atlantic } \\
(\mathrm{WP} \rightarrow \mathrm{EN}) \\
(\mathrm{EN} \rightarrow \mathrm{WP})\end{array}$ & $\begin{array}{l}8.278 \\
5.899\end{array}$ & $\begin{array}{l}6.213 \\
7.964\end{array}$ & 0.23 \\
\hline $\begin{array}{l}\text { Asymmetry Disjunct EN-EP } \\
(\mathrm{EP} \rightarrow \mathrm{EN}) \\
(\mathrm{EN} \rightarrow \mathrm{EP})\end{array}$ & $\begin{array}{l}7.929 \\
5.450\end{array}$ & $\begin{array}{l}8.363 \\
5.016\end{array}$ & 0.83 \\
\hline $\begin{array}{l}\text { Asymmetry Disjunct WN-WP } \\
1(\mathrm{WP} \rightarrow \mathrm{WN}) \\
2(\mathrm{WN} \rightarrow \mathrm{WP})\end{array}$ & $\begin{array}{l}5.850 \\
2.991\end{array}$ & $\begin{array}{l}3.120 \\
5.721\end{array}$ & $<0.01$ \\
\hline
\end{tabular}

fewer of the old and more of the young speciations are retained among the splits documented by extant lineages. Because the ages of a larger number of nodes were fixed in the fully dated set, the amount of bias introduced by the branching clock is smaller for this data set. Furthermore, delayed speciation gave slightly more accurate dates than accelerated speciation because it decreased the bias, even though the differences between these two options were small.

\section{Two-area distributions in the externally dated set}

Figure 11 shows the variation over time of the frequency of two-area distributions in the 27 groups dated with external evidence. The patterns are only given for delayed speciation; accelerated speciation gave almost identical results.

Continental, palaeocontinental and disjunct distributions. Continental distributions within North America (WN-EN, Fig. 11A) and Eurasia (WP-EP, Fig. 11B) are most frequent in the youngest time classes (young and recent; 20-0 Myr). In contrast, disjunct distributions are most frequent in the oldest time classes: EN-EP in the medium time class (70-20 Myr; Fig. 11E) and WN-WP in the old time class (Fig. 11F). Palaeocontinental distributions show an intermediate pattern: WN-EP is most frequent in the 

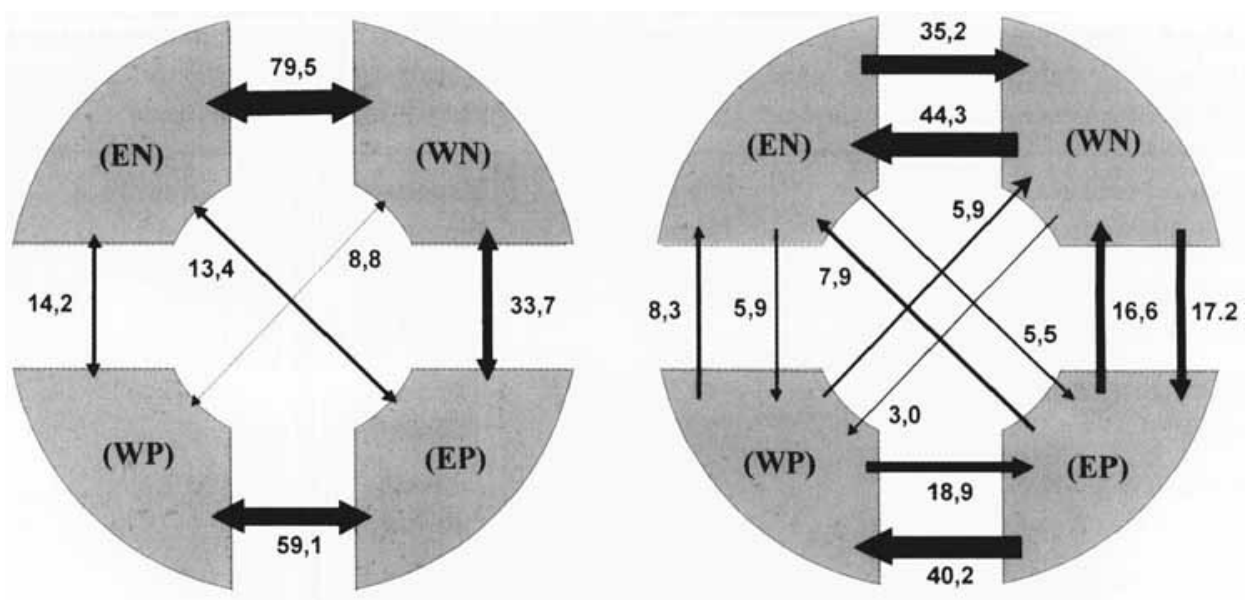

Figure 9. Diagrammatic, polar views of the Holarctic region, showing the frequency of dispersal between different infraregions in the data set. The thickness of the arrows is proportional to the frequency of the dispersal in question. Abbreviations: WN - western Nearctic, EN - eastern Nearctic, WP - western Palaoearctic, EP - eastern Palaeoarctic.

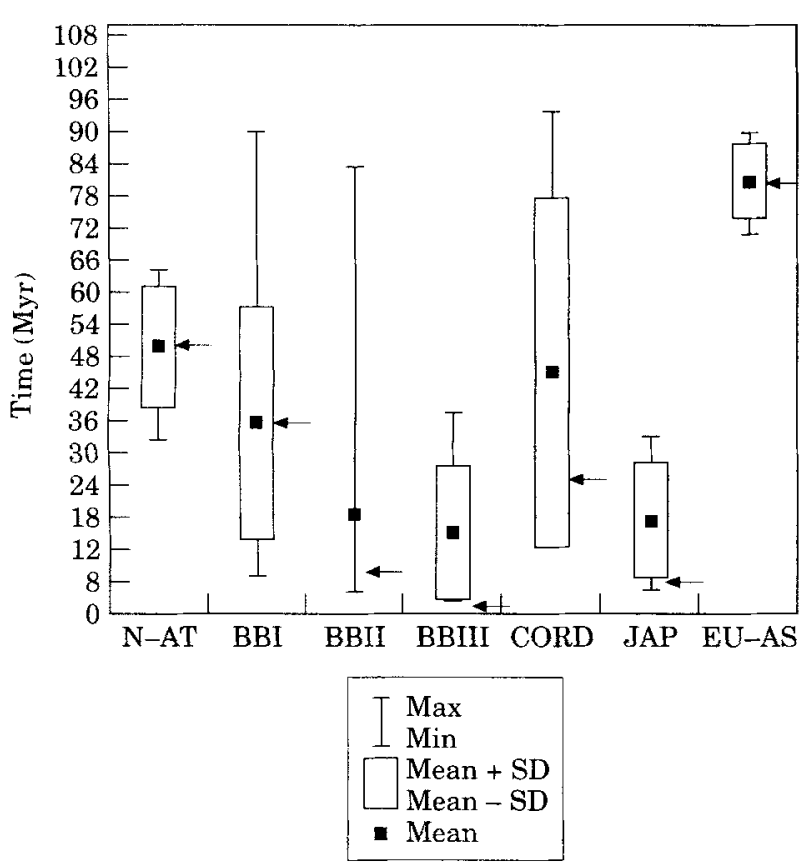

Figure 10. Plot showing the accuracy of the branching clock assessed by the presumed dates of some Holarctic biogeographic events (Table 4). The box-whisker plots show the estimated age of certain nodes (mean, standard deviation and minimum and maximum values) using the branching clock calibrated with external evidence (from the fossil record, non-Holarctic biogeographic events, or molecular evidence). The arrows indicate the presumed age of the same nodes according to Holaretic biogeographic events (Table 4). The number of observations are as follows: Trans-Atlantic (N-AT, $n=6$ ), Beringian Bridge I (BBI, $n=21$ ), Beringian Bridge II (BBII, $n=17$ ), Beringian Bridge III (BBIII, $n=15$ ), Cordilleran orogeny (CORD, $n=8$ ), Japanese sea (JAP, $n=9$ ), Euramerica-Asiamerica vicariance (EU-AS, $n=5)$. recent time class (Fig. 11C), whereas EN-WP is most frequent in the medium class (Fig. 11D).

Continental distributions. The frequency of Nearctic distributions (WN-EN) shows a decrease in the medium time class, followed by a rapid increase in the young and recent time classes (Fig. 11A). This pattern differs significantly from that expected by chance $(P<0.01)$. The frequency of Palaeoarctic distributions (WP-EP) is low in the old and medium time classes (>20 Myr) but increases rapidly in the young time class (20-3 Myr; Late Tertiary), followed by a slight decrease in the recent time class (3-0 Myr; Fig. 11B). However, these differences were not significant $(P=$ $0.53)$.

Trans-Beringian and trans-Atlantic distributions. The frequency of trans-Beringian distributions (WN-EP) decreases over time with the lowest value being in the young time class (20-3 Myr), followed by a strong increase in the recent time class (3-0 Myr; Fig. 11C). Differences among frequencies were significantly constrained by phylogeny $(P<0.01)$. The frequency of transAtlantic distributions (EN-WP) shows a distinct peak in the medium time class and decrease strikingly in the young and recent time classes (Fig. 11D). This pattern was close to being statistically significant ( $P=$ $0.11)$.

EN-EP and WN-WP disjunct distributions. The frequency of the disjunct distribution eastern North America-eastern Palaeoarctic (EN-EP) increases rapidly in the medium time class (70-20 Myr) to decrease markedly in the young and recent time classes (20-0 Myr; Fig. 11E). Again, differences among frequencies were close to being statistically significant $(P=0.10)$. 


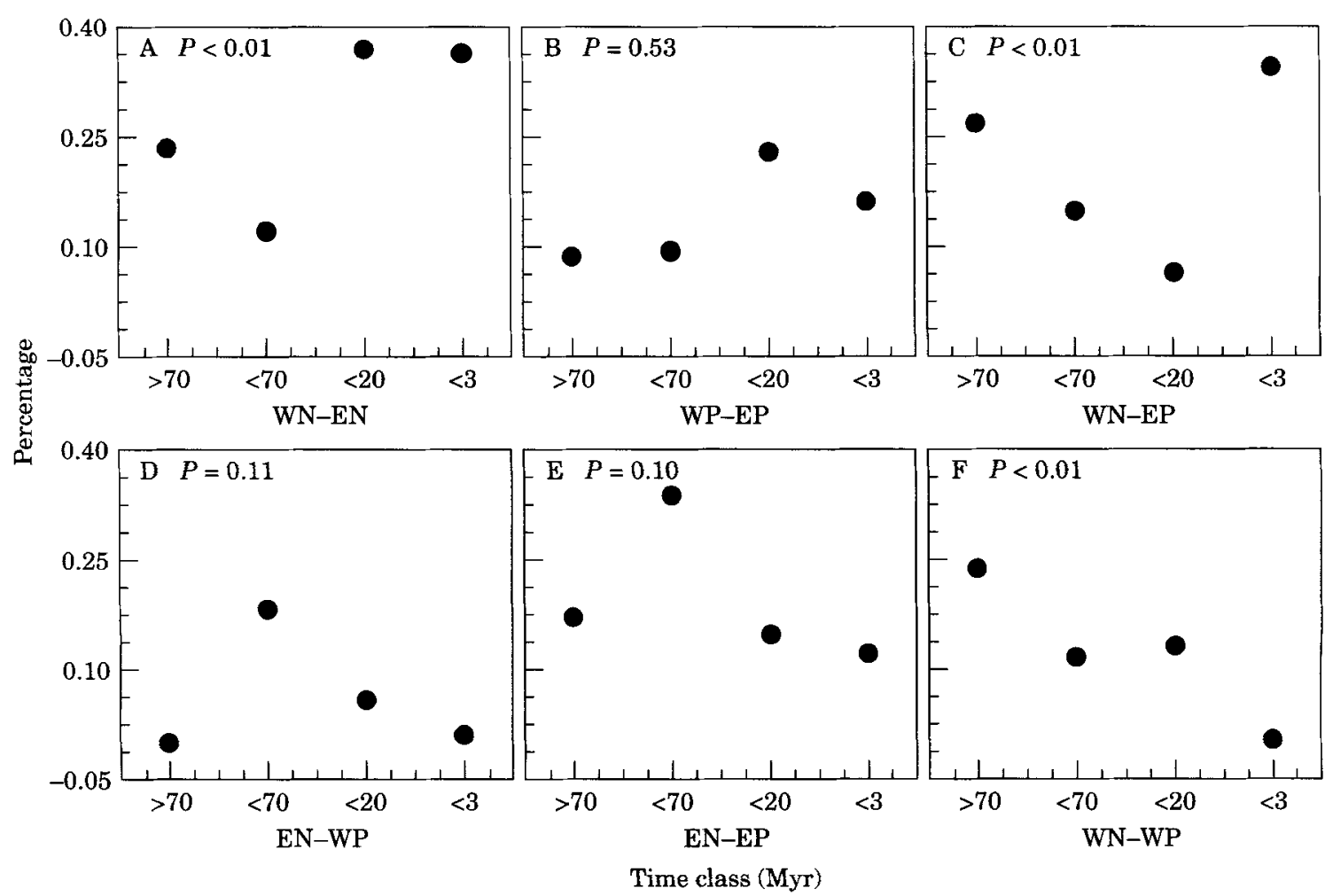

Figure 11. Frequency of the six possible two-infraregion distributions plotted against time for the externally dated set of 27 Holarctic groups. Because some time classes cover a longer time span than others, the frequency of each twoinfraregion distribution is given as a percentage of the total number of two-infraregion distributions in each time class. Abbreviations: WN - western Nearctic, EN - eastern Nearctic, WP - western Palaeoarctic, EP - eastern Palaeoarctic. The $P$ values are based on permutation tests.

In contrast, the frequency of the disjunct distribution western North America-western Palaeoarctic (WNWP) shows a constant decrease over time, with the peak frequency in the old time class, before the Late Cretaceous ( $>70 \mathrm{Myr}$; Fig. 11F). This pattern is highly significant $(P<0.01)$.

\section{Two-area distributions in the fully dated set}

Figure 12 shows the frequency of two-area distributions over time for the 39 groups in the fully dated set using delayed speciation (accelerated speciation gave almost identical results). The observed biogeographic patterns are similar to those found in the smaller externally dated set of phylogenies, with some exceptions. For WN-EN, the distributions are on average dated older, such that the distinct increase in the frequency of these distributions in the two youngest time classes becomes more gradual (Fig. 12A). This presumably occurs because the Holarctic events used for dating (Table 4) push these distributions back in time. For the Palaeoarctic distributions (WP-EP), on the other hand, the increase in the youngest time classes becomes more prominent in the fully dated set, suggesting a significant frequency change between the medium and young time classes (Fig. 12B). Finally, the lowest frequency of trans-Beringian distributions shifts from the young (20-3 Myr; Fig. 11C) to the medium time class (70-20 Myr; Fig. 12C).

\section{The eastern North America-Asia disjunction}

The age of this disjunction was examined in more detail by dividing the medium time class into two subclasses ( $70-45$ and $45-20 \mathrm{Myr}$ ), while pooling the young and recent time classes (Fig. 13). The frequency of the eastern North America-eastern Palaeoarctic (EN-EP) distributions (Fig. 13C, D) and of transAtlantic (EN-WP) distributions (Fig. 13E, F) showed a similar pattern of variation, with a sharp peak in the Early Tertiary time class ( $70-45 \mathrm{Myr})$. In contrast, the frequency of trans-Beringian (WN-EP) distributions dipped in the Early Tertiary, followed by an increase during the later time classes (Fig. 13A, B). The peak of the EN-EP distributions was sharper in the externally dated set than in the fully dated set, in which some (but less than 50\%) of the EN-WP and 


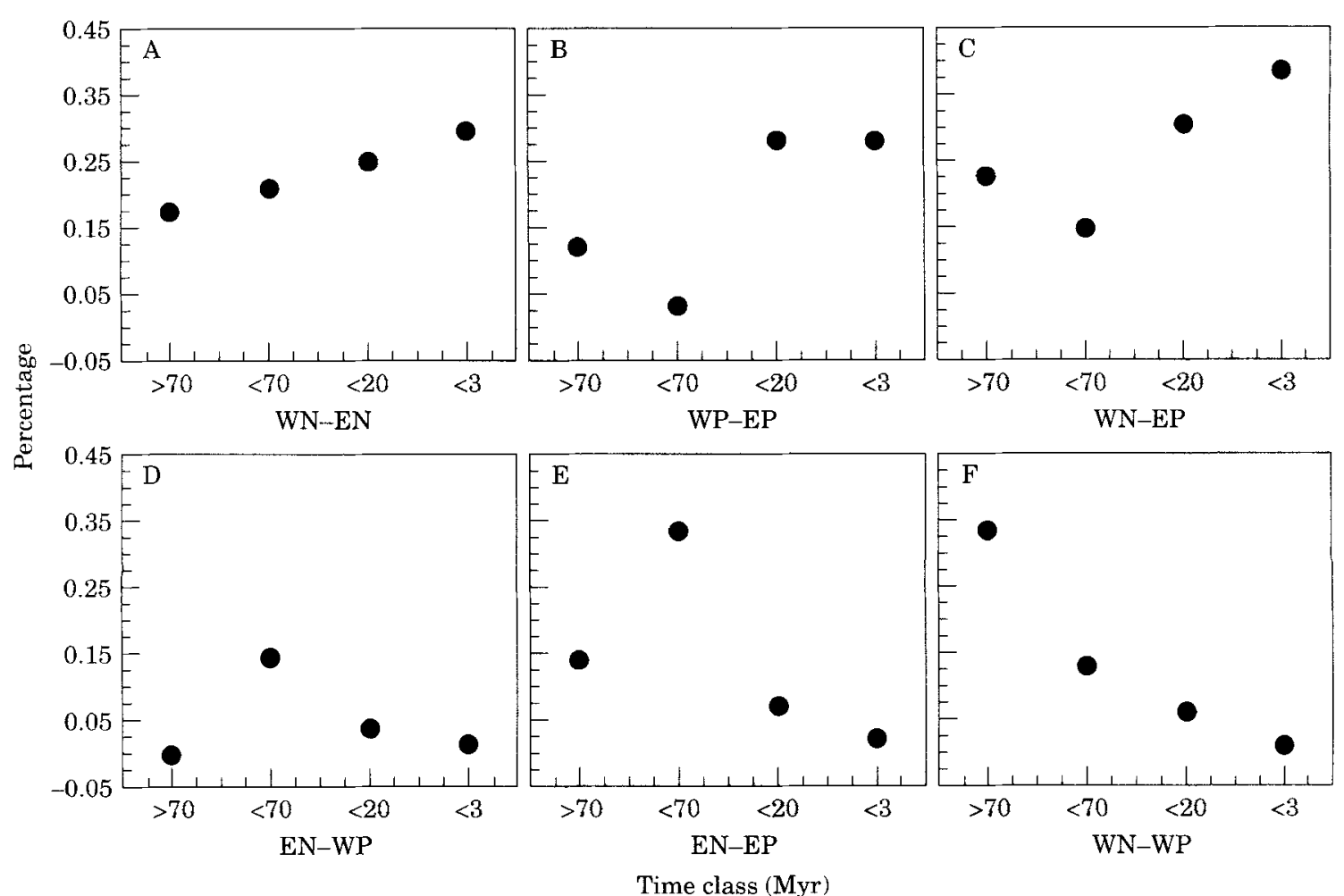

Figure 12. Frequency of the six possible two-infraregion distributions plotted against time classes for the fully dated set of 39 Holarctic groups. The frequency is given as the percentage of the total number of two-infraregion distributions in each time class. Abbreviations: WN - western Nearctic, EN - eastern Nearctic, WP - western Palaeoarctic, EP eastern Palaeoarctic. Permutation tests could not be used to determine the significance of these patterns because the dating of nodes was dependent on the association between terminals and distributions.

WN-EP distributions had been dated using the hypothesized age of certain Holarctic biogeographic events (Table 4).

\section{Diversification and changes in species richness}

The plots of species richness and diversification over time were similar for the externally and fully dated sets; here, the trends are shown for the considerably larger fully dated set (Figs 14, 15). The eastern Palaeoarctic (Fig. 14D) and eastern North America (Fig. 14B) show a similar pattern of variation, with an increase during the Tertiary (70-3 Myr), followed by a decrease in the Quaternary (3-0 Myr). The decrease is more noticeable in eastern North America than in the eastern Palaeoarctic. In contrast, western North America (Fig. 14A) and the western Palaeoarctic (Fig. 14C) showed a low or relatively low species richness during the Tertiary (70-3 Myr), followed by a distinct increase during the Quaternary. The western Palaeoarctic (Fig. 14C) presents the lowest species richness of all infraregions in all four time classes. Similar patterns were found when diversification within infraregions was plotted against time (Fig. 15).

\section{DISCUSSION}

\section{A GENERAL AREA CLADOGRAM FOR THE HOLARCTIC?}

Enghoff (1995) presented a general area cladogram for the Holarctic reflecting the present continental configuration: ((WN, EN), (WP, EP)). He found strong support for this pattern in his genus clades but he used pattern-based methods and did not test the statistical significance of the signal.

Our data set is similar to Enghoff's genus clades. Thus, it is not surprising that we find similar results for our data and for the genus clades. The area cladogram presented by Enghoff, reflecting current continental configurations, fits the observations in both sets better than any other hierarchical scenario. However, this is almost entirely due to the prevalence of continental distributions among widespread terminals. The phylogenies do not predominantly group areas according to the continental area cladogram and, thus, the latter does not fit the data better than expected by chance. Actually, it fits the data much worse than expected by chance and this result occurs because terminal species are often found in the same area as their closest relatives. Maximum vicariance analysis is excessively 

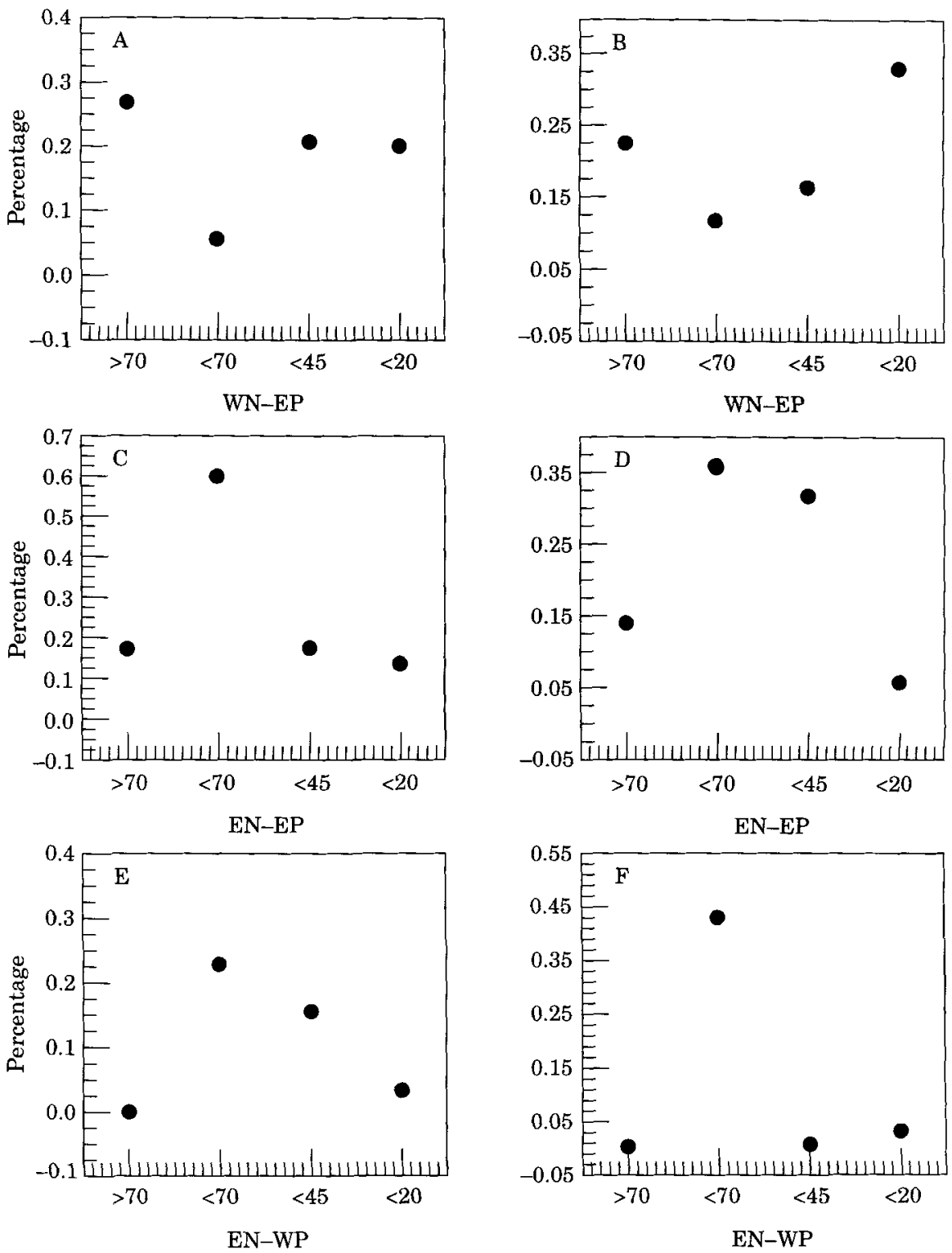

Time class (Myr)

Figure 13. Frequency of trans-Beringian (WN-EP), trans-Atlantic (EN-WP) and disjunct distributions (EN-EP) plotted against time for the externally dated set (27 groups) (A, C, E) and for the fully dated set (39 groups) (B, D, F). To increase resolution in the Early Tertiary, a different division into time classes was used. Note that some of the trans-Beringian and trans-Atlantic events were dated according to the presumed age of the corresponding biogeographic event in the fully dated set $(B, F)$. However, the disjunct distributions (D) were not dated.

sensitive to such distribution duplication patterns (Ronquist, in press). When they are common, randomly permuted data sets tend to have more vicariance events than the observed data.

For the family clades, which presumably document older biogeographic events, Enghoff (1995) did not find a clearly dominant pattern using pattern-based methods. Under the free and ancient options of treating widespread taxa, we find that the family clades behave as the genus clades. However, under the recent option, a different hierarchical scenario is favoured, and the support for this scenario is significantly larger than expected by chance. Recall that the recent option disregards any evidence for area relationships provided by widespread terminals and only groups areas based on older clades. Thus, the chance of detecting phylogenetically determined biogeographic patterns is better with the recent option than with the free and ancient options.

The scenario supported by the family clades under 


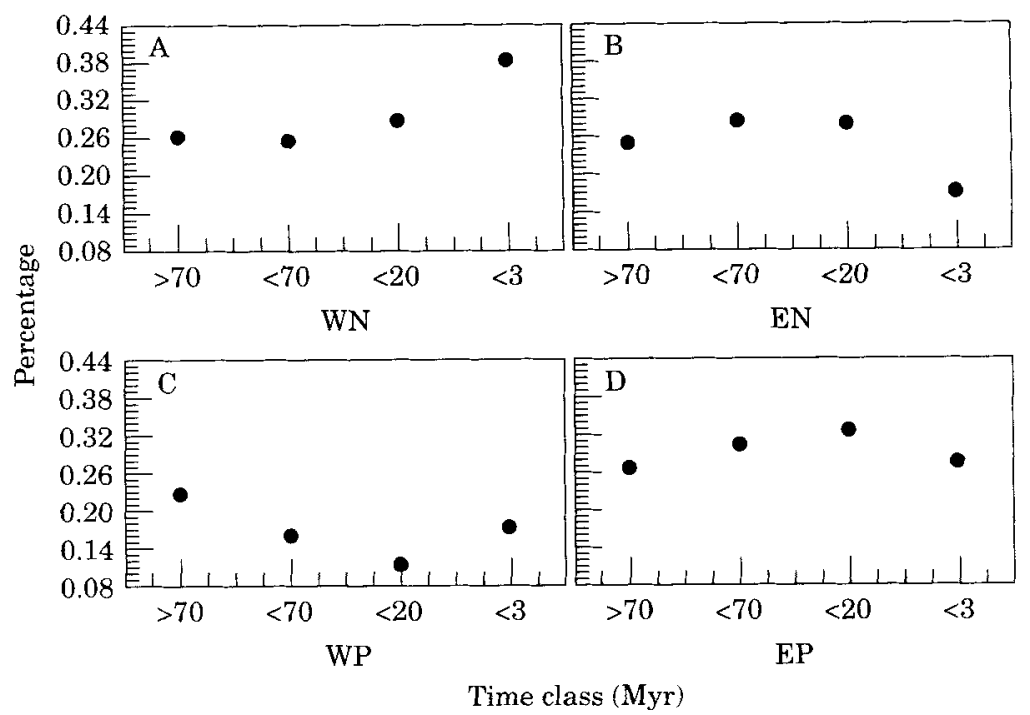

Figure 14. Species richness per infraregion plotted against time for the fully dated set (39 groups) (the externally dated set showed similar trends). Species richness is measured as the number of nodes (ancestral species) occurring in each infraregion. To correct for the unequal duration of time classes, the species richness per region is given as the percentage of the total species richness in each time class.

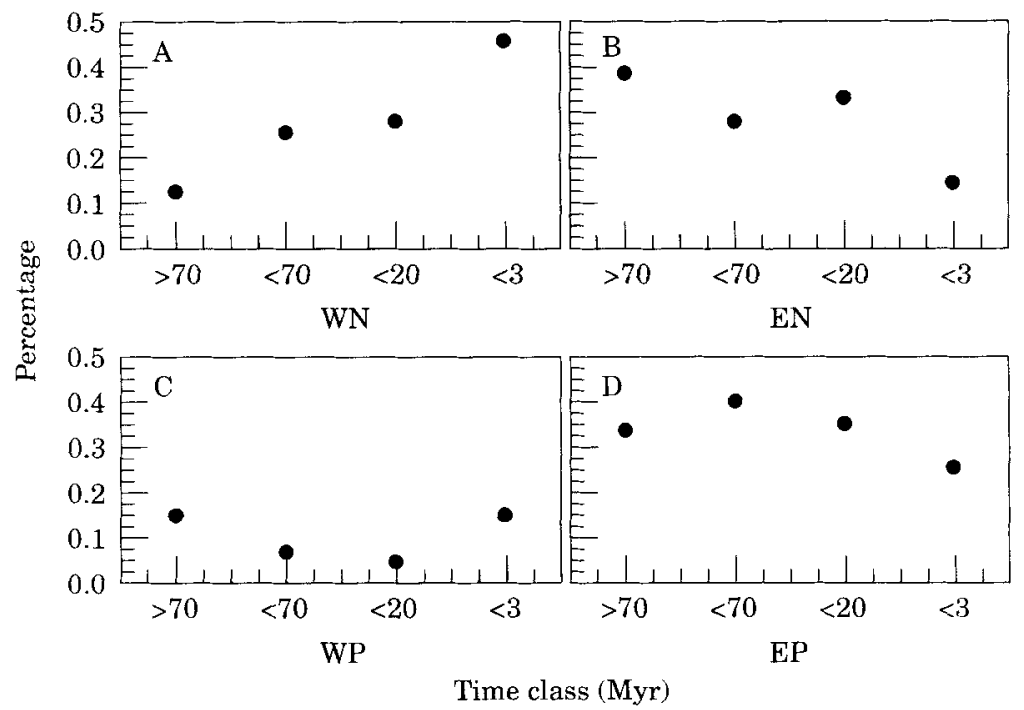

Figure 15. Diversification per infraregion plotted against time in the fully dated set ( 39 groups) (the externally dated set showed similar trends). Diversification is measured as the number of speciation events occurring exclusively within each infraregion (i.e. among-region vicariance events are not considered). Diversification per region is given as the percentage of the total number of diversification events in each time class.

the recent option is number 17 (Fig. 6). This scenario has an initial division between the palaeocontinents Euramerica and Asiamerica, followed by vicariance first within Euramerica and then within Asiamerica. Interestingly, Enghoff (1995) found the same pattern (his RAC 15) to be the most frequent for his family clades when he treated widespread taxa using assumption 2, a pattern-based option similar to the free option in event-based analysis. However, because it was not clearly dominant, he did not consider this a general Holarctic biogeographic pattern. Our analysis indicates that this is the only robust hierarchical pattern in Enghoff's (1995) data sets. Interestingly, this MV result agrees well with the variation of two-area distributions over time in that it clearly dates the Euramerican (EN-WP) vicariance as being older than 
the Asiamerican (WN-EP) vicariance (compare scenario 17 in Fig. 6 with Figs 11-13).

In conclusion, although old Holarctic biogeographic events documented by higher phylogenies appear to fit a Euramerican-Asiamerican pattern, it is clear that no general area cladogram can adequately describe Holarctic area relationships as evidenced by our data or the data of Enghoff's genus clades.

\section{LARGE-SCALE HOLARCTIC PATTERNS}

Enghoff (1995) found that continental dispersals (within the present continents) were significantly more frequent than palaeocontinental dispersals (between areas once connected in the former continents Asiamerica and Euramerica), and these in turn were more frequent than disjunct dispersals (between infraregions never connected) in his data set of 73 Holarctic groups. This result was based on a test of deviation from equal probabilities of all dispersals. However, the Holarctic infraregions are not equally well represented in his data set, nor are they in ours (Fig. 5B), and hence dispersal frequencies should be expected to differ considerably even if they were assigned randomly to categories. Our test based on random permutation of terminal distributions takes the unequal species diversity of different infraregions into account. Nevertheless, Enghoff's result holds: continental dispersals are more frequent than palaeocontinental dispersals, which are more common than disjunct dispersals.

This pattern is undoubtedly an effect of time and past continental connections (Enghoff, 1995). According to palaeogeographic reconstructions, the palaeocontinental configuration persisted for a long time, even longer than the present configuration. Thus, we might have expected Asiamerican (trans-Beringian) and Euramerican (trans-Atlantic) dispersals to be at least as frequent as continental dispersals. However, extinction has undoubtedly wiped out the traces of many of the palaeocontinental events, making them rarer than the continental events among the dispersals documented by extant species and their phylogenies. Disjunct dispersals could be rare because the disjunct areas have never been connected directly, or because disjunct patterns are the remnants of very old events. The variation in the frequency of two-area distributions over time (Figs 11, 12) suggests that the second explanation is more important. Disjunct distributions, particularly EN-EP, are not rare; they are common in the old time classes. This should not be interpreted to mean that these distributions or dispersals were necessarily originally disjunct. In most cases, the old distributions were presumably continuous and the dispersals took place between adjacent infraregions. The disjunct pattern arose later by extinction in intervening areas.

\section{CONTINENTAL PATTERNS}

Enghoff (1995) found that dispersals within North America (WN↔EN) were more frequent in his data set than dispersals within the Palaeoarctic region (WP↔EP). He did not test whether this difference was significant but he nevertheless attributed it to the difference in duration of the epicontinental seaways, which were presumably important dispersal barriers for the terrestrial and limnic fauna. The Nearctic was divided by the Mid-Continental Seaway for only 30 Myr, from 100 to $70 \mathrm{Myr}$, while the Turgai Strait divided the Palaeoarctic much longer, from 180 to 30 Myr. However, the dominance of American dispersals is probably entirely due to the overrepresentation of American taxa in Enghoff's data set. Using permutation tests we find that, considering the number of lineages that could have dispersed, faunal exchange has actually been significantly more extensive in the Palaeoarctic than in the Nearctic. This does not mean that the Turgai Strait was not an effective barrier: the dated phylogenies show that almost all of the Palaeoarctic exchange occurred after the closing of the Turgai Strait in the Oligocene, 30 Myr (Figs 11, 12). However, it does imply that faunal exchange has been less extensive between the Nearctic infraregions after the disappearance of the Mid-Continental Seaway than one might have expected.

The variation in the frequency of Palaeoarctic distributions over time (Figs 11,12) fits palaeogeographic reconstructions well. During the time it was open, the Turgai Strait apparently provided an effective barrier to dispersal between the eastern and western Palaeoarctic, resulting in a very low frequency of WP-EP distributions in the Cretaceous and Early-Mid Tertiary time classes ( $>20 \mathrm{Myr}$ ). The closing of the Turgai Strait about $30 \mathrm{Myr}$ made it possible for groups present in Asia or in Europe to expand their ranges, leading to a distinct increase in WP-EP distributions in the Late Tertiary time class (20-3 Myr). Dispersal rates remained high in the Quaternary ( $3-0 \mathrm{Myr}$ ). Thus, recent Palaeoarctic barriers, like the Pleistocene WestSiberian barrier (Beschovski, 1984), do not seem to have been effective in preventing Palaeoarctic faunal exchange.

The Nearctic pattern is more difficult to interpret (Figs 11, 12). The two predicted dispersal waves, first after the closing of the Mid-Continental Seaway about $70 \mathrm{Myr}$ and then after the erosion of the early Rocky Mountains in the Oligocene (30 Myr) are not evident in the Early-Mid Tertiary time class (70-20 Myr). However, it is possible that these events are entirely concealed by the effects of the uplift of the early Rocky Mountains in the Palaeocene-Eocene in this broad time class. The predicted dispersal waves and the effects of Rocky Mountain orogeny may eventually be detected using more narrow time classes, a larger set 
of phylogenies, and more accurate dating. Neither the uplift of the Cordilleran range in the Late OligoceneMiocene (25-20 Myr), nor the Quaternary glaciations appear to have been significant in preventing faunal exchange between the western and eastern Nearctic, since WN-EN distributions are common in both the Late Tertiary and Quaternary (20-0 Myr) (Figs 11, 12). In plants, the close biogeographic relationship found between western and eastern North America also suggests that the Cordilleran range was not an effective barrier to floristic exchange between the eastern and western Nearctic (Wen, 1999).

The highly significant directional asymmetries in continental dispersals (Table 5) show that, during the Tertiary and Quaternary, western North America and the eastern Palaeoarctic acted as the main source areas of continental dispersals in the Nearctic and Palaeoarctic, respectively. This agrees with Enghoff's (1995) conclusions and with observations by other authors (Kavanaugh, 1988). The predominance of eastward dispersals in the Nearctic is expected based primarily on the orogenic activity in the west. The uplift of the early Rocky Mountains and subsequently the Cordilleran Range created cooler climates in western North America. This presumably drove the evolution of cold-adapted organisms, which could spread to the east when climatic cooling later created similar conditions there. Mountain building also created an increasingly large rain shadow to the east, causing aridification of central North America. The spread of dry habitats in turn pressed wet-adapted elements to the east. These habitat changes were presumably associated with large-scale eastward dispersal of both dry-adapted and wet-adapted organisms. The mixedmesophytic forest, for instance, which had extended across the continent in the Early-Mid Tertiary, shifted eastward in the Late Tertiary and was replaced in the west by more xerophytic plants, such as Pinus (Tiffney, 1985a). Many animals dependent upon this forest followed it to eastern North America (Rosen, 1978; Askevold, 1991), where they continued to diversify. This pattern is, for instance, observed in the most speciesrich phytophagous groups of beetles, Curculionidae and Chrysomelidae, which are both maximally diverse in eastern North America (Allen, 1983; Noonan, 1986, 1988a; Askevold, 1991). The effects of the Pleistocene glaciations may also have contributed to the predominantly easterly dispersals in the Nearctic. The Pacific slope of North America was hit harder by the glaciations than the Atlantic slope, and since this made it more difficult for organisms to survive in the west, long-distance dispersals to glacial refugia in the east may have been more successful than dispersals in the other direction (Pielou, 1979; Latham \& Ricklefs, 1993).

It is more difficult to explain the directional dispersal asymmetry in the Palaeoarctic. It is clear that the extant fauna of the eastern Palaeoarctic is considerably richer than that of the western Palaeoarctic and the difference is often assumed to be the effect of extinction in the western Palaeoarctic during Pleistocene glaciations. However, because the permutation tests correct for differences in species richness, the dispersal asymmetry cannot simply be an artefact due to massive extinction in the western Palaeoarctic. It is possible that orogenic activity and the development of arid habitats in the eastern Palaeoarctic favoured the evolution of species that became successful invaders of Europe, similar to the hypothesised forces driving asymmetric dispersal in the Nearctic. According to Tiffney (1985b), the final closure of the Turgai straits in the Oligocene (30 Myr) initiated an influx of Asiatic and eastern European vertebrate fauna and flora into western Europe, which resulted in the extinction and replacement of the local biota ('The Grande Coupure'). Another possibility is that extinction rates were higher in the western Palaeoarctic in the Tertiary because Europe mostly consisted of a number of isolated islands during this time period. Species that went extinct due to the small size of these islands could have been continuously replaced from the east, causing directional dispersal asymmetry. Future studies will have to further clarify the reasons for the predominantly easterly dispersal of the Palaeoarctic fauna during the Tertiary and Quaternary.

\section{TRANS-BERINGIAN AND TRANS-ATLANTIC EXCHANGE}

Intercontinental disjunctions between North America and Eurasia are usually explained as the remnants of ancient distributions spanning across the Bering land bridge, whereas cross-Atlantic distributions are considered less important (Darlington, 1957; Andersen, 1993). The main reason for this is the long duration of the Bering land bridge, which existed from the Early Tertiary to the Late Pliocene-Pleistocene. In contrast, the most important North Atlantic connection, the Thulean route, was only favourable for dispersal in the earliest part of the Early Eocene, and was broken around 50 Myr (McKenna, 1983). Furthermore, the climate of the Beringian area was warmer than today through most of the Tertiary and Quaternary, facilitating dispersal of warm-adapted groups.

However, it has also been suggested that the Atlantic route, via the Thulean Bridge, was more important than the Beringian route in the Early Tertiary. According to palaeogeographic reconstructions of this time period, Beringia was situated closer to the North Pole than it is today. This means that it would have been in a considerably higher palaeolatitude than the North Atlantic Bridge (McKenna, 1983), so dispersal across Beringia should have been severely constrained by climate and light regimes (Tiffney, 1985b). 
Two other, more northern trans-Atlantic bridges continued to exist after the disappearance of the Thulean Bridge: the De Geer route and the Greenland-Faeroes bridge. However, the former was in the far north and was presumably restricted to cold-adapted groups, while the latter was no more than a chain of islands. Therefore, most authors seem to agree that after the Thulean Bridge was broken 50 Myr (Early Eocene), the main dispersal route between North America and Eurasia definitely switched to Beringia, since the Beringian region became warmer and the North Atlantic wider (Pielou, 1979). According to Raven \& Axelrod (1974), Beringia has been more important than the North Atlantic Bridge for migrating land plants since the Middle Eocene (45 Myr).

The variation in the frequency of two-area distributions over time (Figs 11-13) suggests that the latter scenario is essentially correct for cross-Atlantic faunal exchange. Trans-Atlantic distributions (ENWP) are frequent in the Early Tertiary (70-45 Myr), coinciding with the time period when the North Atlantic Thulean Bridge existed (Fig. 13E). The frequency decreases during the Mid Tertiary (45-20 Myr), just after the Thulean route was closed $50 \mathrm{Myr}$, and almost reaches zero in later time periods. Presumably, dating errors causes the peak of cross-Atlantic distributions to extend slightly into the Mid Tertiary, rather than being entirely restricted to the Early Tertiary (Fig. $13 \mathrm{E})$. In the fully dated set, where $40 \%$ of the crossAtlantic events were dated, the remaining cross-Atlantic events were all sorted into the Early Tertiary time class (Fig. 13F). Overall, our data showed no significant difference between the amount of transBeringian and trans-Atlantic dispersal (Table 5). This indicates that, despite the short duration of the Thulean Bridge, it was a more important dispersal route than has commonly been assumed.

As described in the introduction, faunal migration over the Bering Bridge was primarily controlled by the prevailing climatic and floristic conditions. Thus, it is possible to recognise three consecutive time periods of exchange across the Bering area. The first Beringian Bridge (Early-Mid Tertiary), which partly coincided with the Thulean Bridge, was covered with mixedmesophytic forest and was presumably dominated by dispersal of faunal elements associated with this forest. The second bridge (Late Tertiary) was covered by taiga forest and inhabited by associated faunal elements, whereas the third bridge (Quaternary) was dominated by tundra habitats.

Our time plots (Figs 11-13) suggest that the first Beringian Bridge (Early-Mid Tertiary) was relatively unimportant for intercontinental faunal exchange. Instead, Early Tertiary intercontinental exchange appears to have been dominated by the trans-Atlantic Thulean Bridge. Faunal exchange was more important across the second Beringian Bridge (Late Tertiary time class, 20-3 Myr, Fig. 12) and even more frequent across the third bridge (Quaternary, 3-0 Myr, Figs 11, 12). The relatively high frequency of trans-Beringian distributions in the Cretaceous time-class (before $70 \mathrm{Myr}$ ) is unexpected. Before $70 \mathrm{Myr}$, western North America and the eastern Palaeoarctic were only connected at high latitudes. However, Alaska and Siberia may have had a much warmer climate in the Mid and Late Cretaceous than they have today (Cox, 1974).

Contrary to expectations, we did not find any predominance of eastward dispersals across the Beringian land bridge due to the effect of Pleistocene glaciations. Actually, dispersals from western North America to the eastern Palaeoarctic were more common than dispersals in the other direction, although the difference was not significant (Table 5). This result may indicate that most of the dispersal evidenced by our data occurred before the Pleistocene glaciations or in interglacial periods across the Bering Strait.

\section{THE EASTERN NORTH AMERICA-ASIA DISJUNCTION}

Disjunctions between eastern North America and eastern Asia (EN-EP) are well known in the temperate flora of the Northern Hemisphere (Wen, 1999). Similar disjunctions have also been reported in arachnids (Suzuki et $a l$., 1977), fresh-water fishes (Patterson, 1981), pondskater bugs (Andersen \& Spence, 1992); millipedes (Enghoff, 1993), parasitic wasps (Nordlander et al., 1996), and Diptera (Savage \& Wheeler, 1999) but our study is one of the first to document the EN-EP disjunction in a large set of animal groups.

The disjunction has traditionally been explained as the remnants of a widely distributed warm-temperate forest in the Northern Hemisphere during the EarlyMid Tertiary, which disappeared in western North America owing to the orogeny and climatic changes during the Late Tertiary and Quaternary, and then became extinct in Europe during the Quaternary glaciations (Wen, 1999).

One might expect animals living in this temperate forest to show similar EN-EP disjunctions. Thus, Savage \& Wheeler (1999) pointed out an association between groups of insects of Early-Mid Tertiary origin and the EN-EP disjunction (which they attributed to the arise of the Western Cordillera in the Mid Tertiary and the subsequent drying of the Great Plains in the rain shadow of the mountains). Our study, based on a large and more diverse group of animals, even more clearly supports the association between the EN-EP disjunction and the boreotropical-mixed-mesophytic forest. Almost all EN-EP distributions date back to the medium time class (Early-Mid Tertiary, 70-20 Myr), corresponding to the height in the development of the mixed-mesophytic forest, whereas the frequency 
is low both in younger time classes and in older time periods (Figs 11, 12).

The spread of the boreotropical flora could have taken place during the Early Tertiary, when climates were uniformly warm and humid across the Northern Hemisphere, and continental connections facilitated exchange between the Palaeoarctic and Nearctic (Tiffney, 1985b). During that period, two different routes were available. One route involved dispersal across the first Beringian Bridge, preceded or followed by dispersal between western and eastern North America through the mid-continental area. Alternatively, the exchange could mainly have been through transAtlantic dispersal on the Thulean Bridge, preceded or followed by dispersal between Asia and Europe across the Turgai Strait. Botanists have often considered the first route as the most likely for two reasons ( $\mathrm{Li}, 1952$; Gould \& Donoghue, 1998; Li et al., 1998; Qian \& Ricklefs, 1999, 2000). First, the Beringian land bridge lasted longer than the North Atlantic Bridge. Second, dispersal between Asia and Europe was prevented from the Mid Jurassic (180 Myr) to the Oligocene ( 30 Myr) by the presence of the Turgai Strait, whereas the Mid-Continental Seaway separating eastern and western North America disappeared at the end of the Cretaceous, allowing Nearctic exchange during the Early Tertiary.

However, some palaeobotanists (Wolfe, 1975; Tiffney, 1985b) have defended the importance of the transAtlantic route. Tiffney (1985b: 265) said "the similarities of the modern flora of eastern Asia and eastern North America were probably due to an Early Tertiary linkage between the two areas, involving the North Atlantic land bridge". To explain dispersal between Asia and Europe, they invoke migration along the coasts and islands of the Tethys Seaway, which ran in an easterly-westerly direction. Furthermore, they point out the high palaeolatitude of the Beringian Bridge in the Early Tertiary, and the adverse climatic conditions and light regimes that must have existed there at this period compared to the more favourable conditions prevailing on the Thulean Bridge (McKenna, 1983, Tiffney, 1985b). These conditions would have effectively prevented dispersal of the subtropical elements of the boreotropical flora across the Beringian Bridge. Palaeobotanical evidence indicates that the Eocene Beringian Bridge was primarily covered by deciduous hardwood forests, with only a thin southern fringe of evergreen, subtropical communities (Wolfe, 1975; Tiffney, 1985b). It has also been suggested that the terranes containing the Early Tertiary subtropical flora of Alaska actually represent more southern continental fragments that were ripped off the western coast of North America and collided with southern Alaska relatively recently (Tiffney, 1985b).

Our detailed time plots (Fig. 13) suggest that the
trans-Atlantic route was the most important pathway for the spread of boreotropical elements. Most EN-EP disjunctions date back to the Early Tertiary (70-45 Myr), before the breaking of the Thulean Bridge at 50 Myr, whereas few disjunctions date to the terminal Eocene event ( $35 \mathrm{Myr}$ ) considered the most important vicariance event for warm-temperate elements in the Bering area. This pattern is very clear in the externally dated set (Fig. 13C). In the fully dated set (Fig. 13D), where some trans-Atlantic (EN-WP) and trans-Beringian (WN-EP) events had been dated, the age of the EN-EP disjunctions became somewhat less certain, contrary to expectations. It is difficult to determine currently if this means that, after all, some of the boreotropical exchange took place through the Beringian route, or whether the fully dated set failed in improving the date estimates. Our results contrast with those from plants, where molecular estimates of divergence times in 11 genera place the origin of the EN-EP disjunction between 2 and 25 Myr, "at least into the Early Miocene" (Wen, 1999). Even younger estimates (Xiang et al., 1998a,b) exist but they refer to a broader, not comparable disjunct pattern, involving eastern Asia as the sister-area to both western and eastern North America. Tiffney (1985b) considered that the floristic exchange between eastern North America and the eastern Palaeoarctic could have taken place at five different periods during the Tertiary, but that the majority of boreotropical taxa (many evergreen) migrated in the Early Eocene through the North Atlantic Bridge.

Eastern Asia has been suggested as the centre of origin of the boreotropical flora because the greatest diversity of this flora is now found there. If so, most dispersal of boreotropical elements should have been from Asia to other areas. However, our study shows no significant difference between the frequency of Asia and eastern North America as the source area of EN-EP dispersals ( $P=0.83$, Table 5 ). This fits better with the idea that the boreotropical flora had a diffuse origin involving several areas of the Northern Hemisphere (Wolfe, 1975; Tiffney, 1985a), and that there was no directionality in the spread of the boreotropical flora (Tiffney, 1985b).

\section{THE WESTERN NORTH AMERICA-EUROPE DISJUNCTION}

In contrast to the EN-EP disjunction, the disjunction between western North America and Europe (WN-WP) has hardly been discussed at all in the literature. However, the WN-WP disjunction was not significantly less frequent than the EN-EP disjunction in our data (Table 5), so this pattern decidedly deserves more attention. Like the EN-EP disjunction, the WN-WP disjunction could have arisen in two different ways. It 
could have resulted through dispersal between Europe and North America across the Atlantic, followed by subsequent extinction in eastern North America. Alternatively, it could have resulted from dispersal between North America and Asia through the Beringian Bridge, followed by dispersal to Europe and then extinction in Asia. The trans-Atlantic route seems the most likely since most WN-WP disjunctions date back to the oldest time class, before the latest Cretaceous (>70 Myr, Figs 11, 12). Europe and eastern North America were connected by land as early as the Early Jurassic, through the proto-British Isles and a narrow Atlantic ocean (Smith et al., 1994), whereas Asia and western North America were not connected by land until the Late Cretaceous, when Asiamerica formed. Even after that, cross-Beringian connections were at high latitudes, whereas Euramerica was connected in the south as well as in the north (Cox, 1974). It is true that between the Mid and Latest Cretaceous, the MidContinental seaway separated the western and eastern parts of North America. However, the required dispersal between the Nearctic infraregions, if the WN-WP pattern originated by trans-Atlantic faunal connections, could have taken place both before and after this time period.

There is a clear asymmetry in the directionality of dispersal creating the WN-WP distributions. Europe was more frequently the source area for these dispersals than western North America, and this difference was statistically significant $(P<0.01$, Table 5). It is worth noting that EN-WP dispersals, which are presumably trans-Atlantic, show a similar asymmetry in that dispersals from the western Palaeoarctic to eastern North America are more common than dispersals in the other direction, and almost significantly more frequent than expected by chance $(P=0.07)$. If, as indicated above, WN-WP disjunctions also arose through trans-Atlantic dispersal, there may be a general direction in dispersals across the Atlantic, from Europe to North America. The reason for this asymmetry is unclear, particularly since the WN-WP and the EN-WP dispersals appear to be of different age (Figs 11, 12).

\section{DIVERSIFICATION PATTERNS}

The eastern Palaeoarctic and eastern North America show a similar pattern of diversification over time: elevated diversification rates and increased species richness during the Tertiary (70-3 Myr), followed by a decrease during the Quaternary (3-0 Myr) (Figs 14, 15). These patterns may reflect the development of the boreotropical-mixed-mesophytic forest and its associated fauna, which survived to a larger extent in these regions than elsewhere in the Northern Hemisphere. The decrease in species richness and diversification during the Quaternary appears to have been more pronounced in eastern North America than in the eastern Palaeoarctic (Asia); this may be due to the effects of Pleistocene glaciations. Although the two regions share similar climatic and ecological conditions today (Boufford \& Spongberg, 1983), the Pleistocene glaciations supposedly struck eastern North America much harder than Asia. Among other factors, this was due to the north-south orientation of the Appalachian Mountains, which conveyed cold Arctic air masses to interior eastern North America (Tiffney, 1985a). Furthermore, warm-adapted elements of eastern North America could not easily disperse to low-latitude tropical regions during the glacial periods. This scenario is supported by our data, in which a severe Quaternary effect on the eastern Nearctic fauna was evident, despite that the eastern Nearctic was better represented in current distributions than the eastern Palaeoarctic (cf. Fig. 5B). On the other hand, Latham \& Ricklefs (1993) found little evidence of extinction of genera of temperate trees in North America during the Late Tertiary and Holocene. Instead, fossil data reveal that eastern North America had lower tree diversity than eastern Asia in the Early Tertiary, suggesting that diversification in Asia, rather than extinction in North America, explains the diversity difference between both regions (Qian \& Ricklefs, 1999, 2000 , but see Tiffney, 1985b for the opposite view).

Today, Asia has the most diverse temperate forests in the Northern Hemisphere, both in terms of species richness and taxonomic composition, while the forests of the western Palaeoarctic have the lowest diversity (Latham \& Ricklefs, 1993). Similarly, many groups of animals are most diverse in eastern Asia (Table 2; see also Tangelder, 1988; Nordlander et al., 1996; MartínPiera \& Sanmartín, 1999, and references cited therein). These patterns agree well with our data set, in which the western Palaeoarctic is the poorest region (Fig. 5B). The eastern Palaeoarctic is considerably richer, and it is presumably only under-sampling that prevents it from being the most diverse infraregion.

Botanists have traditionally attributed the regional diversity differences to differential extinction during Pleistocene glaciations (the refugium hypothesis). Eastern Asia was less affected by the Pleistocene glaciations and is presumed to have served as a refugium for thermophilic taxa during glacial periods (Tiffney, 1985a). Several factors contributed to this. First, the extent of land covered by ice was smaller in Asia than in other infraregions. Second, a corridor of mesic forest connected the tropical and temperate floras in Asia, allowing southward movement of warm-adapted organisms to low-latitude regions during glaciations. This was not possible in any other Northern Hemisphere region. Third, Asia was protected from Arctic air masses by east-west oriented mountains, which nevertheless had sufficient passages permitting south- 
north movement of organisms (Tiffney, 1985a). In contrast, Europe was almost completely covered by ice sheets during the glacial periods, and the east-west orientation of the mountains effectively prevented organisms from migrating to southern refugia. Consequently, massive extinctions occurred in both the European flora and fauna (Pielou, 1979; Latham \& Ricklefs, 1993; see Coope, 1978 for a different view). During this period, the last remnants of the mixedmesophytic forest became extinct in Europe (Tiffney, 1985b).

Other authors argue that Pleistocene rarefaction of a widespread Holarctic fauna is unlikely to explain differences in species diversity among Holarctic infraregions. In the Tertiary, continuous land connection between all Holarctic regions occurred only briefly during the Early Eocene (McKenna, 1983). Therefore, it is unlikely that the Holarctic shared a similar flora and fauna in the Late Tertiary, before the first glaciations. Instead, considerable regional species richness differences probably arose already in the Tertiary and these differences may at least partly have survived the Quaternary (the diversification hypothesis) (Nordlander et al., 1996). In particular, the rich eastern Palaeoarctic fauna and flora may have evolved in the Tertiary because tropical and temperate Asia was a major centre of diversification (Simpson, 1953; Wolfe, 1972; Goulet, 1983; Tangelder, 1988; Latham \& Ricklefs, 1993; Nordlander et al., 1996). The region was topologically diverse and encompassed a rich mosaic of habitats and climates, which presumably accelerated speciation rates compared to other infraregions (Qian \& Ricklefs, 2000).

The glaciations have been associated with mass extinction but also with elevated speciation rates. For instance, most divergence in insect groups at the species level has traditionally been explained as a consequence of isolation in glacial refugia (Darlington, 1957). Pleistocene speciation is also the most commonly invoked cause for recent divergence in mammals (George, 1988; Talbot \& Shields, 1996) and birds (Voelker, 1999a, and references herein). However, there appears to be an emerging consensus that these ideas are incorrect and that the speciation rate was actually lower in the Pleistocene than in any other period. For instance, most of the insect fossil record from the Quaternary corresponds to extant species, whereas the youngest beetle fossils, which can be safely assigned to extinct or ancestral species, date back to the Late Miocene (Mathews, 1977; Coope, 1970; Spanton, 1988; Asquith \& Lattin, 1990; Pollock, 1991). Similarly, Voelker (1999a,b) argued that the Pleistocene glaciations had little effect in generating modern species of passerine birds.

Our study suggests that the differences between eastern and western Palaeoarctic faunal richness cannot be explained simply by Pleistocene extinction (Figs $14,15)$. If so, then the western and eastern Palaeoarctic patterns would be similar, except that the western Palaeoarctic values would generally be lower and would decrease more in the youngest time class. Instead, it appears that the latest Tertiary and Quaternary was characterised by considerably elevated rates of speciation in the western Palaeoarctic, perhaps but not necessarily associated with the Pleistocene glaciations. Based on our data, it is not possible to exclude the possibility that the eastern and western Palaeoarctic faunas developed similarly in the Tertiary, and then the Tertiary fauna was almost completely wiped out in the western Palaeoarctic in the Late Pleistocene by massive glacial extinction. Latham \& Ricklefs (1993) found that the fossil tree genera of Europe in the Tertiary are just as rich as in the eastern Palaeoarctic, suggesting extinction as the main cause for differences in contemporary diversity between the two infraregions. However, a simpler explanation of the differences is that the net diversification rate was lower in the western Palaeoarctic through most of the Tertiary. Note that the diversification rate and species richness of the western Palaeoarctic appears to have decreased in the Tertiary compared to the Cretaceous, contrary to the pattern seen in the eastern Palaeoarctic (Figs 14, 15). This decrease is unlikely to be the effect of massive extinction of a western Palaeoarctic Tertiary fauna similar to that of the eastern Palaeoarctic.

Like the western Palaeoarctic fauna, the western Nearctic fauna appears to have developed in a different fashion than the eastern Palaeoarctic and eastern Nearctic faunas. The diversification and species richness increased in this region in the later part of the Tertiary and in the Quaternary. It is unlikely that elevated speciation rates during Pleistocene glaciations contributed significantly to this trend, since the increase in diversity apparently started before the Quaternary. Instead, the accelerated diversification rate is probably mainly due to the increased lithospheric and climatic complexity of the region in the Mid-Late Tertiary due to the uplift of the Rocky Mountains and the Cordilleran Range. The Cordilleran orogeny, and subsequent aridification, appears to have favoured an extraordinary diversification of herbaceous plant taxa in western North America in the Mid-Late Tertiary (Qian \& Ricklefs, 2000).

\section{CONCLUSIONS}

Analytical historical biogeography has been characterized by considerable methodological controversies during the last decades and few significant general results have appeared from the empirical work. This has created a well-justified scepticism among other 
workers for the usefulness of phylogeny-based biogeography. We hope with this study to have shown that analyses of large sets of dated phylogenies using process-based methods and statistical evaluation of the results allow powerful testing of specific hypotheses and can contribute significantly to the development of historical biogeographic reconstructions.

\section{ACKNOWLEDGEMENTS}

We are grateful to J. J. Morrone \& R.E. Ricklefs for comments that helped to improve the manuscript. This work was supported by Fundación Pedro Barrié de la Maza (grant to IS) and by the Swedish Natural Science Research Council (grant to FR).

\section{REFERENCES}

Adamson ML, Richardson JPM. 1989. Historical biogeography and host distribution of Chabaudgolvania spp., nematode parasites of salamanders. The Journal of Parasitology 75: 892-897.

Allen RT. 1980. A review of the subtribe Myadi: description of a new genus and species, phylogenetic relationships, and biogeography (Coleoptera: Carabidae: Pterostichini). The Coleopterists Bulletin 34: 1-29.

Allen RT. 1983. Distribution patterns among arthropods of the north temperate deciduous forest biota. Annals of the Missouri Botanical Garden 70: 616-628.

Andersen NM. 1990. Phylogeny and taxonomy of water striders, genus Aquarius Schellenberg (Insecta, Hemiptera, Gerridae). Steenstrupia 16: 37-81.

Andersen NM. 1993. Classification, phylogeny, and zoogeography of the pond skater genus Gerris Fabricius (Hemiptera: Gerridae). Canadian Journal of Zoology 71: 2473-2508.

Andersen NM, Spence JR. 1992. Classification and phylogeny of the Holarctic water strider genus $\mathrm{Lim}$ noporus Stål (Hemiptera: Gerridae). Canadian Journal of Zoology 70: 753-785.

Askevold IS. 1991. Classification, reconstructed phylogeny, and geographic history of the New World members of Plateumaris Thomson, 1859 (Coleoptera: Chrysomelidae: Donaciinae). Memoirs of the Entomological Society of Canada 157: 5-175.

Asquith A, Lattin JD. 1990. Nabicula (Limnonabis) propinqua (Reuter) (Heteroptera: Nabidae): Dimorphism, phylogenetic relationships and biogeography. Tijdschrift voor Entomologie 133: 3-16.

Bae YJ, McCafferty WP. 1991. Phylogenetic systematics of the Potamanthidae (Ephemeroptera). Transactions of the American Entomological Society 117: 1-143.

Ball GE, Erwin TL. 1969. A taxonomic synopsis of the tribe Loricerini (Coleoptera: Carabidae). Canadian Journal of Zoology 47: 877-907.

Barron EJ, Harrison CGA, Sloan II JL, Hay WW. 1981. Paleogeography, 180 million years ago to the present. Eclogae geologicae Helvetiae 74: 443-470.

Beschovski VL. 1984. A Zoogeographic Review of Endemic
Palearctic Genera of Chloropidae (Diptera) in View of Their Origin and Formation. Acta Zoologica Bulgarica 24: 3-26.

Boufford DE, Spongberg SA. 1983. Eastern AsianEastern North American phytogeographical relationships - A history from the time of Linnaeus to the twentieth century. Annals of the Missouri Botanical Garden 70: $423-439$.

Campbell JM. 1993. A review of the species of Nitidotachinus new genus (Coleoptera: Staphylinidae: Tachyporinae). The Canadian Entomologist 125: 521-548.

Catley KM. 1994. Descriptions of new Hypochilus species from New Mexico and California with a cladistic analysis of the Hypochilidae (Araneae). American Museum Novitates 3088: 1-27.

Chu PC. 1998. A phylogeny of the gulls (Aves: Larinae) inferred from osteological and integumentary characters. Cladistics 14: 1-43.

Coope GR. 1970. Interpretation of Quaternary insect fossils. Annual Review of Entomology 15: 97-120.

Coope GR. 1978. Constancy of insect species versus inconstancy of Quaternary environments. In: Mound LA, Waloff N, eds. Diversity of insect faunas. Symposia Royal Entomological Society London 9: 176-187.

Cox CB. 1974. Vertebrate palaeodistributional patterns and continental drift. Journal of Biogeography 1: 75-94.

Cumming JM. 1989. Classification and evolution of the Eumenine wasp genus Symmorphus Wesmael (Hymenoptera: Vespidae). Memoirs of the Entomological Society of Canada 148: 5-168.

Cunningham CW, Collins TM. 1994. Developing model systems for molecular biogeography: vicariance and interchange in marine invertebrates. In: Schierwater B, Streit B, Wagner GP, DeSalle R, eds. Molecular Ecology and Evolution, Approaches and Application. Basel, Switzerland: Birkhauser Verlag, 405-433.

Darlington PJ. 1957. Zoogeography: The Geographical Distribution of Animals. New York: John Wiley and Sons.

De Jong H. 1998. In search of historical biogeographic patterns in the western Mediterranean terrestrial fauna. Biological Journal of the Linnean Society 63: 99-164.

Dietrich CH, Whitcomb RF, Black IV WC. 1997. Phylogeny of the grassland leafhopper genus Flexamia (Homoptera: Cicadellidae) based on mitochondrial DNA sequences. Molecular Phylogenetics and Evolution 8: 139-149.

Domanico MJ, Phillips RB. 1995. Phylogenetic analysis of Pacific salmon (genus Oncorrhynchus) based on mitochondrial DNA sequence data. Molecular Phylogenetics and Evolution 4: 366-371.

Duellman WE. 1993. Amphibian species of the World: additions and corrections. Lawrence, Kansas: The University of Kansas.

Enghoff H. 1993. Phylogenetic biogeography of a Holarctic group: the Julian millipedes. Cladistic subordinateness as an indicator of dispersal. Journal of Biogeography 20: 525-536.

Enghoff H. 1995. Historical biogeography of the Holarctic: area relationships, ancestral areas, and dispersal of nonmarine animals. Cladistics 11: 223-263.

Frost D. (ed.) 1985. Amphibian species of the World. 
Lawrence, Kansas: Allen Press and The Association of Systematic Collections.

George SB, 1988. Systematics, historical biogeography, and evolution of the genus Sorex. Journal of Mammalogy 69: $443-461$.

Gould KR, Donoghue MJ. 1998. Phylogeny and biogeography of Triosteum (Dipsacales, Lonicereae). American Journal of Botany 85: 133

Goulet H, Smetana A. 1983. A new species of Blethisa Bonelli from Alaska, with proposed phylogeny, biogeography and key to known species (Coleoptera: Carabidae). The Canadian Entomologist 115: 551-558.

Goulet H. 1983. Genera of Holarctic Elaphrini and species of Elaphrus Fabricius (Coleoptera: Carabidae): Classification, phylogeny and zoogeography. Quaestiones Entomologicae 19: 219-482.

Gray A. 1840. Dr. Siebold, Flora Japonica; sectio prima. Plantas ornutai vel usui inservientes; digessit Dr. J. G. Zuccarini: fasc. 1-10, fol. (A review). American Journal of Science 39: 175-176.

Guo Q. 1999. Ecological comparisons between Eastern Asia and North America: historical and geographical perspectives. Journal of Biogeography 26: 199-206.

Hormiga G. 1994. A revision and cladistic analysis of the spider family Pimoidae (Araneoidea: Araneae). Smithsonian Contributions to Zoology 549: 1-104.

Howard R, Mooe A. 1991. A complete checklist of the birds of the World. Second edition. London: Academic Press.

Iverson JB. 1992. A revised checklist with distribution maps of the turtles of the World. Privately printed, Richmond, Indiana

Kavanaugh DH. 1988. The insect fauna of the Pacific Northwest coast of North America: present patterns and affinities and their origins. Memoirs of the Entomological Society of Canada 144: 125-149.

Kelley RW. 1985. Revision of the micro-caddisfly genus Oxyethira (Trichoptera: Hydroptilidae). Part II: subgenus Oxyethira. Transactions of the American Entomological Society 111: 223-253.

Klimaszewski J. 1979. A revision of the Gymnusini and Deinopsini of the world. Research Branch, Agriculture Canada. Monograph no. 25, Ottawa.

Kruckenhauser L, Pinsker W, Haring E, Arnold W. 1998. Marmot phylogeny revisited: molecular evidence for a diphyletic origin of sociality. Joumal of Zoological Systematics and Evolutionary Research 37: 49-56.

Lafontaine JD, Mikkola K, Kononenko VS. 1983. A revision of the genus Xestia subg. Schoyenia Auriv. (Lepidoptera: Noctuidae), with descriptions of four new species and a new subspecies. Entomologica scandinavica 14: $337-369$.

Lafontaine JD, Kononenko VS. 1986. A revision of the genus Trichosilia Hampson (Lepidoptera: Noctuidae) with descriptions of four new species. The Canadian Entomologist 118: 1079-1113.

Lafontaine JD, Wood DM. 1988. A zoogeographic analysis of the Noctuidae (Lepidoptera) of Beringia, and some inferences about past Beringian habitat. Memoirs of the Entomological Society of Canada 144: 109-123.

Latham RE, Ricklefs RE. 1993. Continental comparisons of temperate-zone tree species diversity. In: Ricklefs
RE, Schluter D, eds. Species Diversity in Ecological Communities. Chicago and London: The University of Chicago Press, 294-314.

Lehman N, Pfrender ME, Morin PA, Crease TJ, Lynch M. 1995. A hierarchical molecular phylogeny within the genus Daphnia. Molecular Phylogenetics and Evolution 4: 395-407.

Li HL. 1952. Floristic relationships between eastern Asia and eastern North America. Transactions of the American Philosophic Society 42: 371-429.

Li S, Adair KT. 1994. Species pools in eastern Asia and North America. Sida 16: 281-299.

Li JH, Donoghue MJ, Bogle AL, Klein AS. 1998. Phylogeny and biogeography of Hamamelis (Hamamelidaceae): an update. American Journal of Botany 85: 141 .

Liebherr JK. 1991. Phylogeny and revision of the Anchonemus clade: the genera Tetraleucus, Anchonemus, Sericoda and Elliptoleus (Coleoptera: Carabidae: Platynini). Bulletin American Museum of Natural History 202: 1-163.

Macey JR, Schulte II JA, Larson A, Tuniyev BS, Orlov N, Papenfuss TJ. 1999. Molecular phylogenetics, tRNA evolution, and historical biogeography in anguid lizards and related taxonomic families. Molecular Phylogenetics and Evolution 12: 250-272.

McKenna MC. 1983. Cenozoic paleogeography of North Atlantic land bridges. In: Bott MHP, Saxov S, Talwani M, Thiede J, eds. Structure and development of the Greenland-Scotland bridge: New concepts and Methods. New York: Plenum, 351-395.

Martín-Piera F, Sanmartín I. 1999. Biogeografía de áreas y Biogeografía de artrópodos Holárticos y Mediterráneos. In: Melic A, De Haro JJ, Ribera I, eds. Evolución y Filogenia de Arthropoda, vol. 26. Zaragoza: Boletín de la Sociedad Entomológica Aragonesa, 535-560.

Mathews JV. 1977. Tertiary Coleoptera fossils from the North American Arctic. The Coleopterists Bulletin 31: 297-308.

Mathews JV. 1979. Tertiary and Quaternary Environments: Historical Background for an Analysis of the Canadian Insect Fauna. In: Danks HV, ed. Canada and its Insect Fauna. Memoirs of the Entomological Society of Canada 108: 31-86.

Mathis WN, Zatwarnicki T, Krivosheina MG. 1993. Studies of Gymnomyzinae (Diptera: Ephydridae), V: A revision of the shore-fly genus Mosillus Latreille. Smithsonian Contributions to Zoology 548: 1-38.

Matile L. 1990. Recherches sur la systématique et l'évolution des Keroplatidae (Diptera, Mycetophiloidea). Mémoires du Muséum national d'Histoire naturelle Paris, Zoologie 148: 1-682.

Mönkkönen M, Viro P. 1997. Taxonomic diversity of the terrestrial bird and mammal fauna in temperate and boreal biomes of the northern hemisphere. Journal of Biogeography 24: 603-612.

Morrone JJ, Crisci JV. 1995. Historical biogeography: Introduction to methods. Annual Review of Ecology and Systematics 26: 373-401.

Nelson GJ. 1972. Cephalic sensory canals, pitlines, and the classification of Esocoid fishes, with notes on galaxiids 
and other teleosts. American Museum Novitates 2492: $1-49$.

Nielsen EF. 1982. The maple leaf-cutter moth and its allies: a revision of Paraclemensia (Incurvariidae, s. str.). Systematic Entomology 7: 217-238.

Nilsson AN, Larson DJ. 1990. A review of the Agabus affinis group (Coleoptera: Dytiscidae), with the description of a new species from Siberia and a proposed phylogeny. Systematic Entomology 15: 227-239.

Noonan GR. 1986. Distribution of insects in the Northern Hemisphere: Continental drift and epicontinental seas. Bulletin of the Entomological Society of America 31: 80-84.

Noonan GR. 1988a. Biogeography of North American and Mexican insects, and a critique of vicariance biogeography. Systematic Zoology 37: 366-384.

Noonan GR. 1988b. Faunal relationship between eastern North America and Europe as shown by insects. Memoirs of the Entomological Society of Canada 144: 39-53.

Nordlander G, Liu Z, Ronquist F. 1996. Phylogeny and historical biogeography of the cynipoid wasp family Ibaliidae (Hymenoptera). Systematic Entomology 21: 151166.

Norrbom AL, Kim KC. 1984. The taxonomic status of Lotophila Lioy, with a review of L. atra (Meigen) (Diptera: Sphaeroceridae). Proceedings of the Entomological Society of Washington 86: 305-311.

Norrbom AL, Marshall SA. 1988. New species and phylogenetic analysis of Lotophila Lioy (Diptera: Sphaeroceridae). Proceedings of the Entomological Society of Ontario 119: 17-33.

Paepke HJ. 1983. Die Stichlinge. Gasterosteidae. Die Neue Brehm-Bücherei, Vol. 10. A. Ziemsen Verlag, Wittenberg Lutherstadt.

Page RDM. 1994. Parallel phylogenies: Reconstructing the history of host-parasite assemblages. Cladistics 10: 155-173.

Patterson C. 1981. The development of the North American fish fauna - a problem of historical biogeography. In: Forey PL, ed. Chance, Change and Challenge, vol. 2, The Evolving Biosphere. London: Br. Mus. (Nat. Hist.) and Cambridge Univ. Press, 265-281.

Pielou EC. 1979. Biogeography. New York: John Wiley \& Sons.

Platnick NI. 1975. A revision of the Holarctic spider genus Callilepis (Araneae, Gnaphosidae). American Museum Novitates 2573: 1-32.

Platnick NI. 1976. Drifting species or continents? Vicariance biogeography of the spider subfamily Larioniinae (Araneae, Gnaphosidae). Systematic Zoology 25: 101-109.

Pollock DA. 1991. Natural history, classification, reconstructed phylogeny, and geographic history of Pytho Latreille (Coleoptera: Heteromera: Pythidae). Memoirs of the entomological Society of Canada 154: 3-104.

Qian H, Ricklefs RE. 1999. A comparison of the taxonomic richness of vascular plants in China and the United States. The American Naturalist 154: 160-181.

Qian H, Ricklefs RE. 2000. Large-scale processes and the Asian bias in species diversity of temperate plants. The American Naturalist 154: 160-181.

Randi E. 1996. A mitochondrial cytochrome B phylogeny of the Alectoris partridges. Molecular Phylogenetics and Evolution 6: 214-227.

Raven PH, Axelrod DI. 1974. Angiosperm biogeography and past continental movements. Annals of the Missouri Botanical Garden 61: 539-673.

Ronquist F. 1995. Reconstructing the history of hostparasite associations using generalised parsimony. Cladistics 11: 73-89.

Ronquist F. 1996. DIVA, ver. 1.1. User's Manual. Computer program for MacOS and Win32. Available from http:/ www.ebc.uu.se/systzoo/research/diva/diva.html

Ronquist F. 1997. Dispersal-Vicariance analysis: a new biogeographic approach to the quantification of historical biogeography. Systematic Biology 46: 195-203.

Ronquist F. 1998a. Phylogenetic approaches in coevolution and biogeography. Zoologica scripta 26: 313-322.

Ronquist F. 1998b. Three dimensional cost-matrix optimization and minimum cospeciation. Cladistics 14: 167-172.

Ronquist F. 1999. Phylogeny, classification and evolution of Cynipoidea. Zoologica scripta 28: 139-164.

Ronquist F. 2001. TreeFitter ver. 1.0.Software available from http://www.ebc.uu.se/systzoo/research/treefitter/treefitter.html

Ronquist F (in press). Parsimony analysis of coevolving species associations. In: Page RDM, ed. Cospeciation. Chicago: Chicago University Press.

Rosen DE. 1978. Vicariant patterns and historical explanation in biogeography. Systematic Zoology 27: 159188.

Roughley RE. 1990. A systematic revision of species of Dytiscus Linnaeus (Coleoptera: Dytiscidae). Part 1. Classification based on adult stage. Quaestiones Entomologicae 26: 383-557.

Saether OA. 1975. Nearctic and Palearctic Heterotrissocladius (Diptera, Chironomidae). Bulletin of the Fisheries Research Board of Canada 193: 1-67.

Saether OA. 1976. Revision of Hydrobaenus, Trissocladius, Zalutschia, Paratrissocladius, and some related genera (Diptera, Chironomidae). Bulletin of the Fisheries Research Board of Canada 195: 1-287.

Savage J, Wheeler TA. 1999. Systematics of Cetema Hendel (Diptera: Chloropidae): revision of the Nearctic species and phylogeny and zoogeography of the Holarctic fauna. Entomologica Scandinavica 30: 249-262.

Schwartz MD, Foottit RG. 1998. Revision of the Nearctic species of the genus Lygus Hahn, with a review of the Palearctic species (Heteroptera: Miridae). Memoirs of Entomology, International 10: i-vii, 1-428.

Seberg O. 1991. Biogeographic congruence in the South Pacific. Australian Systematic Botany 4: 127-136.

Shear WA, Gruber J. 1983. The opilionid subfamily Ortholasmatinae (Opiliones, Troguloidea, Nemastomatidae). American Museum Novitates 2757: 1-65.

Sheldlock AM, Parker JD, Crispin DA, Pietsch TW, Burmr GC. 1992. Evolution of the salmonid mitochondrial control region. Molecular Phylogenetics and Evolution 1: 179-192.

Simpson GG. 1953. Evolution and Geography. Condon Lectures, Oregon State System of Higher Education, Eugene. 
Smetana A. 1980. Revision of the genus Hydrochara Berth. (Coleoptera: Hydrophilidae). Memoirs of the Entomological Society of Canada 111: 1-100.

Smith G. 1992. Phylogeny and biogeography of the $\mathrm{Ca}-$ tostomidae, freshwater fishes of North America and Asia. In: Mayden RL, ed. Systematics, historical ecology, and North America fresh-water fishes. Stanford, California: Stanford University Press, 778-826.

Smith AG, Smith DG, Funnell BM. 1994. Atlas of Mesozoic and Cenozoic coastlines. Cambridge: Cambridge University Press.

Söli G. 1997. The systematics and phylogeny of Coelosia Winnertz, 1863 (Diptera, Mycetophilidae). Entomologica scandinavica Supplements 50: 57-139.

Spanton TG. 1988. The Cicindela sylvatica group: geographical variation and classification of the Nearctic taxa, and reconstructed phylogeny and geographical history of the species (Coleoptera: Cicindelidae). Quaestiones Entomologicae 24: 51-61.

Stanger JA, Baumann RW. 1993. A revision of the stonefly genus Taenionema (Plecoptera: Taeniopterygidae). Transactions of the American Entomological Society 119: 171-229.

Stonedahl GM. 1990. Revision and cladistic analysis of the Holarctic genus Atractotomus Fieber (Heteroptera: Miridae: Phylinae). Bulletin American Museum of Natural History 198: 1-88.

Suzuki S, Tomishima K, Yano S, Tsurusaki N. 1977. Discontinuous distributions in relict harvestmen (Opiliones, Arachnida). Acta Arachnologica 27: 121-138.

Talbot SL, Shields GF. 1996. A phylogeny of the bears (Ursidae) inferred from complete sequences of three mitochondrial genes. Molecular Phylogenetics and Evolution 5: 567-575.

Tangelder IRM. 1988. The biogeography of the Holarctic Nephrotoma dorsalis species-group (Diptera, Tipulidae). Beaufortia 38: 1-35.

Taylor DJ, Hebert PDN, Colbourne JK. 1996. Phylogenetics and evolution of the Daphnia longispina group (Crustacea) based on 12S rDNA sequence and allozyme variation. Molecular Phylogenetics and Evolution 5: 495510.

Tiffney BH. 1985a. Perspectives on the origin of the floristic similarity between eastern Asia and eastern North America. Journal of the Arnold Arboretum 66: 73-94.

Tiffney BH. 1985b. The Eocene North Atlantic land bridge: its importance in Tertiary and modern phytogeography of the Northern Hemisphere. Journal of the Arnold Arboretum 66: 243-273.

Voelker G. 1999a. Molecular evolutionary relationships in the avian genus Anthus (Pipits: Motacillidae). Molecular Phylogenetics and Evolution 11: 84-94.

Voelker G. 1999b. Dispersal, vicariance, and clocks: historical biogeography and speciation in a cosmopolitan Passerine genus (Anthus: Motacillidae). Evolution 53: $1536-1552$
Wen J. 1999. Evolution of the eastern Asian and eastern North American disjunct distributions in flowering plants. Annual Review of Ecology and Systematics 30: 421-455.

Williams DJM. 1988. Classification, phylogeny and zoogeographic studies of species of Sathon Mason ( $\mathrm{Hy}$ menoptera: Braconidae). Quaestiones Entomologicae 24: $529-639$

Wilson MVH, Veilleux P. 1982. Comparative osteology and relationships of the Umbridae (Pisces: Salmoniformes). Zoological Journal of the Linnean Society 76: 321-332.

Wolfe JA. 1969. Neogene floristic and vegetational history of the Pacific North-west. Madroño 20: 83-110.

Wolfe JA. 1972. An interpretation of Alaskan Tertiary floras. In: Graham A, ed. Floristics and Paleofloristics of Asia and eastern North America. Amsterdam: Elsevier, 201-233.

Wolfe JA. 1975. Some aspects of plant geography of the northern hemisphere during the Late cretaceous and Tertiary. Annals of the Missouri Botanical Garden 62: 264-279.

Wolfe JA. 1977. Paleogene floras from the Gulf of Alaska region. US Geological Survey Professional Papers 997: $1-108$.

Wolfe JA. 1978. A Paleobotanical interpretation of Tertiary climates in the Northern Hemisphere. The American Scientist 66: 694-703.

Wolfe JA. 1985. Distribution and major vegetational types during the Tertiary. In: Sundquist ET, Broecker WS, eds. The Carbon Cycle and the Atmospheric CO2: Natural Variations Archean to Present. Washington: American Geophysical Union, 357-375.

Wolfe JA. 1987. Late Cretaceous-Cenozoic history of deciduousness and the terminal Cretaceous event. Paleobiology 16: 215-226.

Wolfe GW, Roughley RE. 1990. A taxonomic, phylogenetic and zoogeographic analysis of Laccornis Gozis (Coleoptera: Dytiscidae) with the description of Laccornis, a new tribe of Hydroporini. Quaestiones Entomologicae 26: 273-354.

Wood DM. 1981. Pachyneuridae. In: McAlpine JF, Peterson BV, Shewell GE, Teskey HJ, Vockeroth JR, Wood DM, eds. Manual of Nearctic Diptera. Vol. 1. Research Branch, Agriculture Canada, Hull, Quebec, 213-216.

Xiang QY, Soltis DE, Soltis PS. 1998a. The eastern Asian and eastern and western North American floristic disjunction: congruent phylogenetic patterns in seven diverse genera. Molecular Phylogenetics and Evolution 10: $178-190$.

Xiang QY, Crawford DJ, Wolfe AD, Tang YC, DePamphilis CW. 1998b. Origin and biogeography of Aesculus L. (Hippocastanaceae): a molecular phylogenetic perspective. Evolution 52: 988-997.

Yin HF. 1994. The Palaeobiogeography of China. Oxford: Clarendon.

Zhang YP, Ryder OA. 1994. Phylogenetic relationships of bears (the Ursidae) inferred from mitochondrial DNA sequences. Molecular Phylogenetics and Evolution 3: $351-359$. 


\section{APPENDIX}

Cladograms of the 57 studied groups. Numbers refer to dated nodes in Table 1. Species are followed by their distributions. WN = Western Nearctic, EN = Eastern Nearctic, WP = Western Palaeoarctic, $\mathrm{EP}=$ Eastern Palaeoarctic, $\mathrm{AF}=$ Afrotropical, $\mathrm{AU}=$ Australian, $\mathrm{NT}=\mathrm{=}$ Neotropical, $\mathrm{OR}=$ Oriental.

Xestia (Schoyenia)

(Insecta, Lepidoptera, Noctuidae)

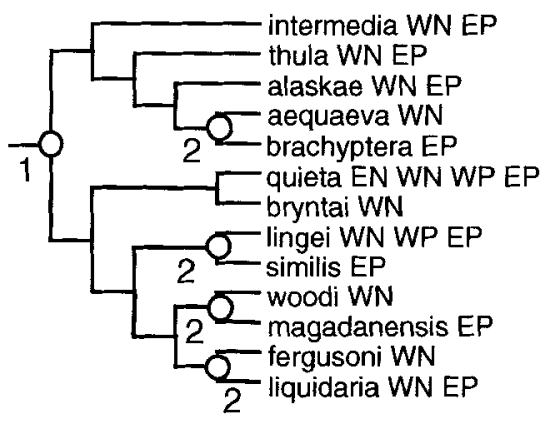

Trichosilia

(Insecta, Lepidoptera, Noctuidae)

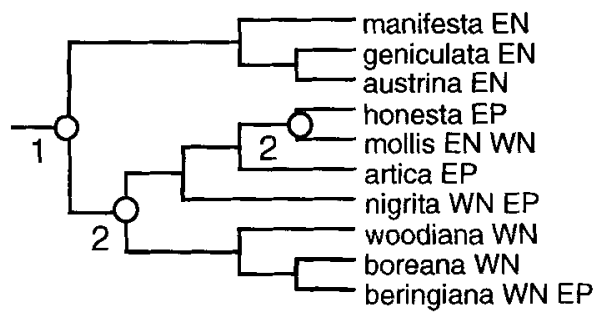

Sathon

(Insecta, Hymenoptera, Braconidae)

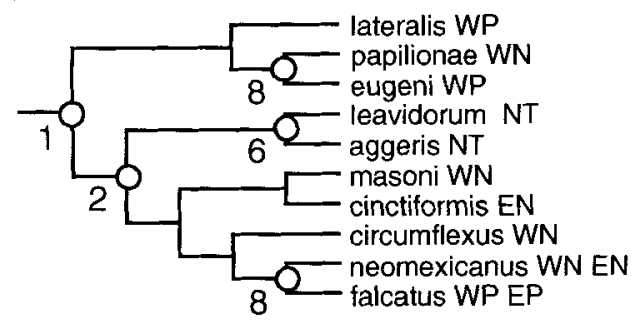

Symmorphus debilitatus-group (Insecta, Hymenoptera, Vespidae)

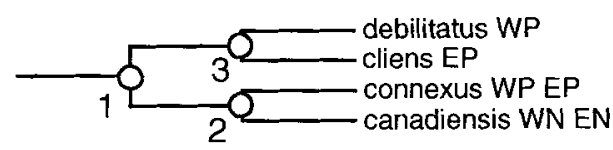

Ibaliidae

(Insecta, Hymenoptera)

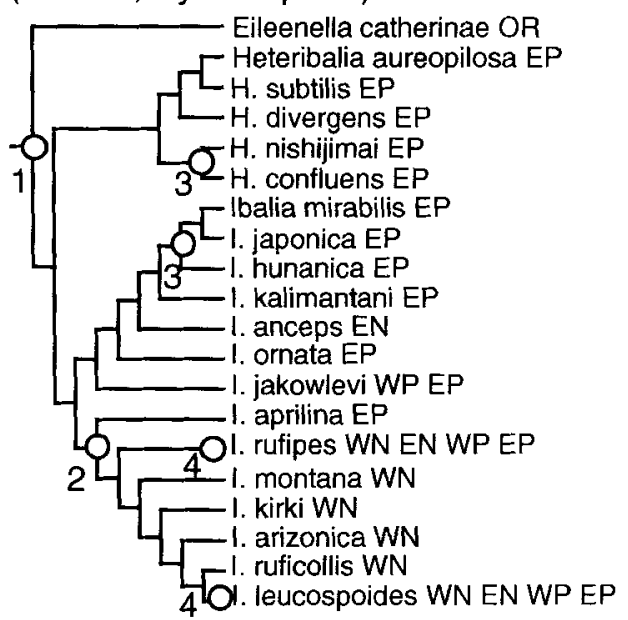

Limnoporus

(Insecta, Hemiptera, Gerridae)

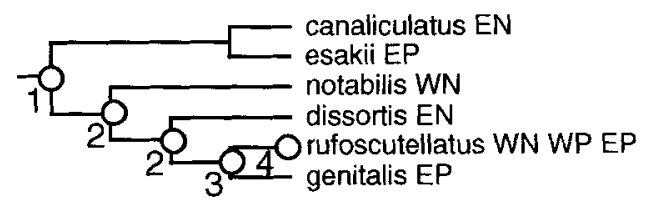

Aquarius

(Insecta, Hemiptera, Gerridae)

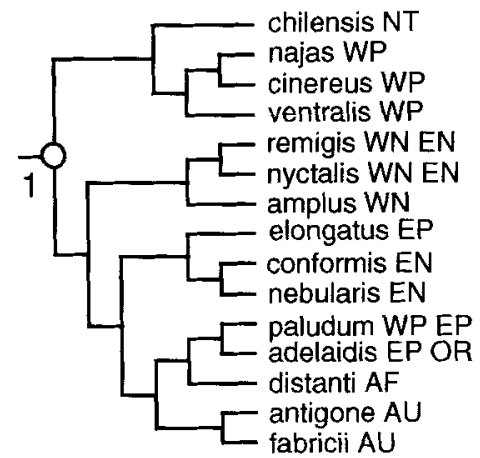


Nabicula (Limnonabis) (Insecta, Heteroptera, Nabidae)
Potamanthidae

(Insecta, Ephemeroptera)

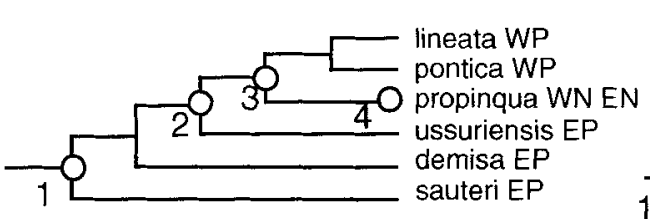

\section{Nephrotoma dorsalis-group (Insecta, Diptera, Tipulidae)}

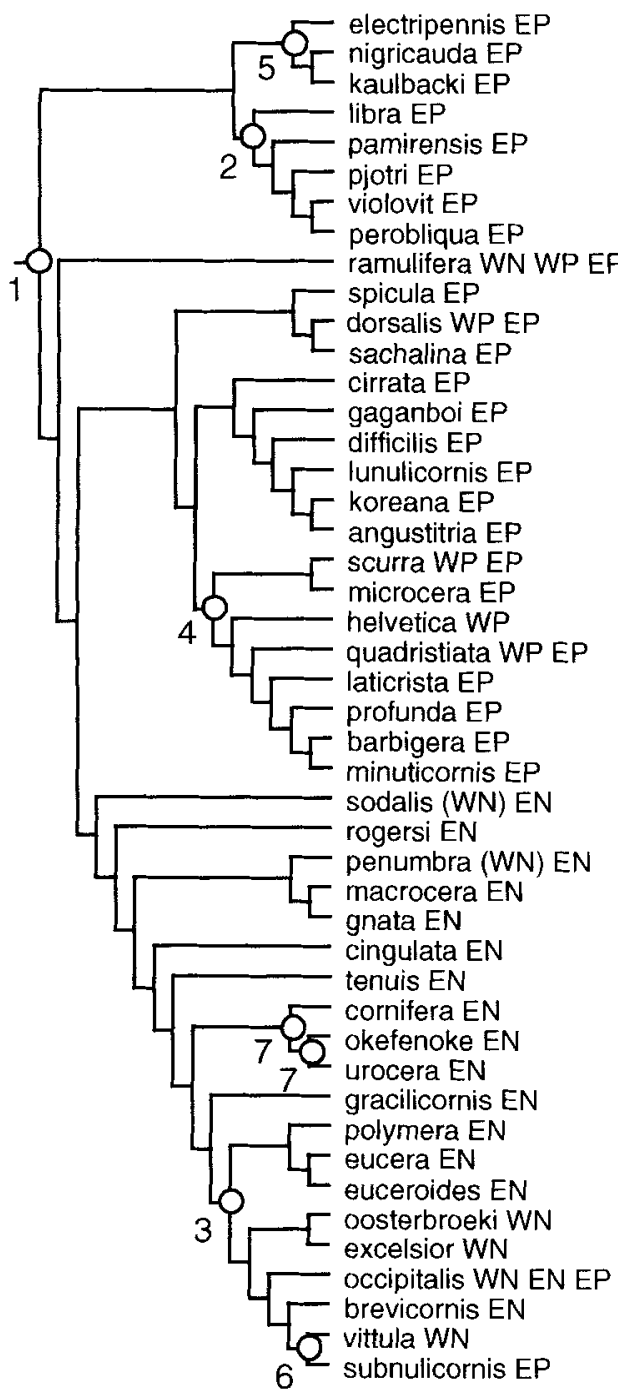

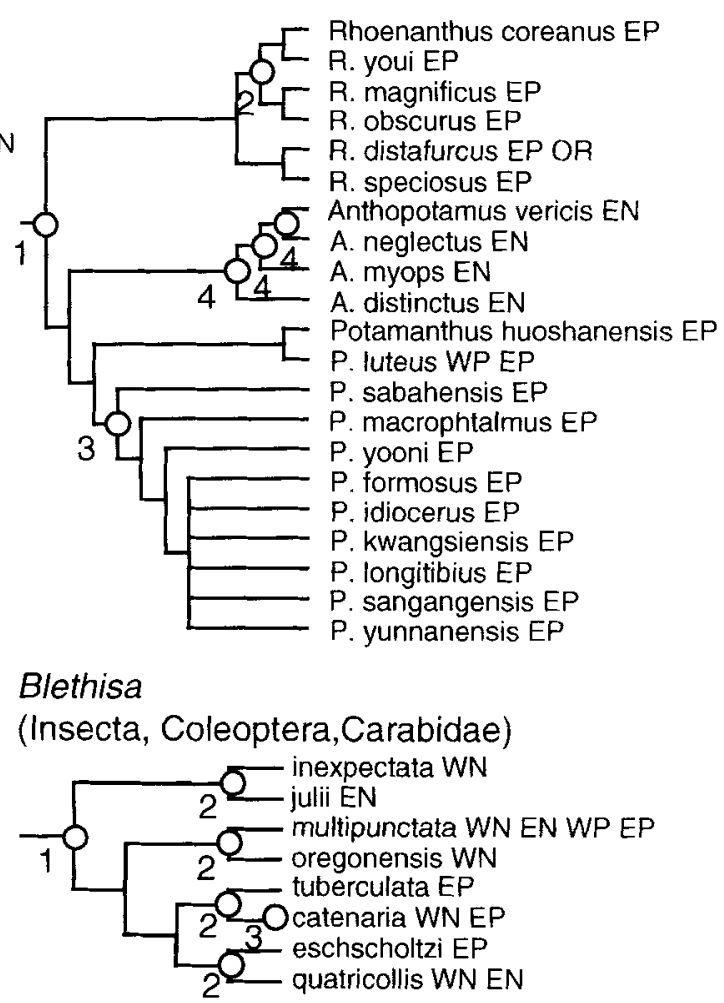

Elaphrus (Elaphroterus) (Insecta, Coleoptera, Carabidae)

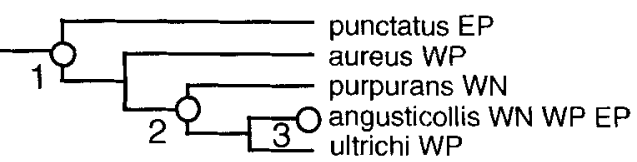

Elaphrus (Neoelaphrus) (Insecta, Coleoptera, Carabidae)

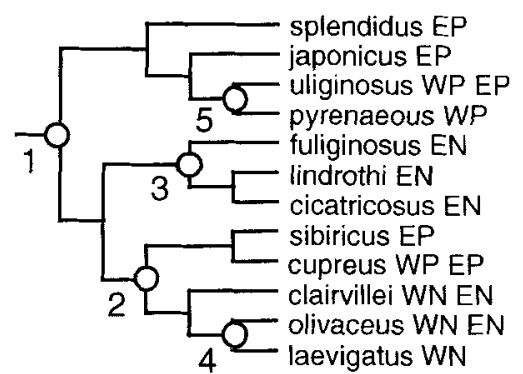




\section{Sericoda}

(Insecta, Coleoptera, Carabidae)
Laccornis

(Insecta, Coleoptera, Dytiscidae)
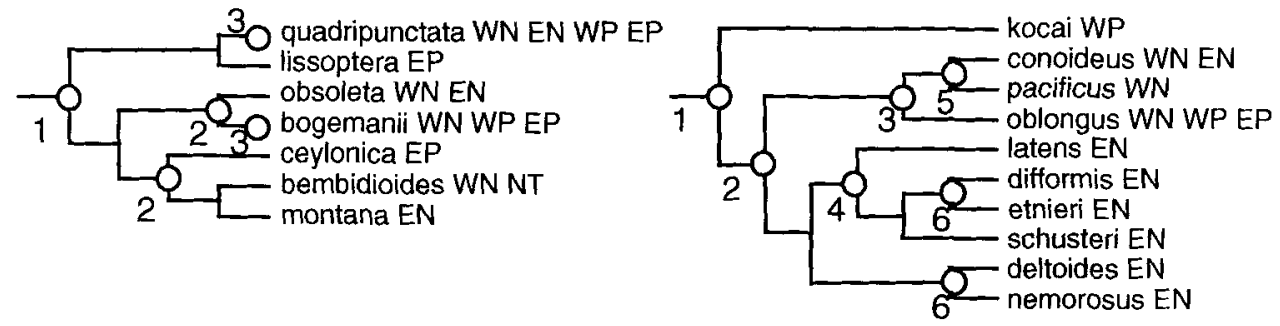

Anchonemus

(Insecta, Coleoptera, Carabidae)

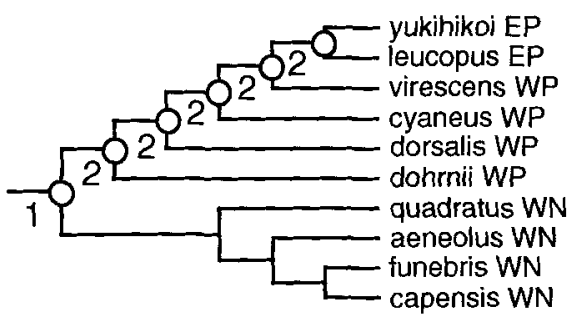

Agabus affinis-group

(Insecta, Coleoptera, Dytiscidae)

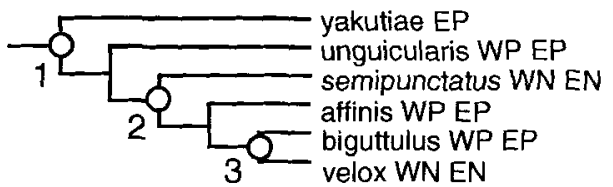

Myadi

(Insecta, Coleoptera, Carabidae)

Dytiscus

(Insecta, Coleoptera, Dytiscidae)

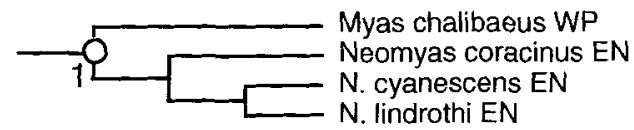

Loricera

(Insecta, Coleoptera, Carabidae)
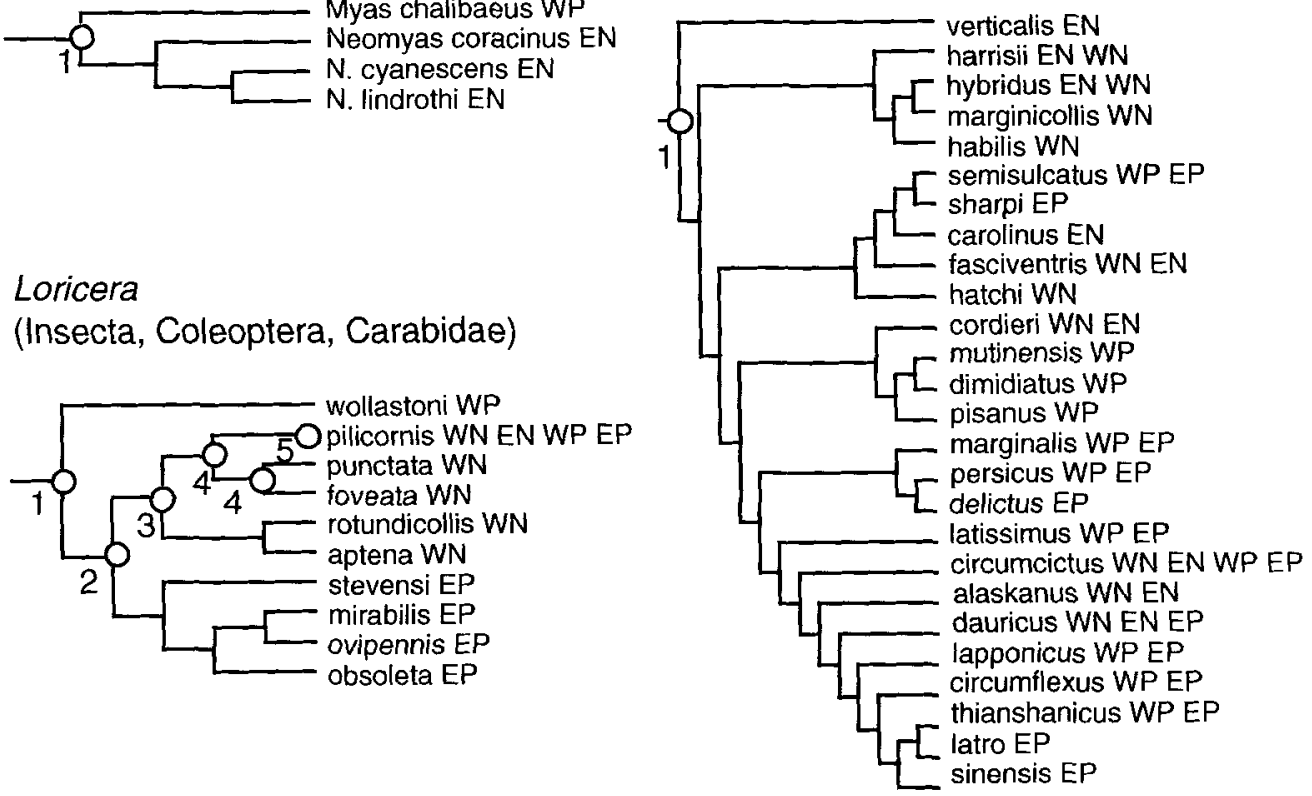
Gymnusa

(Insecta, Coleoptera, Staphylinidae)

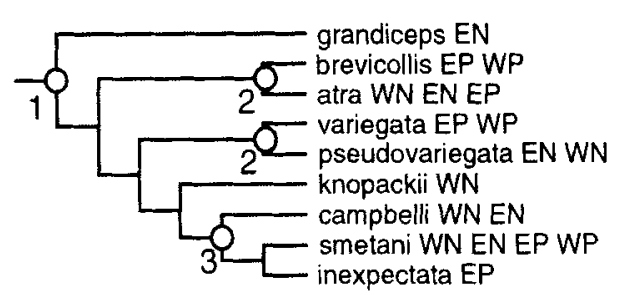

Deinopsis

(Insecta, Coleoptera, Staphylinidae)

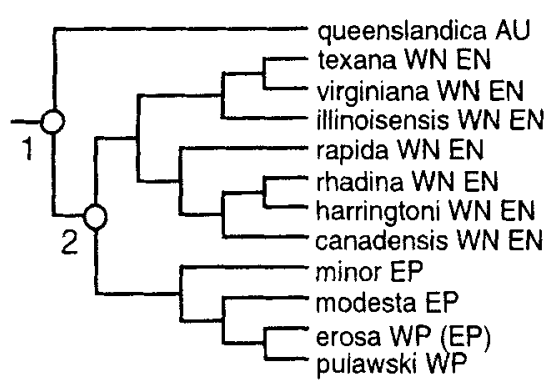

Cicindela sylvatica-group (Insecta, Coleoptera, Cycindelidae)

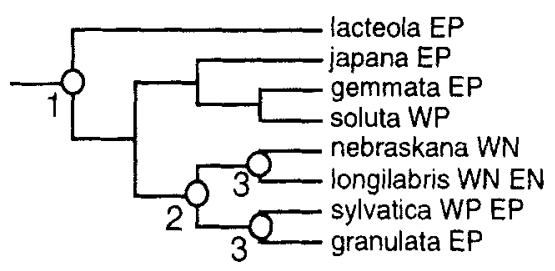

Pytho

(Insecta, Coleoptera, Pythidae)

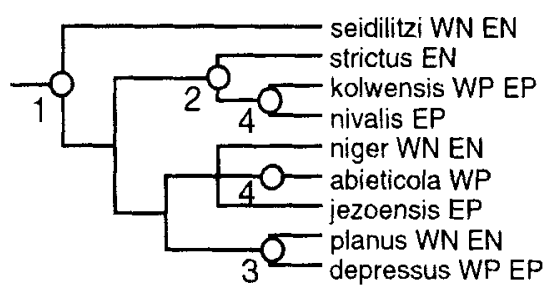

Hydrochara

(Insecta, Coleoptera, Hydrophiliidae)

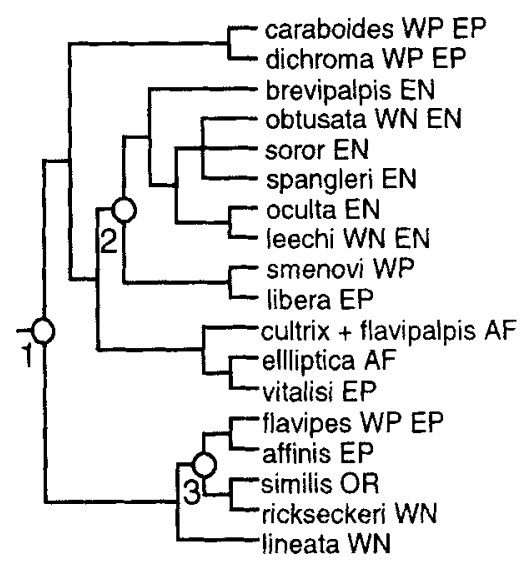

Plateumaris

(Insecta, Coleoptera, Chrysomelidae)

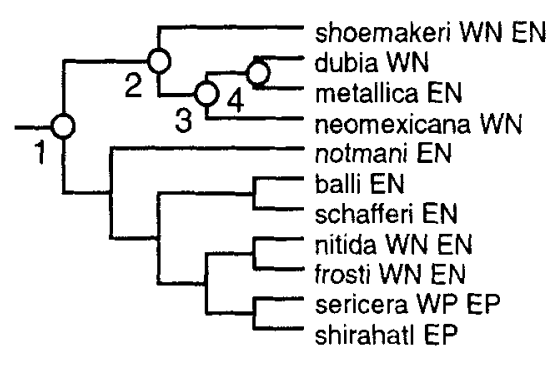

Hypochilus

(Arachnida, Araneae, Hypochilidae)

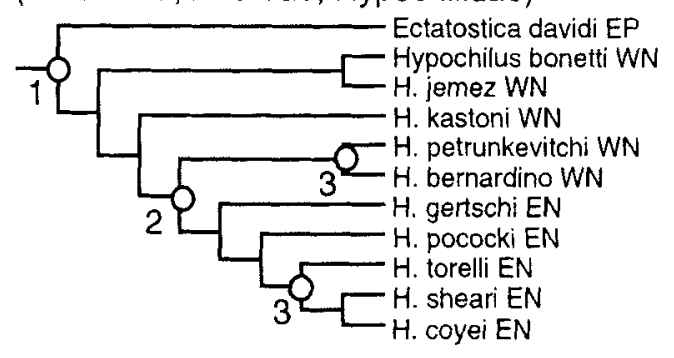


Pimoa

(Arachnida, Araneae, Pimoidae)

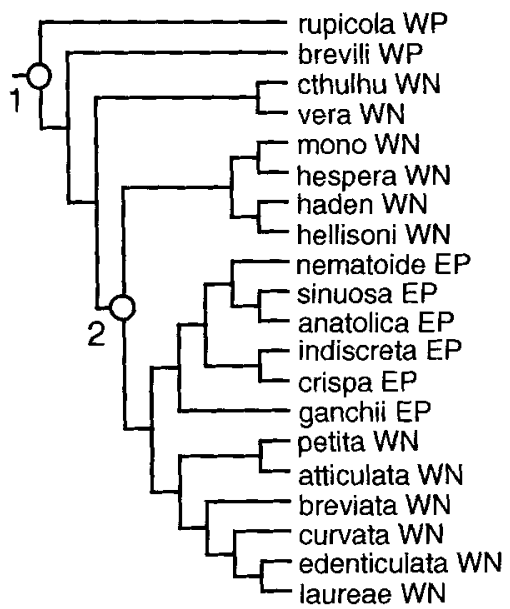

Calillepis

(Arachnida, Araneae, Gnaphosidae)

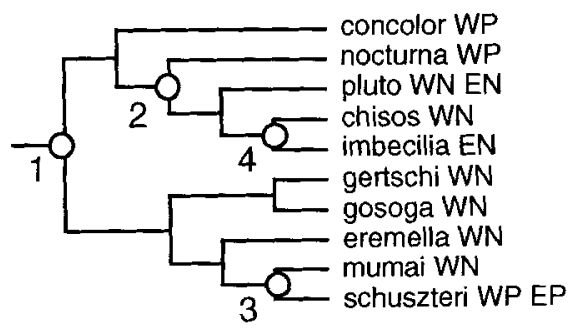

Esox

(Teleostei, Esocidae)

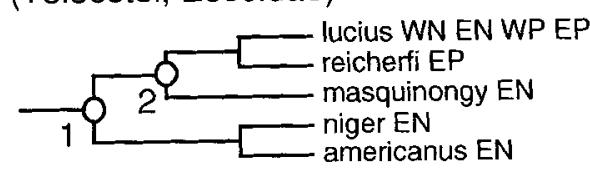

Umbridae

(Teleostei)

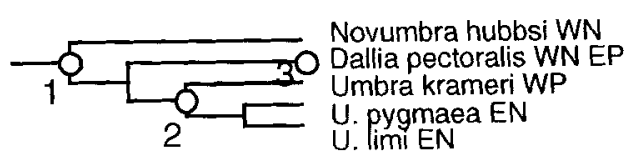

\section{Catostomidae}

(Teleostei)

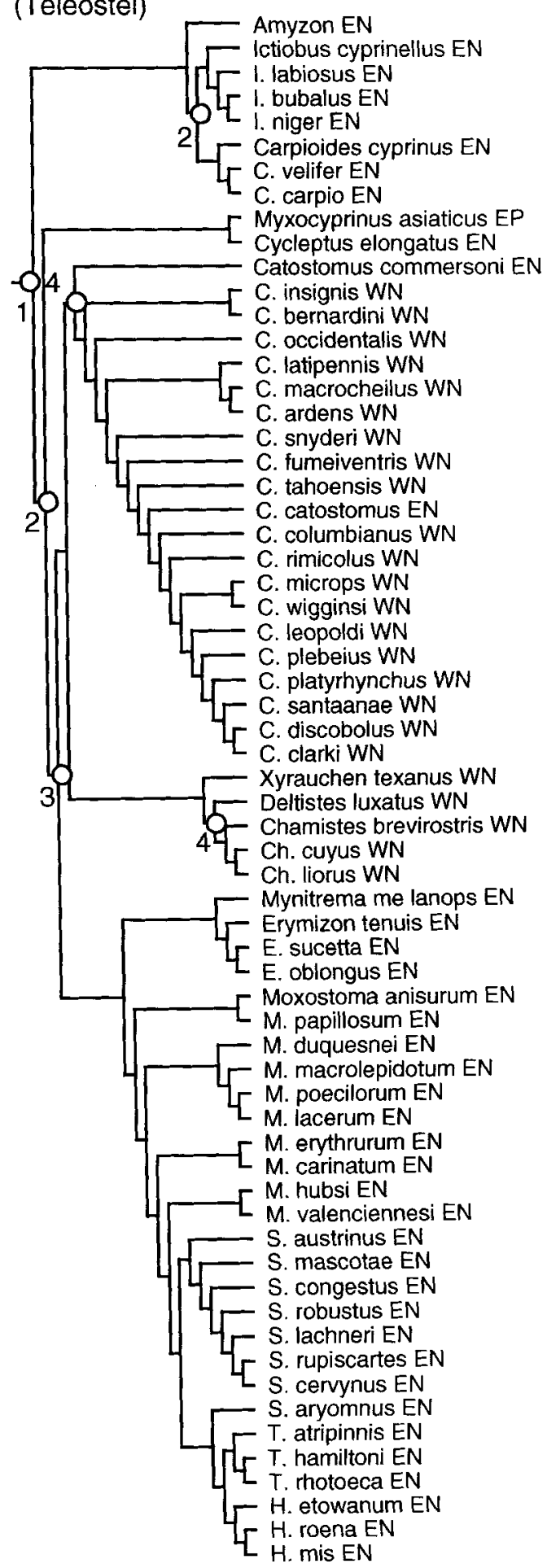


Oncorhynchus

(Teleostei, Salmonidae)

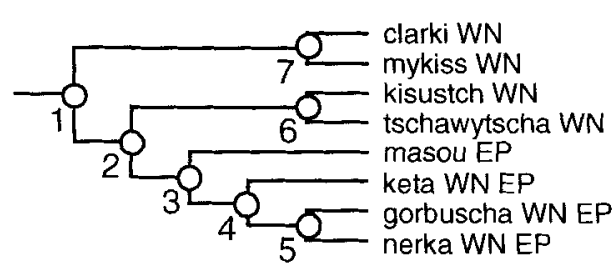

\section{Alectoris}

(Aves, Galliformes, Phasianidae)

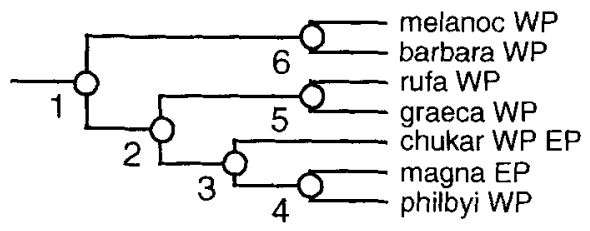

\section{Anthus}

(Aves, Passerifornes, Motacillidae)

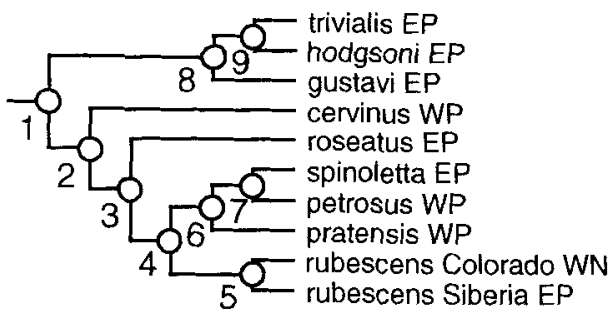

Ursidae (Mammalia, Carnivora)

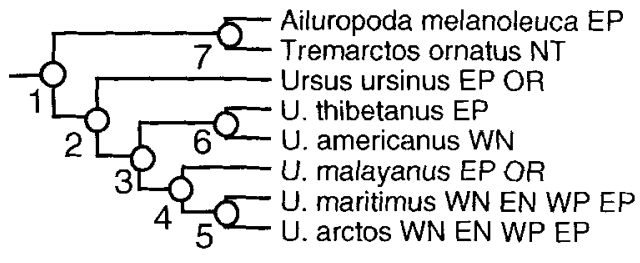

\section{Chabaudgolvania}

(Nematoda, Ascaridida, Quimperiidae)



\section{Daphnia 1}

(Crustacea, Cladocera)

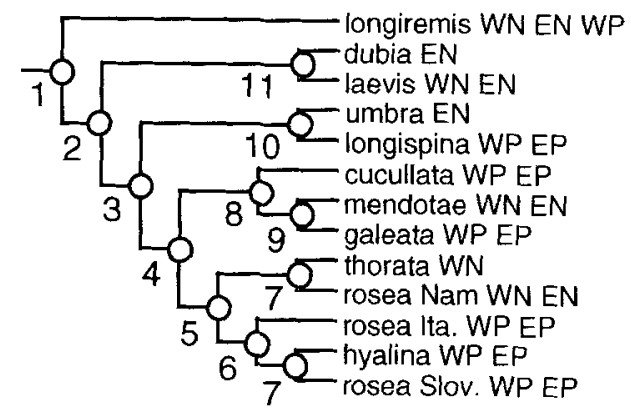

Sorex longirostris-group

(Mammalia, Soricidae)

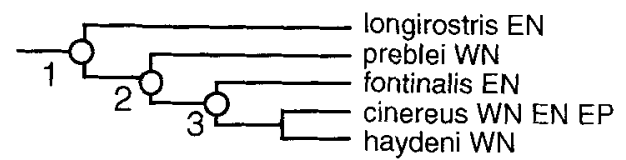




\section{Daphnia 2}

(Crustacea, Cladocera)

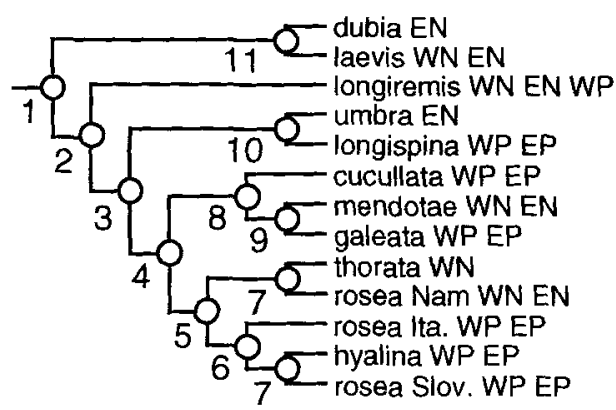

\section{Daphnia 3}

(Crustacea, Cladocera)

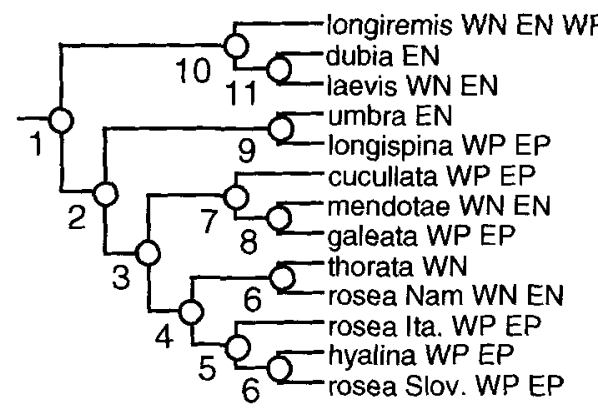

\section{Heterotrissocladius}

(Insecta, Diptera, Chironomidae)

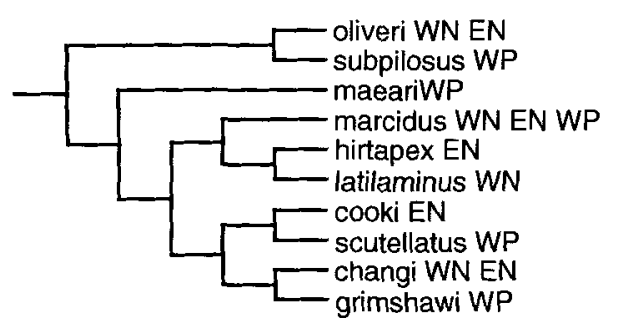

\section{Hydrobaenus}

(Insecta, Diptera, Chironomidae)

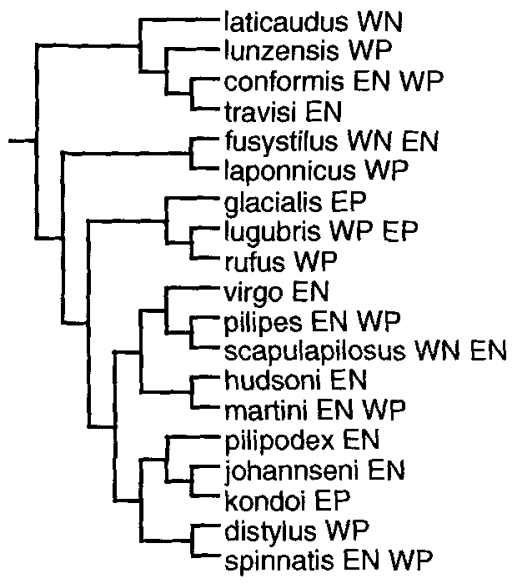

Mosillus

(Insecta, Diptera, Ephydridae)

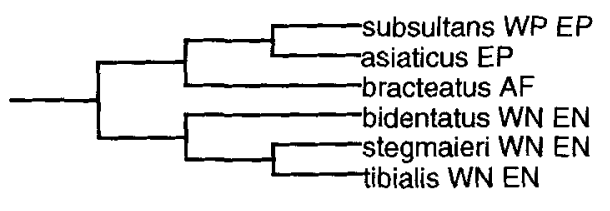

Pachyneuridae

(Insecta, Diptera)

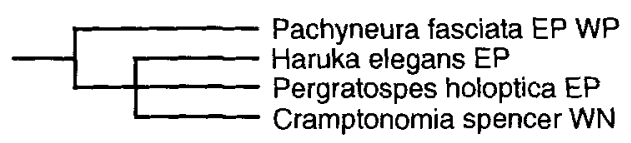

Lotophila

(Insecta, Diptera, Sphaeroceridae)

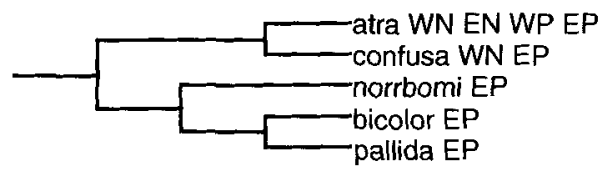




\section{Keroplatus}

(Insecta, Diptera, Keroplatidae)



Rocatelion

(Insecta, Diptera, Keroplatidae)

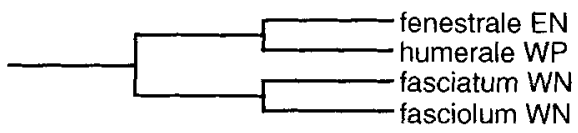

\section{Coelosia}

(Insecta, Diptera, Mycetophilidae)

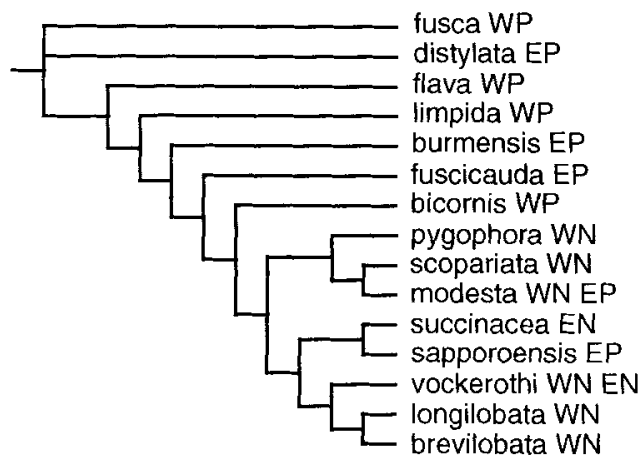

Paraclemensia

(Insecta, Lepidoptera, Incurvariidae)

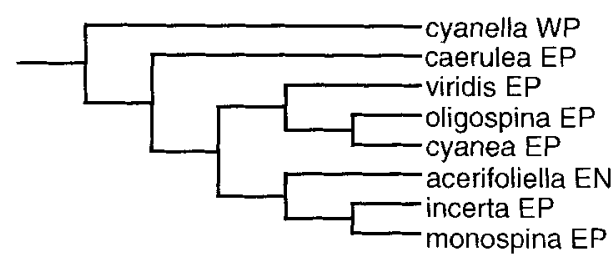

\section{Nitidotachinus}

(Insecta, Coleoptera, Staphylinidae)



Lygus

(Insecta, Heteroptera, Miridae)

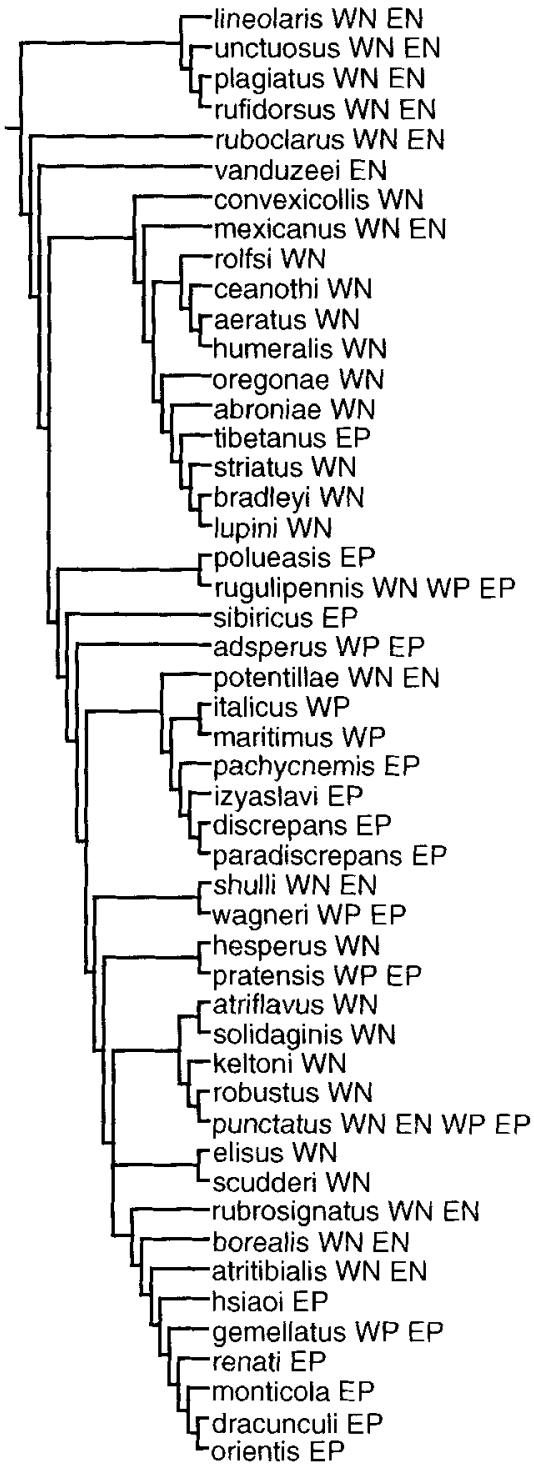




\section{Atractotomus}

(Insecta, Heteroptera, Miridae)

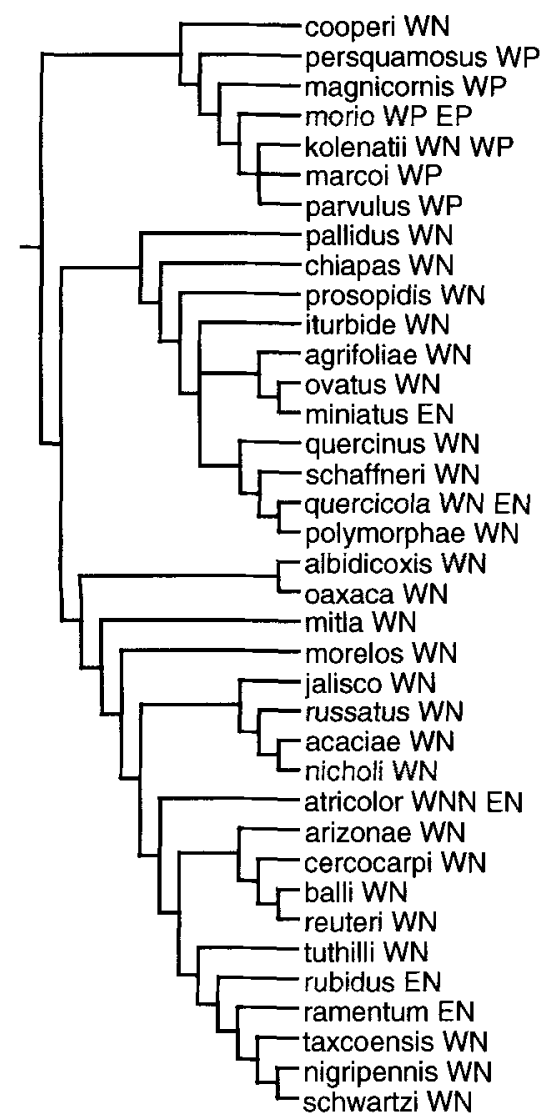

Oxyethira

(Insecta, Trichoptera, Hydroptilidae)

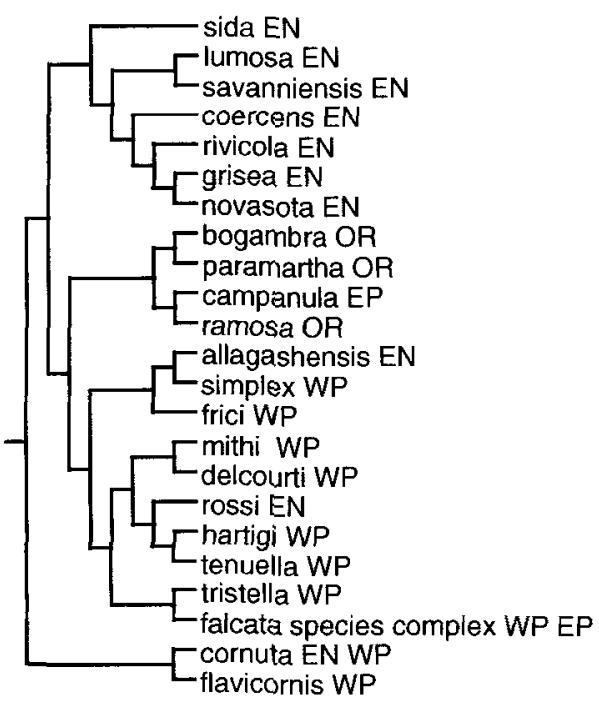

Flexamia

(Insecta, Homoptera, Cicadellidae)

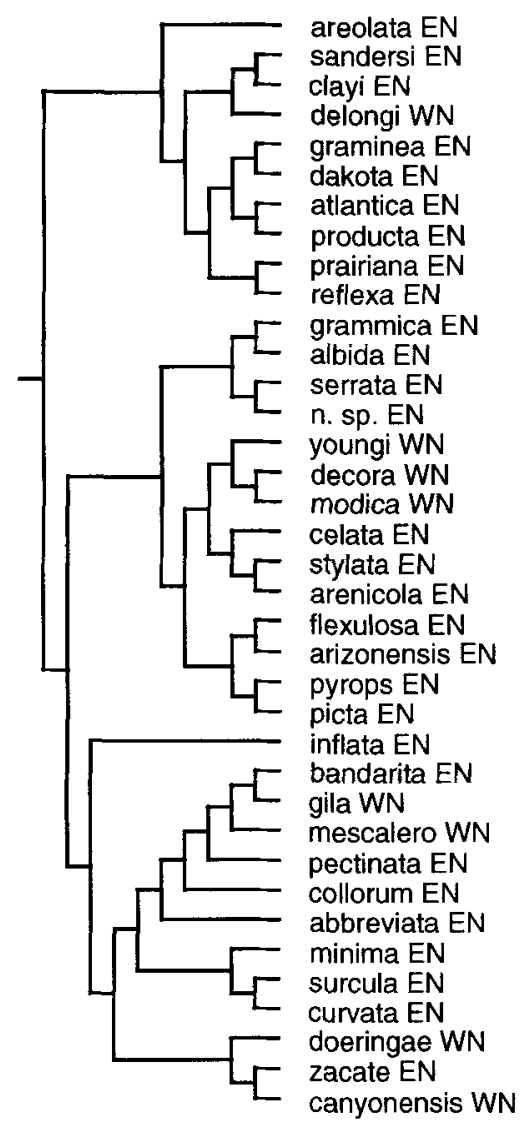

Taenionema

(Insecta, Plecoptera, Taeniopterygidae)

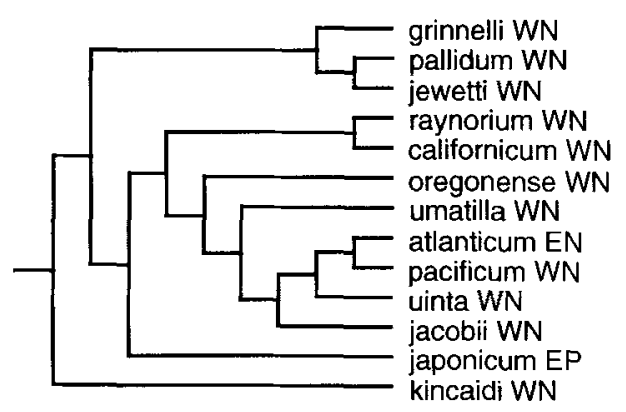




\section{Gasterosteiformes}

(Teleostei)

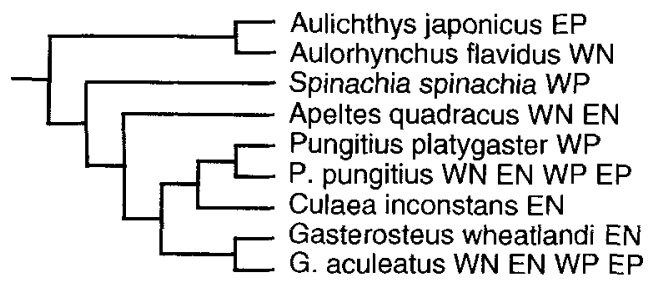

\section{Marmota}

(Mammalia, Rodentia, Sciuridae)

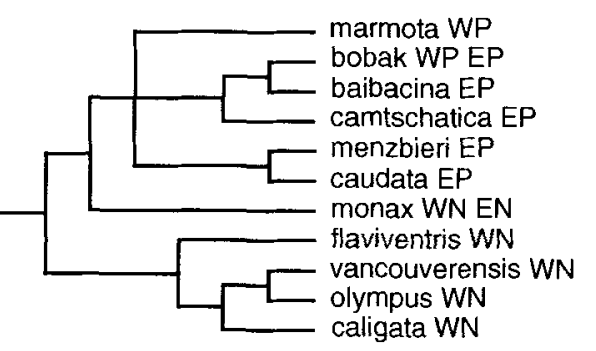

Larus

(Aves, Ciconiiformes, Laridae)

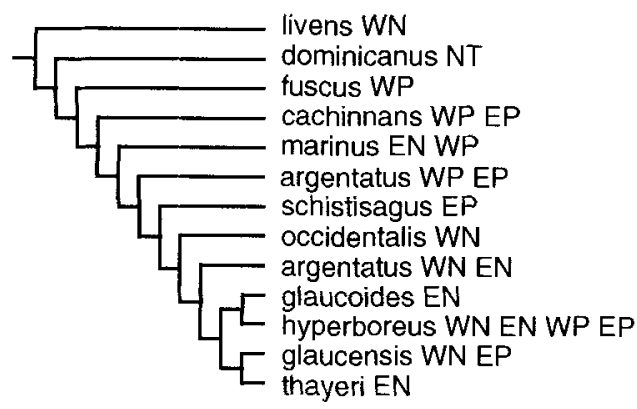

